\title{
Solvent-Induced Luminescence and Structural Transformation of a Dinuclear Au(I)-(Aza-18-crown-6)dithiocarbamate Compound
}

Biing-Chiau Tzeng, ${ }^{*, a}$ Chan-Yan Lin, ${ }^{\text {a Jun-Wei Hung, }}{ }^{a}$ Si-Ying Chen, ${ }^{\text {b }}$ A. Hsiu-Hwa Chang, ${ }^{\text {,b }}$ and Gene-Hsiang Lee ${ }^{\mathrm{c}}$

${ }^{\mathrm{a}}$ Department of Chemistry and Biochemistry, National Chung Cheng University, 168 University Road, Min-Hsiung, Chiayi 62102, Taiwan

b Department of Chemistry, National Dong Hwa University, 1, Sec. 2, Da Hsueh Road, Shoufeng, Hualien 97401, Taiwan

${ }^{\mathrm{C}}$ Department of Chemistry, National Taiwan University, 1, Sec. 4, Roosevelt Road, Taipei 10617, Taiwan 
Table S1. Crystallographic Data of 2-solvates (solvates=2DMF, 2DMSO, 2THF, 2acetone, 1.5toluene, and 1.5anisole).

\begin{tabular}{|c|c|c|c|c|c|c|}
\hline & $2 \cdot 2 \mathrm{DMF}$ & 2.2DMSO & $2 \cdot \mathrm{THF}$ & 2.2acetone & $\mathbf{2} \cdot 1.5$ toluene & 2.1.5anisole \\
\hline Empirical formula & $\mathrm{C}_{32} \mathrm{H}_{62} \mathrm{Au}_{2} \mathrm{~N}_{4} \mathrm{O}_{12} \mathrm{~S}_{4}$ & $\mathrm{C}_{30} \mathrm{H}_{60} \mathrm{Au}_{2} \mathrm{~N}_{2} \mathrm{O}_{12} \mathrm{~S}_{6}$ & $\mathrm{C}_{34} \mathrm{H}_{64} \mathrm{Au}_{2} \mathrm{~N}_{2} \mathrm{O}_{12} \mathrm{~S}_{4}$ & $\mathrm{C}_{32} \mathrm{H}_{60} \mathrm{Au}_{2} \mathrm{~N}_{2} \mathrm{O}_{12} \mathrm{~S}_{4}$ & $\mathrm{C}_{36.5} \mathrm{H}_{58} \mathrm{Au}_{2} \mathrm{~N}_{2} \mathrm{O}_{10} \mathrm{~S}_{4}$ & $\mathrm{C}_{73} \mathrm{H}_{120} \mathrm{Au}_{4} \mathrm{~N}_{4} \mathrm{O}_{23} \mathrm{~S}_{8}$ \\
\hline Formula weight & 1217.04 & 1227.65 & 1215.04 & 1186.99 & 1207.02 & 2466.07 \\
\hline Crystal system & Monoclinic & Monoclinic & Monoclinic & Monoclinic & Orthorhombic & Orthorhombic \\
\hline Space group (No.) & $\mathrm{P} 2{ }_{1} / \mathrm{C}$ & $\mathrm{P} 2{ }_{1} / \mathrm{C}$ & $\mathrm{P} 2{ }_{1} / \mathrm{C}$ & $\mathrm{P} 2{ }_{1} / \mathrm{c}$ & Pba2 & Pba2 \\
\hline a $(\AA)$ & $11.2485(6)$ & 11.1791(14) & $11.1463(2)$ & $11.1808(2)$ & $16.8324(8)$ & $16.8979(6)$ \\
\hline $\mathrm{b}(\AA)$ & $24.4355(13)$ & $23.610(3)$ & $23.7575(5)$ & $23.3936(4)$ & $24.0614(11)$ & $24.0545(10)$ \\
\hline c $(\AA)$ & 16.7081(9) & $16.798(2)$ & $17.0155(3)$ & $16.8189(4)$ & $11.0995(5)$ & 11.1702(4) \\
\hline$\beta\left(^{\circ}\right)$ & $99.820(1)$ & $100.439(2)$ & $101.6283(6)$ & $101.1871(6)$ & & \\
\hline $\mathrm{V}\left(\AA^{3}\right), \mathrm{Z}$ & 4525.1(4), 4 & 4360.3(9), 4 & 4413.36(15), 4 & 4315.55(15), 4 & 4495.4(4), 4 & 4540.4(3), 2 \\
\hline $\mathrm{F}(000)(\mathrm{e})$ & 2400 & 2410 & 2400 & 2336 & 2372 & 2428 \\
\hline$\mu(\mathrm{Mo}-\mathrm{K} \alpha)\left(\mathrm{mm}^{-1}\right)$ & 6.718 & 7.062 & 6.887 & 7.041 & 6.758 & 6.695 \\
\hline $\mathrm{T}(\mathrm{K})$ & $296(2)$ & 173(2) & $150(2)$ & $200(2)$ & $200(2)$ & $220(2)$ \\
\hline \begin{tabular}{|l|} 
Reflections collected \\
\end{tabular} & 34651 & 43091 & 30623 & 30174 & 30558 & 26932 \\
\hline $\begin{array}{c}\text { ndependent reflections } \\
(\mathrm{Fo} \geq 2 \sigma(\mathrm{Fo}))\end{array}$ & $\begin{array}{c}10028 \\
\left(R_{\text {int }}=0.023\right)\end{array}$ & $\begin{array}{c}8128 \\
\left(\mathrm{R}_{\mathrm{int}}=0.040\right)\end{array}$ & $\begin{array}{c}10099 \\
\left(\mathrm{R}_{\text {int }}=0.0433\right)\end{array}$ & $\begin{array}{c}9897 \\
\left(\mathrm{R}_{\text {int }}=0.0287\right)\end{array}$ & $\begin{array}{c}10217 \\
\left(\mathrm{R}_{\mathrm{int}}=0.0249\right)\end{array}$ & $\begin{array}{c}9630 \\
\left(\mathrm{R}_{\text {int }}=0.0444\right)\end{array}$ \\
\hline Refined parameters & 492 & 484 & 487 & 473 & 494 & 511 \\
\hline Goodness-of-fit on $\mathrm{F}^{2}$ & 1.062 & 0.858 & 1.085 & 1.045 & 1.094 & 1.080 \\
\hline $\mathrm{R}^{\mathrm{a}}, \mathrm{R}_{\mathrm{w}}^{\mathrm{b}}(\mathrm{I} \geq 2 \sigma(\mathrm{I}))$ & $0.0346,0.0795$ & $0.0380,0.1035$ & $0.0363,0.0665$ & $0.0275,0.0526$ & $0.0332,0.0662$ & $0.0524,0.1121$ \\
\hline $\mathrm{R}^{\mathrm{a}}, \mathrm{R}_{\mathrm{w}}^{\mathrm{b}}$ (all data) & $0.0553,0.0881$ & $0.0592,0.1187$ & $0.0780,0.0860$ & $0.0479,0.0617$ & $0.0767,0.0851$ & $0.1409,0.1556$ \\
\hline
\end{tabular}

${ }^{\mathrm{a}} \mathrm{R}=\Sigma|| \mathrm{F}_{\mathrm{o}}|-| \mathrm{F}_{\mathrm{c}}|| / \Sigma\left|\mathrm{F}_{\mathrm{o}}\right| \cdot{ }^{\mathrm{b}} \mathrm{wR}_{2}=\left\{\left[\Sigma \mathrm{w}\left(\mathrm{F}_{\mathrm{o}}{ }^{2}-\mathrm{F}_{\mathrm{c}}{ }^{2}\right)^{2} / \Sigma\left[\mathrm{w}\left(\mathrm{F}_{\mathrm{o}}{ }^{2}\right)^{2}\right]\right\}^{1 / 2}\right.$. 
Table S2. The B3LYP/LanL2DZ energies ( $\left.\mathrm{T}_{1}-\mathrm{S}_{0}\right)$, HOMO and LUMO of $\mathrm{S}_{0}$ states for (a) one, (b) two, and (c) three Au $\mathbf{u}_{2}$ complex units of $2 \cdot$ solvates. (solvates = Toluene, Acetonitrile, Anisole, THF, Acetone, DMSO, m-Xylene, DMF, and tert-Butylbenzene- $\mathrm{H}_{2} \mathrm{O}$ ).

(a) Au2 complexes

\begin{tabular}{|c|c|c|c|c|c|c|c|c|}
\hline & \multirow{2}{*}{$\mathbf{A u} \cdots \mathbf{A u}_{\text {intra }}()$} & \multirow{2}{*}{$\mathbf{A u} \cdots \mathbf{A u}_{\text {inter }}()$} & \multirow{2}{*}{ States } & \multirow{2}{*}{$\begin{array}{c}\text { B3LYP/LanL2DZ } \\
\text { (hartree) }\end{array}$} & \multicolumn{2}{|c|}{$\mathbf{S}_{\mathbf{0}}$} & \multirow{2}{*}{$\begin{array}{c}\Delta \mathbf{E}\left(\mathbf{T}_{1}-\mathbf{S}_{\mathbf{0}}\right) \\
\quad(\mathbf{n m})\end{array}$} & \multirow{2}{*}{$\lambda_{\text {em }}(\exp )$} \\
\hline & & & & & НОМО & LUMO & & \\
\hline \multirow{5}{*}{ Toluene } & \multirow[b]{2}{*}{2.717} & \multirow[b]{2}{*}{-} & $\mathrm{S}_{0}$ & -2191.937750 & $\mathrm{Au}(52 \%)$ & SCN (75\%) & \multirow[b]{2}{*}{348.0} & \multirow{4}{*}{604} \\
\hline & & & $\mathrm{T}_{1}$ & & & & & \\
\hline & \multirow[b]{2}{*}{2.728} & \multirow[b]{2}{*}{-} & $\mathrm{S}_{0}$ & -2191.923891 & $\mathrm{Au}(45 \%)$ & SCN (73\%) & \multirow[b]{2}{*}{346.9} & \\
\hline & & & & & & & & \\
\hline & \multirow{4}{*}{2.719} & \multirow{4}{*}{-} & & & & & \multirow{4}{*}{340.2} & \multirow{7}{*}{600} \\
\hline \multirow{6}{*}{ Acetonitrile } & & & $\mathrm{S}_{0}$ & -2191.744153 & $\mathrm{Au}(55 \%)$ & SCN (72\%) & & \\
\hline & & & & & & & & \\
\hline & & & $\mathrm{T}_{1}$ & -2191.610246 & & & & \\
\hline & \multirow{3}{*}{2.725} & \multirow{3}{*}{-} & $\mathrm{S}_{0}$ & -2191.767550 & $\mathrm{Au}(46 \%)$ & SCN (73\%) & \multirow{3}{*}{346.2} & \\
\hline & & & & & & & & \\
\hline & & & $\mathrm{T}_{1}$ & -2191.635943 & & & & \\
\hline \multirow{5}{*}{ Anisole } & \multirow{3}{*}{2.728} & \multirow{3}{*}{-} & $\mathrm{S}_{0}$ & -2191.785940 & $\mathrm{Au}(51 \%)$ & SCN (75\%) & \multirow{3}{*}{344.5} & \multirow{5}{*}{597} \\
\hline & & & & & & & & \\
\hline & & & $\mathrm{T}_{1}$ & -2191.653694 & & & & \\
\hline & \multirow[b]{2}{*}{2.733} & \multirow[b]{2}{*}{-} & $\mathrm{S}_{0}$ & -2191.731094 & $\mathrm{Au}(44 \%)$ & SCN (73\%) & \multirow[b]{2}{*}{349.8} & \\
\hline & & & $\mathrm{T}_{1}$ & -2191.600834 & & & & \\
\hline \multirow{3}{*}{ THF } & \multirow{3}{*}{2.733} & \multirow{3}{*}{-} & $\mathrm{S}_{0}$ & -2191.938794 & $\mathrm{Au}(56 \%)$ & SCN (72\%) & & \\
\hline & & & & & & & 341.2 & 581 \\
\hline & & & $\mathrm{T}_{1}$ & -2191.805255 & & & & \\
\hline
\end{tabular}




\begin{tabular}{|c|c|c|c|c|c|c|c|c|}
\hline & 2.735 & - & $\begin{array}{l}\mathrm{S}_{0} \\
\mathrm{~T}_{1}\end{array}$ & $\begin{array}{l}-2191.961966 \\
-2191.830261\end{array}$ & $\mathrm{Au}(47 \%)$ & SCN (73\%) & 345.9 & \\
\hline \multirow{2}{*}{ Acetone } & 2.735 & - & $\begin{array}{l}\mathrm{S}_{0} \\
\mathrm{~T}_{1}\end{array}$ & $\begin{array}{l}-2191.935283 \\
-2191.802343\end{array}$ & $\mathrm{Au}(55 \%)$ & SCN (73\%) & 342.7 & \multirow{2}{*}{590} \\
\hline & 2.738 & - & $\begin{array}{l}\mathrm{S}_{0} \\
\mathrm{~T}_{1}\end{array}$ & $\begin{array}{l}-2191.958051 \\
-2191.825486\end{array}$ & $\mathrm{Au}(50 \%)$ & SCN (73\%) & 343.7 & \\
\hline \multirow{2}{*}{ DMSO } & 2.729 & - & $\begin{array}{l}\mathrm{S}_{0} \\
\mathrm{~T}_{1}\end{array}$ & $\begin{array}{l}-2191.866326 \\
-2191.734658\end{array}$ & $\mathrm{Au}(52 \%)$ & SCN (72\%) & 346.0 & \multirow{2}{*}{600} \\
\hline & 2.739 & - & $\begin{array}{l}\mathrm{S}_{0} \\
\mathrm{~T}_{1}\end{array}$ & $\begin{array}{l}-2191.951536 \\
-2191.818492\end{array}$ & $\mathrm{Au}(47 \%)$ & SCN (72\%) & 342.4 & \\
\hline \multirow{3}{*}{ m-Xylene } & 2.755 & - & $\begin{array}{l}\mathrm{S}_{0} \\
\mathrm{~T}_{1}\end{array}$ & $\begin{array}{l}-2191.894455 \\
-2191.760983\end{array}$ & $\mathrm{Au}(51 \%)$ & SCN (74\%) & 341.3 & \multirow{3}{*}{590} \\
\hline & 2.764 & - & $\begin{array}{l}\mathrm{S}_{0} \\
\mathrm{~T}_{1}\end{array}$ & $\begin{array}{l}-2191.904815 \\
-2191.776073\end{array}$ & $\mathrm{Au}(55 \%)$ & SCN (77\%) & 353.9 & \\
\hline & 2.755 & - & $\begin{array}{l}\mathrm{S}_{0} \\
\mathrm{~T}_{1}\end{array}$ & $\begin{array}{l}-2191.767941 \\
-2191.633890\end{array}$ & $\mathrm{Au}(56 \%)$ & SCN (73\%) & 339.9 & \\
\hline \multirow[t]{2}{*}{ DMF } & 2.741 & - & $\begin{array}{l}\mathrm{S}_{0} \\
\mathrm{~T}_{1}\end{array}$ & $\begin{array}{l}-2191.710110 \\
-2191.576365\end{array}$ & $\mathrm{Au}(57 \%)$ & SCN (72\%) & 340.7 & \multirow[t]{2}{*}{588} \\
\hline & 2.746 & - & $\mathrm{S}_{0}$ & -2191.706322 & $\mathrm{Au}(45 \%)$ & SCN (73\%) & 347.3 & \\
\hline
\end{tabular}




\begin{tabular}{cccccccc} 
& \multicolumn{9}{c}{$\mathrm{T}_{1}$} & -2191.575132 & & & \\
\cline { 2 - 7 } tert-Butylbenzene. $\mathrm{H}_{2} \mathrm{O}$ & 2.771 & $\mathrm{~S}_{0}$ & -2191.875988 & Au (42\%) & $\mathrm{SCN}(75 \%)$ & 347.1 & 554 \\
\hline
\end{tabular}




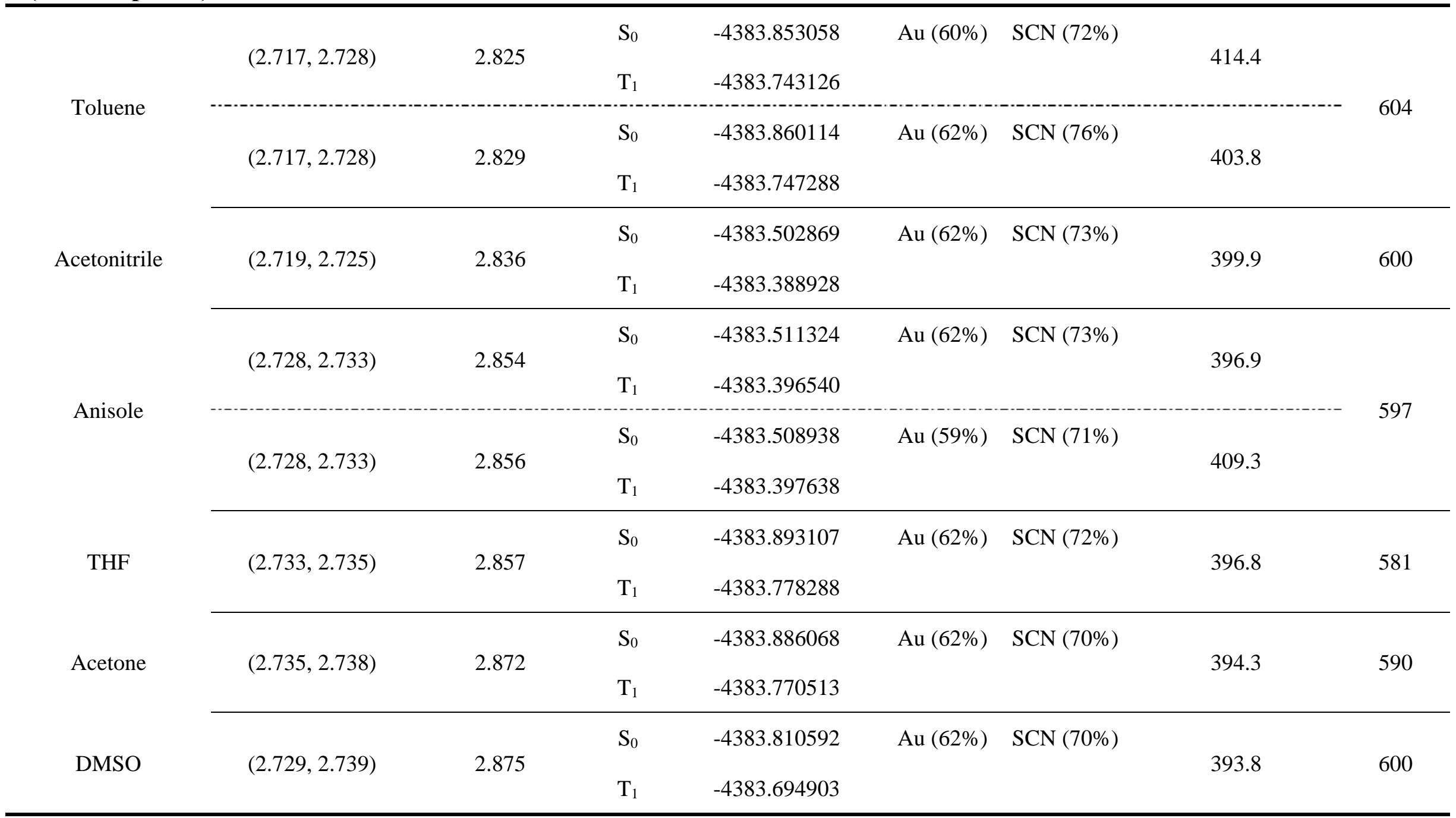




\begin{tabular}{|c|c|c|c|c|c|c|c|c|}
\hline & $(2.755,2.755)$ & 2.890 & $\begin{array}{l}\mathrm{S}_{0} \\
\mathrm{~T}_{1}\end{array}$ & $\begin{array}{l}-4383.655788 \\
-4383.540869\end{array}$ & $\mathrm{Au}(61 \%)$ & SCN (71\%) & 396.5 & \\
\hline m-Xylene & $(2.764,2.764)$ & 2.893 & $\begin{array}{l}\mathrm{S}_{0} \\
\mathrm{~T}_{1}\end{array}$ & $\begin{array}{l}-4383.804903 \\
-4383.695015\end{array}$ & $\mathrm{Au}(59 \%)$ & SCN (75\%) & 414.6 & 590 \\
\hline & $(2.755,2.755)$ & 2.902 & $\begin{array}{l}\mathrm{S}_{0} \\
\mathrm{~T}_{1}\end{array}$ & $\begin{array}{l}-4383.656800 \\
-4383.538602\end{array}$ & $\mathrm{Au}(62 \%)$ & SCN (73\%) & 385.5 & \\
\hline DMF & $(2.741,2.746)$ & 2.902 & $\begin{array}{l}\mathrm{S}_{0} \\
\mathrm{~T}_{1}\end{array}$ & $\begin{array}{l}-4383.410588 \\
-4383.294338\end{array}$ & $\mathrm{Au}(62 \%)$ & SCN (71\%) & 391.9 & 588 \\
\hline tert-Butylbenzene $\cdot \mathrm{H}_{2} \mathrm{O}$ & $(2.771,2.771)$ & 2.942 & $\begin{array}{l}\mathrm{S}_{0} \\
\mathrm{~T}_{1}\end{array}$ & $\begin{array}{l}-4383.747613 \\
-4383.627616\end{array}$ & $\mathrm{Au}(62 \%)$ & $\operatorname{SCN}(76 \%)$ & 379.7 & 554 \\
\hline
\end{tabular}




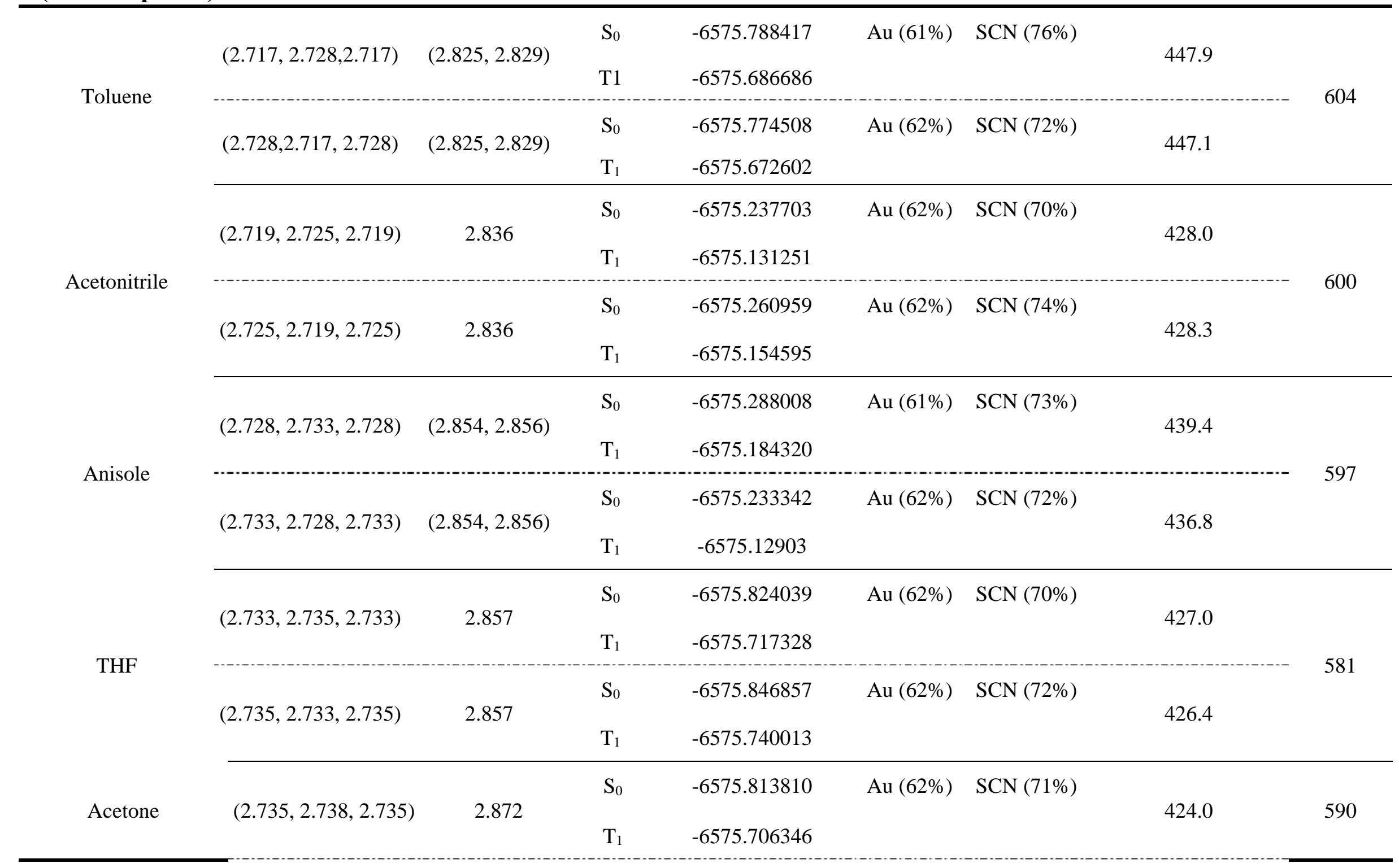




\begin{tabular}{|c|c|c|c|c|c|c|c|c|}
\hline \multirow{2}{*}{ DMSO } & $(2.729,2.739,2.729)$ & 2.875 & $\begin{array}{l}\mathrm{S}_{0} \\
\mathrm{~T}_{1}\end{array}$ & $\begin{array}{l}-6575.669320 \\
-6575.561705\end{array}$ & $\mathrm{Au}(62 \%)$ & SCN (71\%) & 423.4 & \multirow{2}{*}{600} \\
\hline & $(2.739,2.729,2.739)$ & 2.875 & $\begin{array}{l}\mathrm{S}_{0} \\
\mathrm{~T}_{1}\end{array}$ & $\begin{array}{l}-6575.754183 \\
-6575.646250\end{array}$ & $\mathrm{Au}(62 \%)$ & SCN (72\%) & 422.1 & \\
\hline \multirow{3}{*}{ m-Xylene } & $(2.755,2.755,2.755)$ & $(2.890,2.902)$ & $\begin{array}{l}\mathrm{S}_{0} \\
\mathrm{~T}_{1}\end{array}$ & $\begin{array}{l}-6575.544396 \\
-6575.43706\end{array}$ & $\mathrm{Au}(62 \%)$ & SCN (73\%) & 424.5 & \multirow{3}{*}{590} \\
\hline & $(2.764,2.764,2.764)$ & 2.893 & $\begin{array}{l}\mathrm{S}_{0} \\
\mathrm{~T}_{1}\end{array}$ & $\begin{array}{l}-6575.706028 \\
-6575.603021\end{array}$ & $\mathrm{Au}(61 \%)$ & SCN (75\%) & 442.3 & \\
\hline & $(2.755,2.755,2.755)$ & $(2.890,2.902)$ & $\begin{array}{l}\mathrm{S}_{0} \\
\mathrm{~T}_{1}\end{array}$ & $\begin{array}{l}-6575.417999 \\
-6575.308739\end{array}$ & $\mathrm{Au}(62 \%)$ & SCN (74\%) & 417.0 & \\
\hline \multirow{2}{*}{ DMF } & $(2.741,2.746,2.741)$ & 2.902 & $\begin{array}{l}\mathrm{S}_{0} \\
\mathrm{~T}_{1}\end{array}$ & $\begin{array}{l}-6575.114434 \\
-6575.005720\end{array}$ & $\mathrm{Au}(62 \%)$ & SCN (70\%) & 419.1 & \multirow{2}{*}{588} \\
\hline & $(2.746,2.741,2.746)$ & 2.902 & $\begin{array}{l}\mathrm{S}_{0} \\
\mathrm{~T}_{1}\end{array}$ & $\begin{array}{l}-6575.110337 \\
-6575.001258\end{array}$ & $\mathrm{Au}(62 \%)$ & SCN (72\%) & 417.7 & \\
\hline \multicolumn{2}{|c|}{ tert-Butylbenzene $\cdot \mathrm{H}_{2} \mathrm{O}(2.771,2.771,2.771)$} & 2.942 & $\begin{array}{l}\mathrm{S}_{0} \\
\mathrm{~T}_{1}\end{array}$ & $\begin{array}{l}-6575.618736 \\
-6575.506896\end{array}$ & $\mathrm{Au}(63 \%)$ & SCN (76\%) & 407.4 & 554 \\
\hline
\end{tabular}




\section{Supporting Information}

Figure S1. The PXRD patterns of the fresh powder samples for 2.2DMF recorded for $4 \mathrm{~h}:$ (i) simulated, (ii) as synthesized - $0 \mathrm{~min}$, (iii) $5 \mathrm{~min}$, (iv) $10 \mathrm{~min}$, (v) $30 \mathrm{~min}$, (vi) $60 \mathrm{~min}$, (vii) $120 \mathrm{~min}$, (viii) $240 \mathrm{~min}$, and (ix) grinding with DMF.

Figure S2. The PXRD patterns of the fresh powder samples for $2 \cdot 2 \mathrm{THF}$ recorded for $4 \mathrm{~h}$ : (i) simulated, (ii) as synthesized - $0 \mathrm{~min}$, (iii) $5 \mathrm{~min}$, (iv) $10 \mathrm{~min}$, (v) $30 \mathrm{~min}$, (vi) $60 \mathrm{~min}$, (vii) $120 \mathrm{~min}$, (viii) 240 min, and (ix) grinding with THF.

Figure S3. The PXRD patterns of the fresh powder samples for $2 \cdot 2$ acetone recorded for $4 \mathrm{~h}:$ (i) simulated, (ii) as synthesized - $0 \mathrm{~min}$, (iii) $5 \mathrm{~min}$, (iv) $10 \mathrm{~min}$, (v) $30 \mathrm{~min}$, (vi) $60 \mathrm{~min}$, (vii) $120 \mathrm{~min}$, (viii) $240 \mathrm{~min}$, and (ix) grinding with acetone.

Figure S4. The PXRD patterns of the fresh powder samples for $2 \cdot 1.5$ anisole recorded for $4 \mathrm{~h}:$ (i) simulated, (ii) as synthesized - $0 \mathrm{~min}$, (iii) $5 \mathrm{~min}$, (iv) $10 \mathrm{~min}$, (v) $30 \mathrm{~min}$, (vi) $60 \mathrm{~min}$, (vii) $120 \mathrm{~min}$, (viii) $240 \mathrm{~min}$, and (ix) grinding with anisole.

Figure S5. TGA trace for 2.solvates.

Figure S6. ${ }^{1} \mathrm{H}$ NMR spectra for 2.2DMF while exposed to air up to $24 \mathrm{hr}: \delta(\mathrm{ppm}) 2.88 \cdot 2.95$ (s, 12H, $\left.\left(\mathrm{CH}_{3}\right)_{2} \mathrm{NCHO}\right), \delta 8.01\left(\mathrm{~s}, 2 \mathrm{H},\left(\mathrm{CH}_{3}\right)_{2} \mathrm{NCHO}\right)$.

Figure S7. ${ }^{1} \mathrm{H}$ NMR spectra for 2.2DMSO while exposed to air up to $24 \mathrm{hr}: \delta(\mathrm{ppm}) 2.61(\mathrm{~s}, 12 \mathrm{H}$, $\left.\left(\mathrm{CH}_{3}\right)_{2} \mathrm{SO}\right)$.

Figure S8. ${ }^{1} \mathrm{H}$ NMR spectra for $2 \cdot 2 \mathrm{THF}$ while exposed to air up to $24 \mathrm{hr}: \delta(\mathrm{ppm}) 1.84(\mathrm{t}, 8 \mathrm{H}$, $\left.\mathrm{OCH}_{2} \mathrm{CH}_{2}-\right), \delta 3.73\left(\mathrm{t}, 8 \mathrm{H}, \mathrm{OCH}_{2} \mathrm{CH}_{2}\right)$.

Figure S9. ${ }^{1} \mathrm{H}$ NMR spectra for 2.2acetone while exposed to air up to $24 \mathrm{hr}: \delta(\mathrm{ppm}) 2.17$ (s, 12H, $\left.\left(\mathrm{CH}_{3}\right)_{2} \mathrm{CO}\right)$.

Figure S10. ${ }^{1} \mathrm{H}$ NMR spectra for $2 \cdot \underline{1.5 t o l u e n e}$ while exposed to air up to $24 \mathrm{hr}: \delta(\mathrm{ppm}) 2.93(\mathrm{~s}, 4.5 \mathrm{H}$, $\left.\mathrm{CH}_{3} \mathrm{C}_{6} \mathrm{H}_{5}\right), 7.14-7.26\left(\mathrm{~m}, 7.5 \mathrm{H}, \mathrm{CH}_{3} \mathrm{C}_{6} \mathbf{H}_{5}\right)$.

Figure S11. ${ }^{1} \mathrm{H}$ NMR spectra for $2 \cdot 1.5$ anisole while exposed to air up to $24 \mathrm{hr}: \delta(\mathrm{ppm}) 3.73$ (s, $4.5 \mathrm{H}$, $\left.\mathrm{CH}_{3} \mathrm{OC}_{6} \mathrm{H}_{5}\right), \delta$ 6.91-7.3 (m, 7.5 $\left.\mathrm{H}_{,} \mathrm{CH}_{3} \mathrm{OC}_{6} \mathrm{H}_{5}\right)$.

Figure S12. The luminescence spectra of the crystalline samples for 2-tert-butylbenzene $\cdot \mathrm{H}_{2} \mathrm{O}$ exposed in air with total time of $4 \mathrm{~h}$ (time interval : $5 \mathrm{~min}$ ). The excitation wavelength is $380 \mathrm{~nm}$.

Figure S13. The luminescence spectra of the crystalline samples for 2.DMF exposed in air with total time of $4 \mathrm{~h}$ (time interval : $5 \mathrm{~min}$ ). The excitation wavelength is $380 \mathrm{~nm}$.

Figure S14. The luminescence spectra of the crystalline samples for $2 \cdot 0.5 m$-xylene exposed in air with total time of $4 \mathrm{~h}$ (time interval : $5 \mathrm{~min}$ ). The excitation wavelength is $380 \mathrm{~nm}$.

Figure S15. The luminescence spectra of the crystalline samples for 2.2THF exposed in air with total time of $4 \mathrm{~h}$ (time interval : $5 \mathrm{~min}$ ). The excitation wavelength is $380 \mathrm{~nm}$. 
Figure S16. The luminescence spectra of the crystalline samples for $2 \cdot 1.5$ toluene exposed in air with total time of $4 \mathrm{~h}$ (time interval : $5 \mathrm{~min}$ ). The excitation wavelength is $380 \mathrm{~nm}$.

Figure S17. HOMO and LUMO of 2. solvates $\mathrm{S}_{0}$ state obtained by B3LYP/LanL2DZ calculations for (a) $\mathrm{Au}_{2}$ complex, (b) two $\mathrm{Au}_{2}$ complexes, (c) three $\mathrm{Au}_{2}$ complexes. 


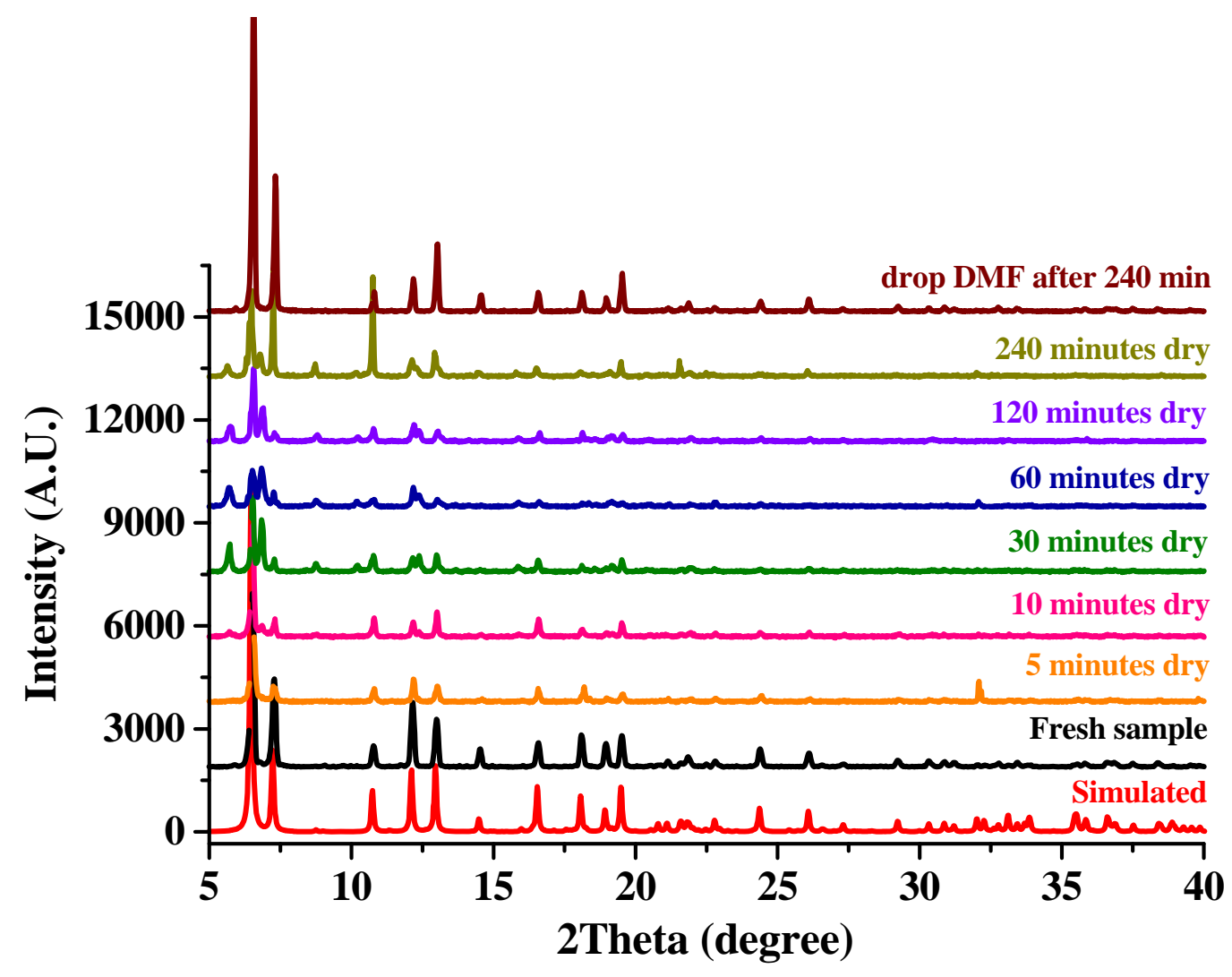

Figure S1. The PXRD patterns of the fresh powder samples for 2.2DMF recorded for $4 \mathrm{~h}$ : (i) simulated, (ii) as synthesized - $0 \mathrm{~min}$, (iii) $5 \mathrm{~min}$, (iv) $10 \mathrm{~min}$, (v) $30 \mathrm{~min}$, (vi) $60 \mathrm{~min}$, (vii) $120 \mathrm{~min}$, (viii) $240 \mathrm{~min}$, and (ix) grinding with DMF. 


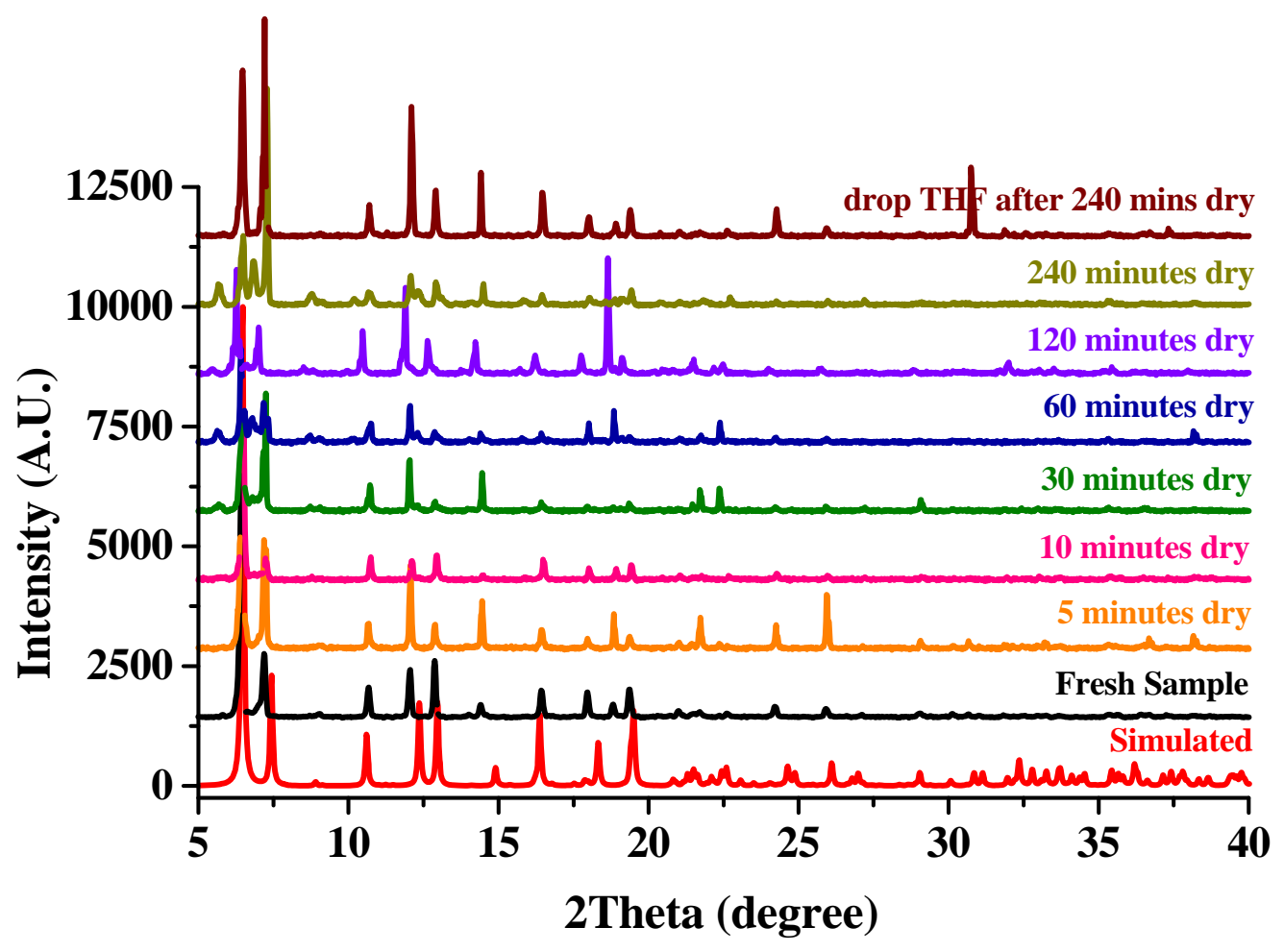

Figure S2. The PXRD patterns of the fresh powder samples for 2.2THF recorded for $4 \mathrm{~h}$ : (i) simulated, (ii) as synthesized - $0 \mathrm{~min}$, (iii) $5 \mathrm{~min}$, (iv) $10 \mathrm{~min}$, (v) $30 \mathrm{~min}$, (vi) $60 \mathrm{~min}$, (vii) $120 \mathrm{~min}$, (viii) $240 \mathrm{~min}$, and (ix) grinding with THF. 


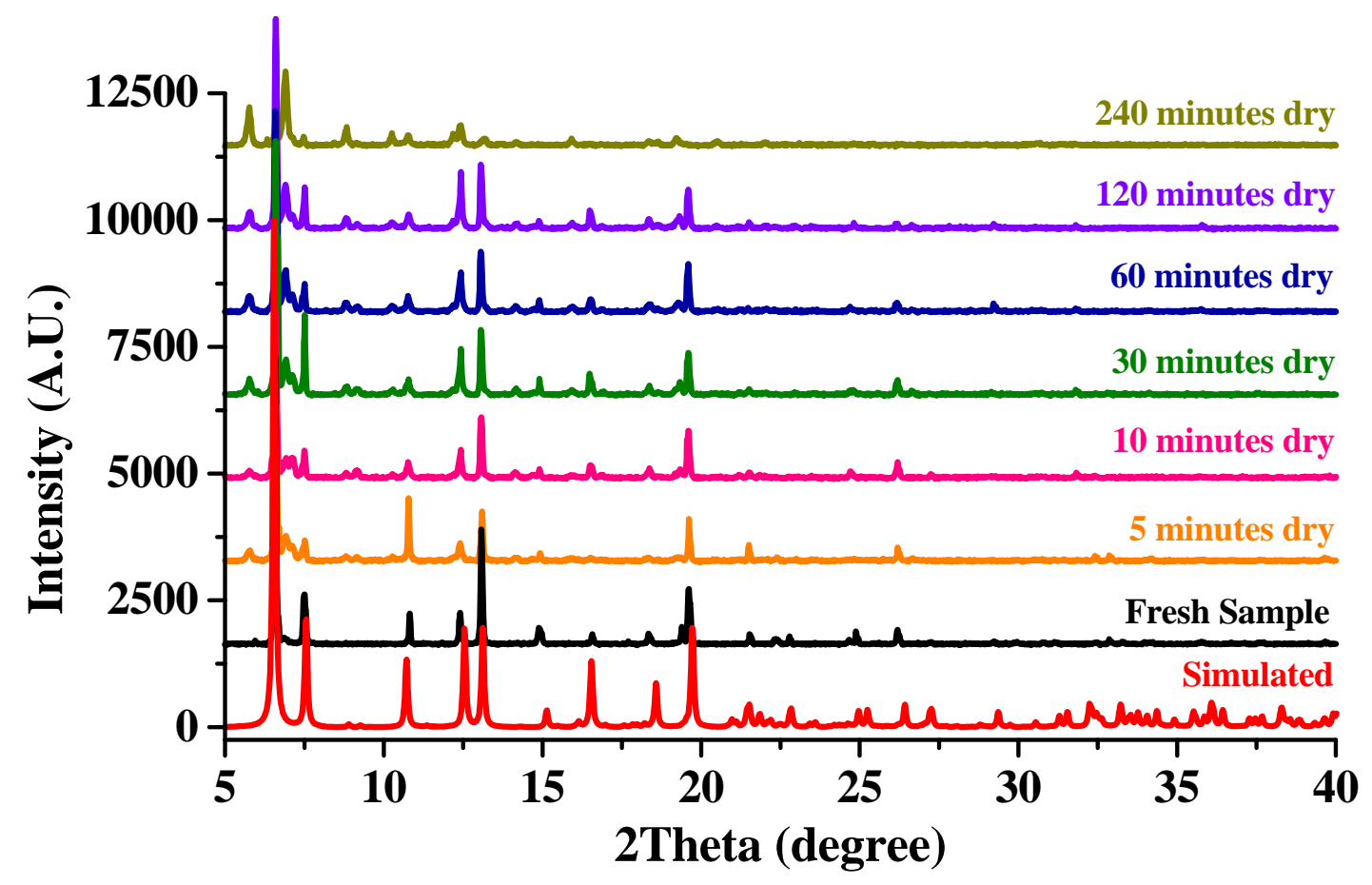

Figure S3. The PXRD patterns of the fresh powder samples for 2.2acetone recorded for $4 \mathrm{~h}$ : (i) simulated, (ii) as synthesized - $0 \mathrm{~min}$, (iii) $5 \mathrm{~min}$, (iv) 10 min, (v) $30 \mathrm{~min}$, (vi) $60 \mathrm{~min}$, (vii) $120 \mathrm{~min}$, (viii) $240 \mathrm{~min}$, and (ix) grinding with acetone. 


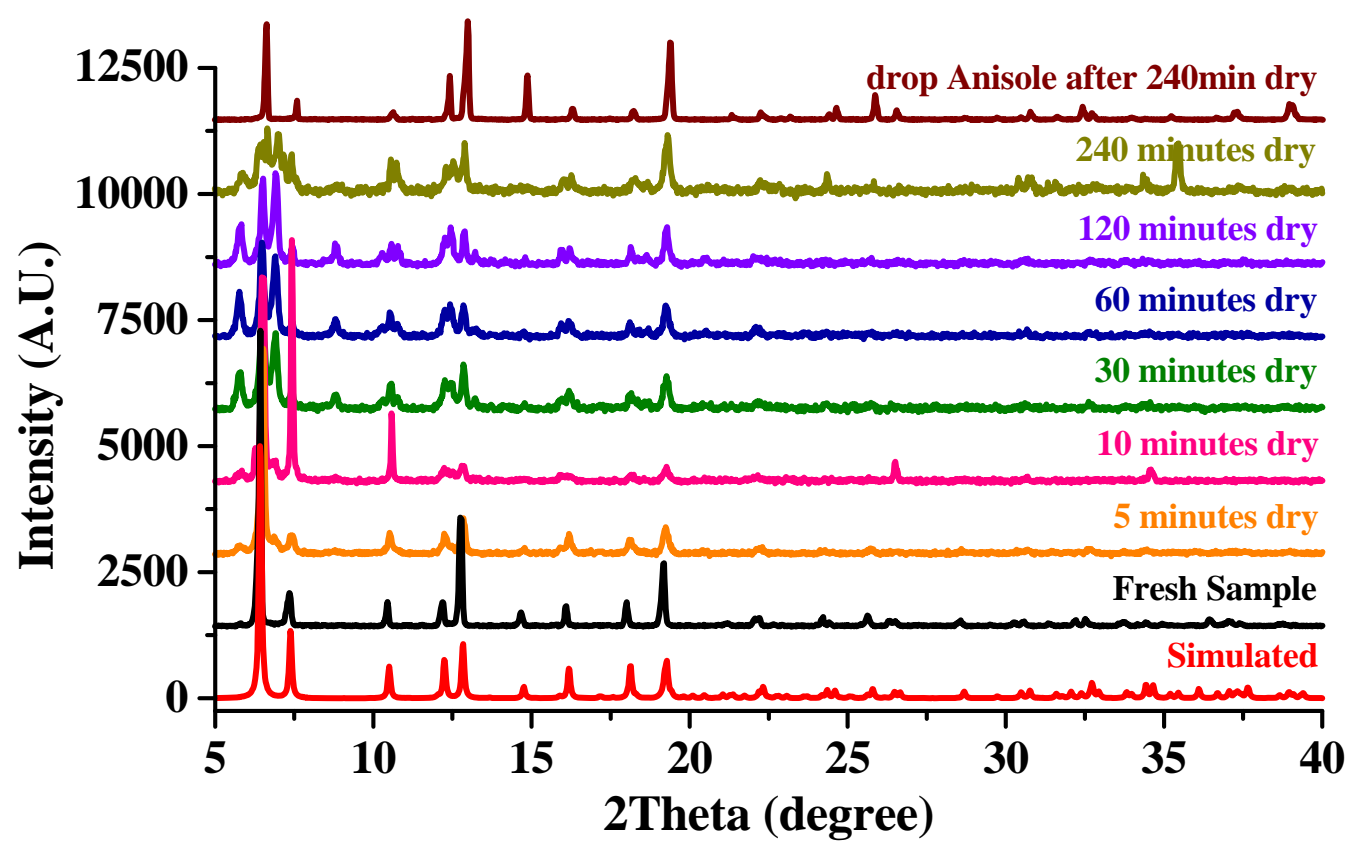

Figure S4. The PXRD patterns of the fresh powder samples for $2 \cdot 1.5$ anisole recorded for $4 \mathrm{~h}$ : (i) simulated, (ii) as synthesized - $0 \mathrm{~min}$, (iii) $5 \mathrm{~min}$, (iv) 10 min, (v) $30 \mathrm{~min}$, (vi) $60 \mathrm{~min}$, (vii) $120 \mathrm{~min}$, (viii) $240 \mathrm{~min}$, and (ix) grinding with anisole. 

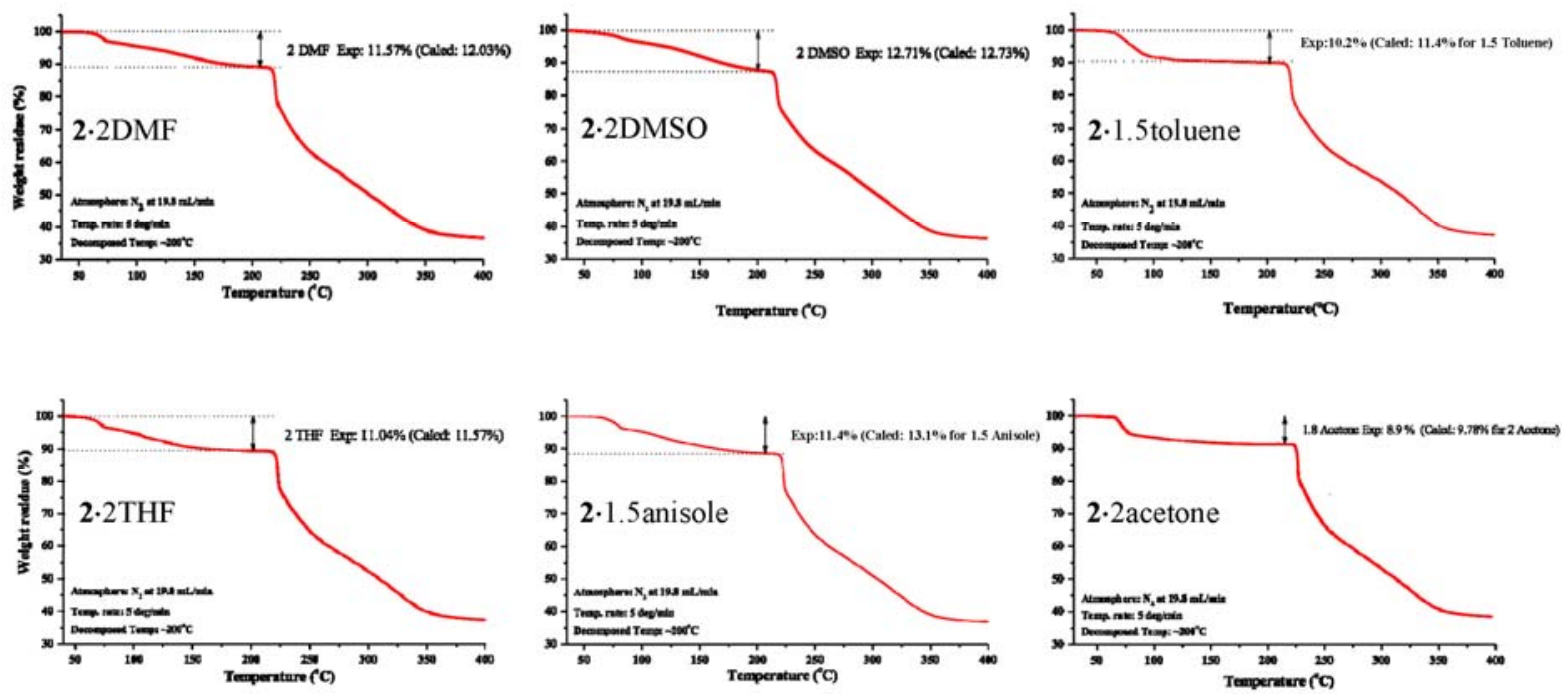

Figure S5. TGA trace for $\mathbf{2}$-solvates. 


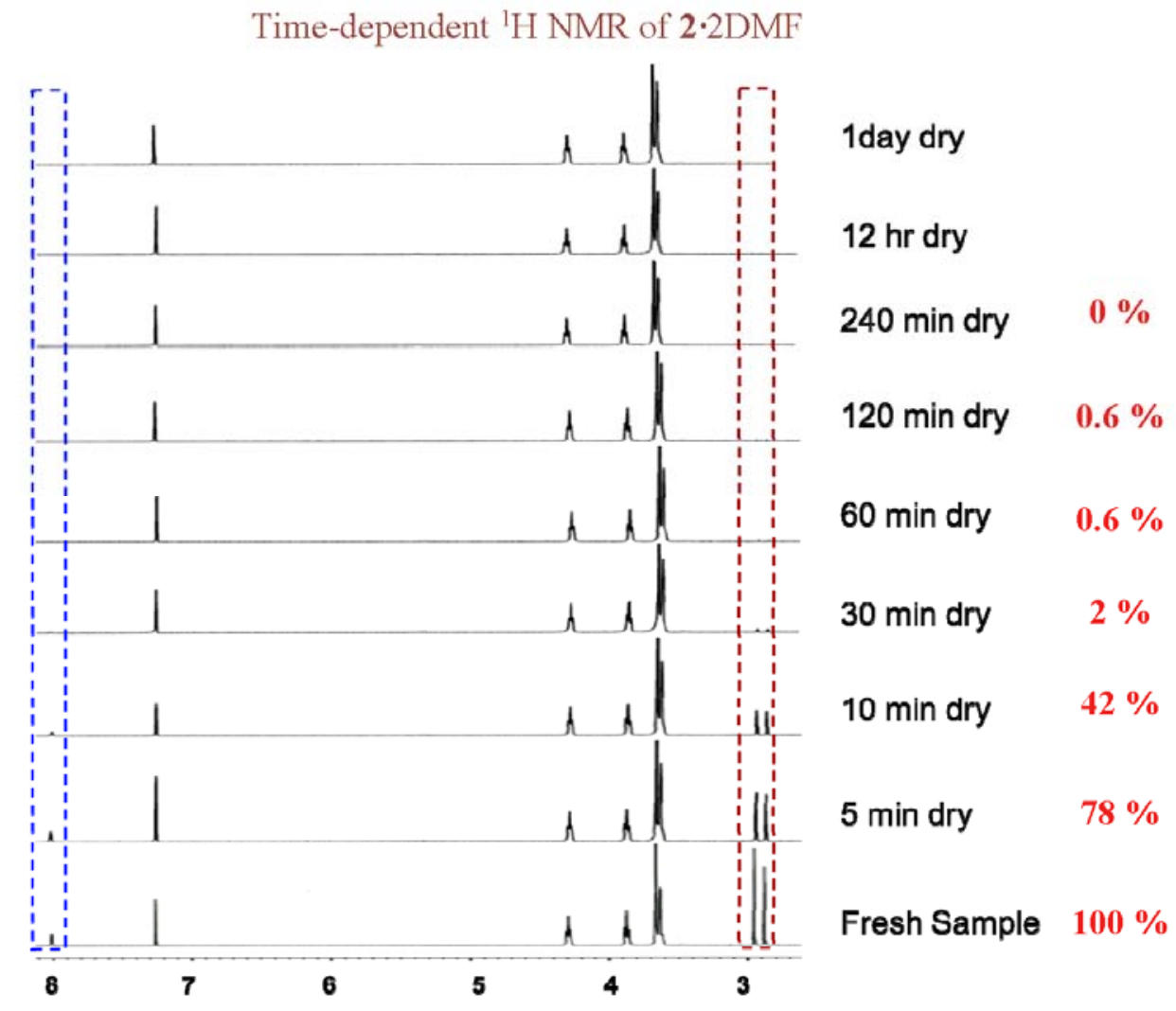

Figure S6. ${ }^{1} \mathrm{H}$ NMR spectra for 2. $2 \mathrm{DMF}$ while exposed to air up to $24 \mathrm{hr}: \delta$ (ppm) 2.88 - $2.95\left(\mathrm{~s}, 12 \mathrm{H},\left(\mathrm{CH}_{3}\right)_{2} \mathrm{NCHO}\right), \delta 8.01\left(\mathrm{~s}, 2 \mathrm{H},\left(\mathrm{CH}_{3}\right)_{2} \mathrm{NCHO}\right)$. 


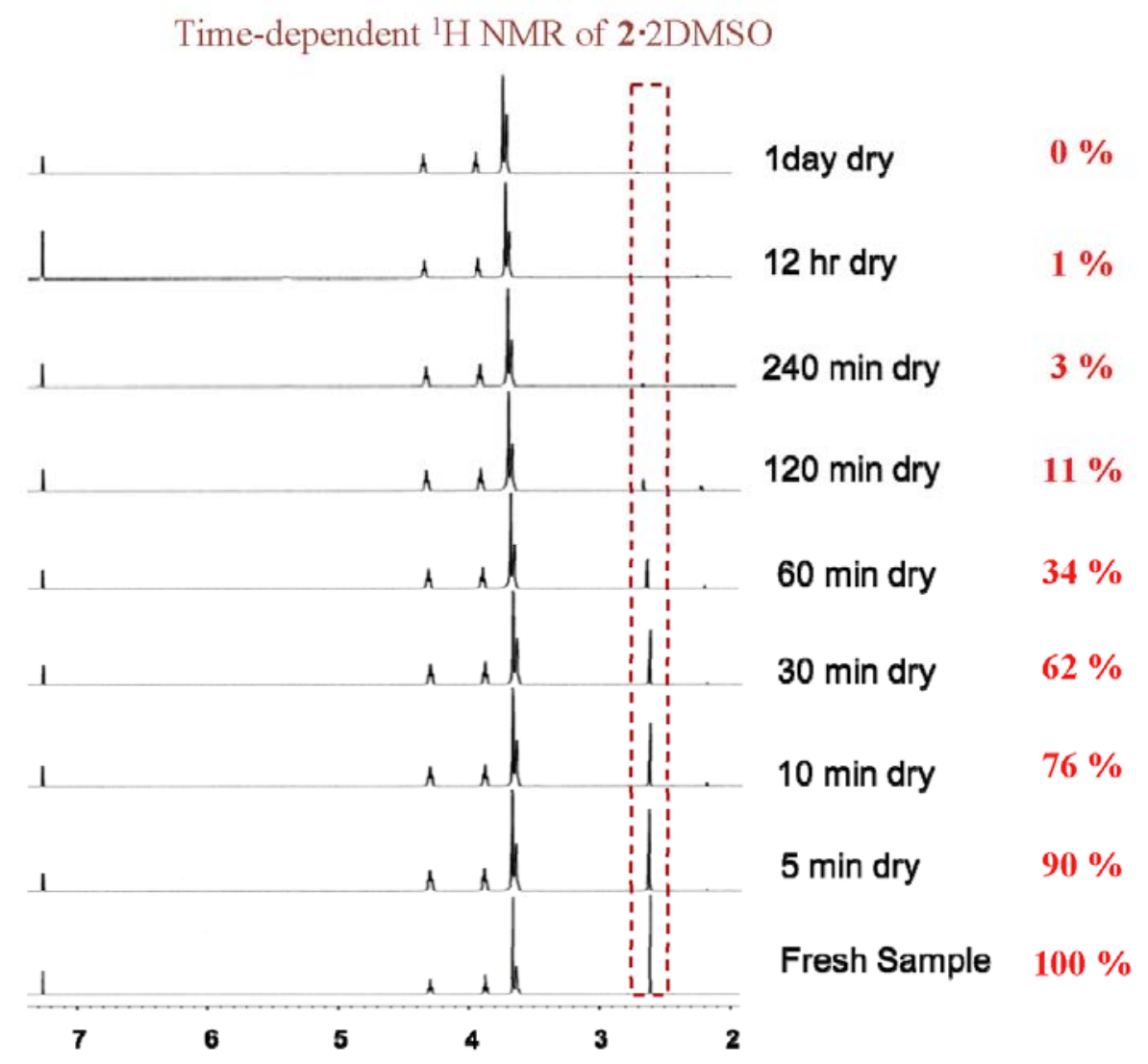

Figure S7. ${ }^{1} \mathrm{H}$ NMR spectra for $2 \cdot 2 \mathrm{DMSO}$ while exposed to air up to $24 \mathrm{hr}: \delta$ (ppm) 2.61 (s, 12H, $\left.\left(\mathrm{CH}_{3}\right)_{2} \mathrm{SO}\right)$. 
Time-dependent ${ }^{1} \mathrm{H}$ NMR of $\mathbf{2} \cdot 2 \mathrm{THF}$

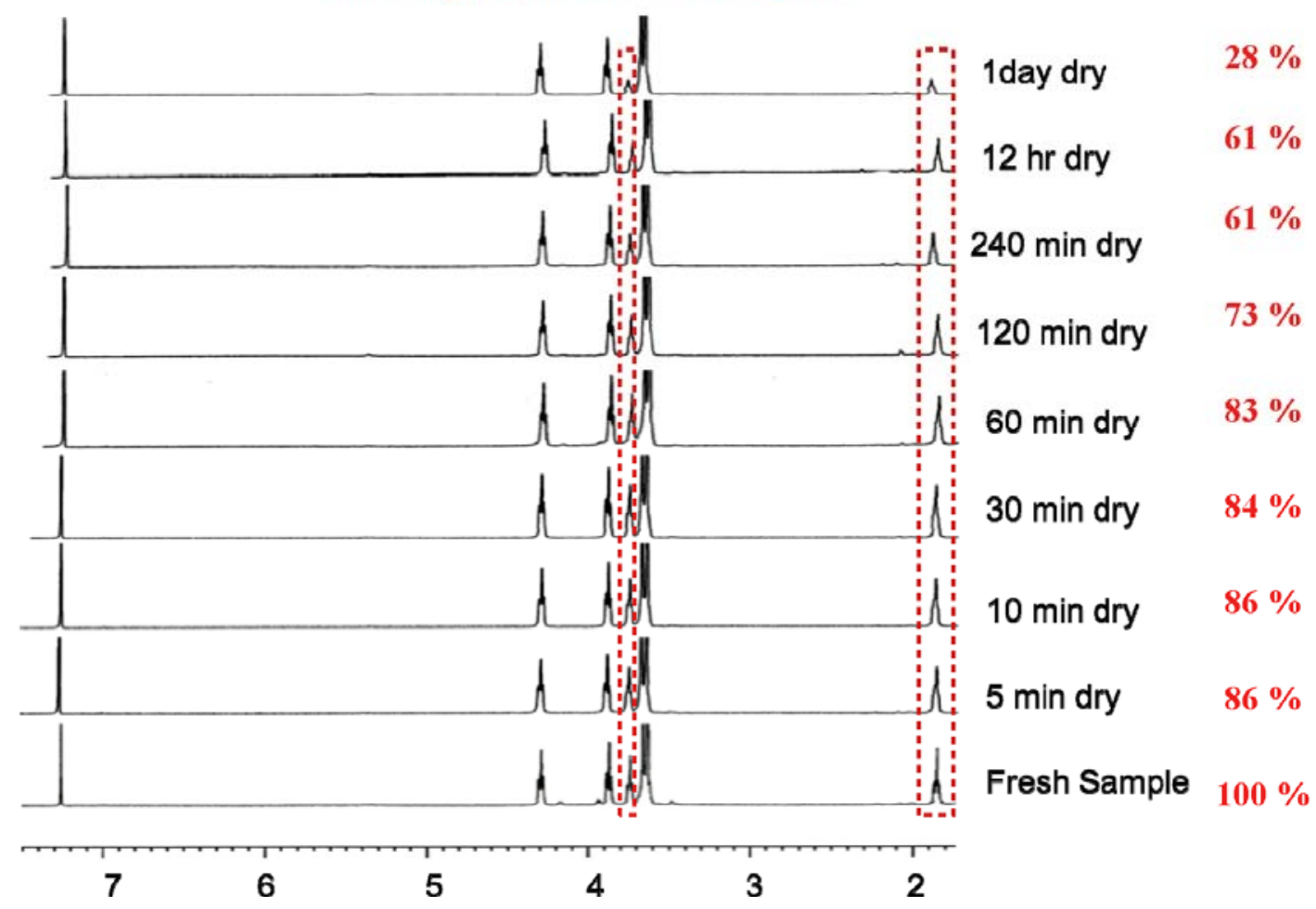

Figure S8. ${ }^{1} \mathrm{H}$ NMR spectra for $2 \cdot 2 \mathrm{THF}$ while exposed to air up to $24 \mathrm{hr}: \delta$ (ppm) 1.84 $\left(\mathrm{t}, 8 \mathrm{H}, \mathrm{OCH}_{2} \mathrm{CH}_{2-}\right), \delta 3.73\left(\mathrm{t}, 8 \mathrm{H}, \mathrm{OCH}_{2} \mathrm{CH}_{2}\right)$. 
Time-dependent ${ }^{1} \mathrm{H}$ NMR of $\mathbf{2} \cdot 2$ acetone

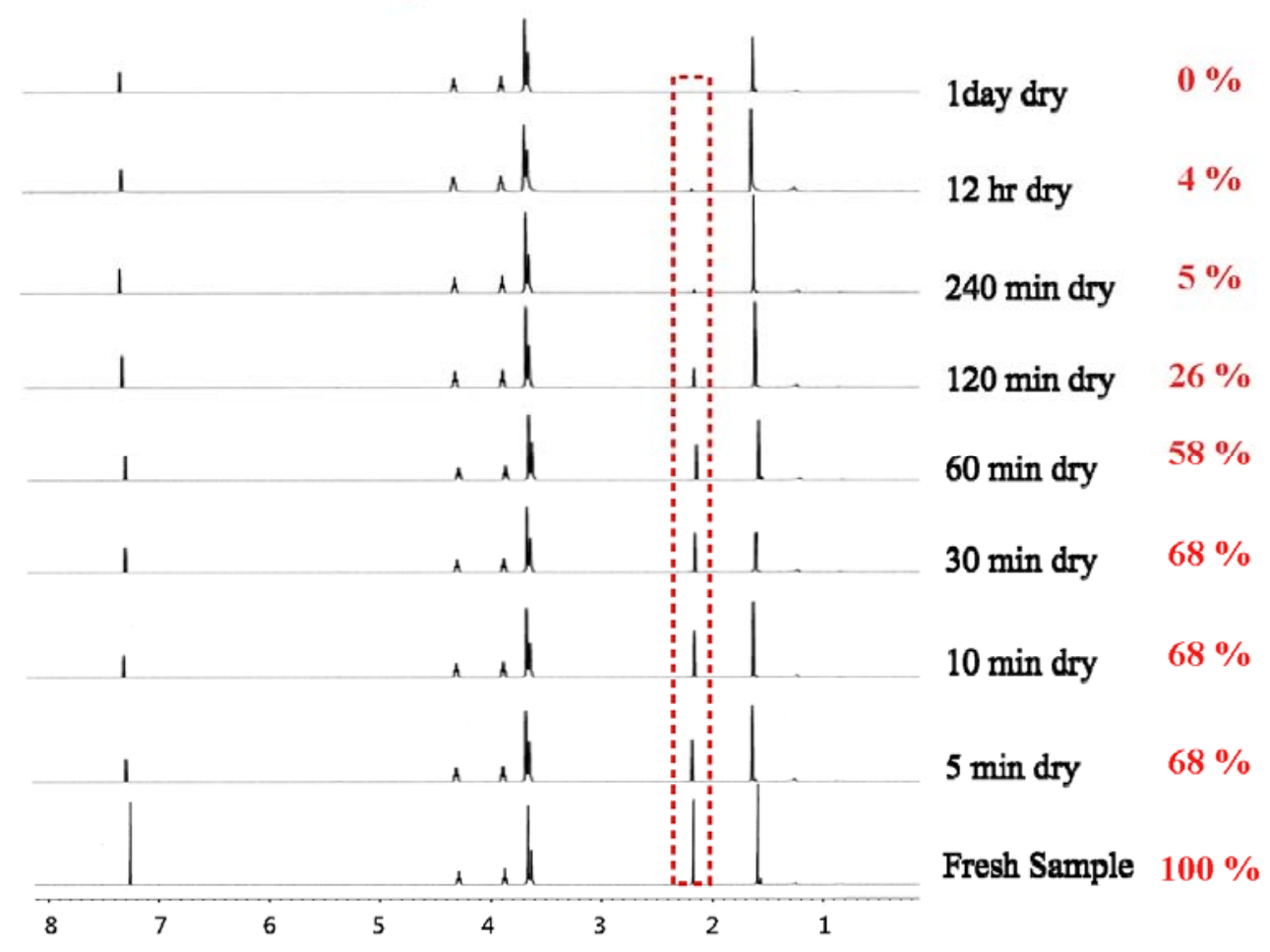

Figure S9. ${ }^{1} \mathrm{H}$ NMR spectra for 2.2acetone while exposed to air up to $24 \mathrm{hr}: \delta$ (ppm) 2.17 (s, 12H, $\left.\left(\mathrm{CH}_{3}\right)_{2} \mathrm{CO}\right)$. 
Time-dependent ${ }^{1} \mathrm{H}$ NMR of $\mathbf{2} \cdot 1.5$ toluene

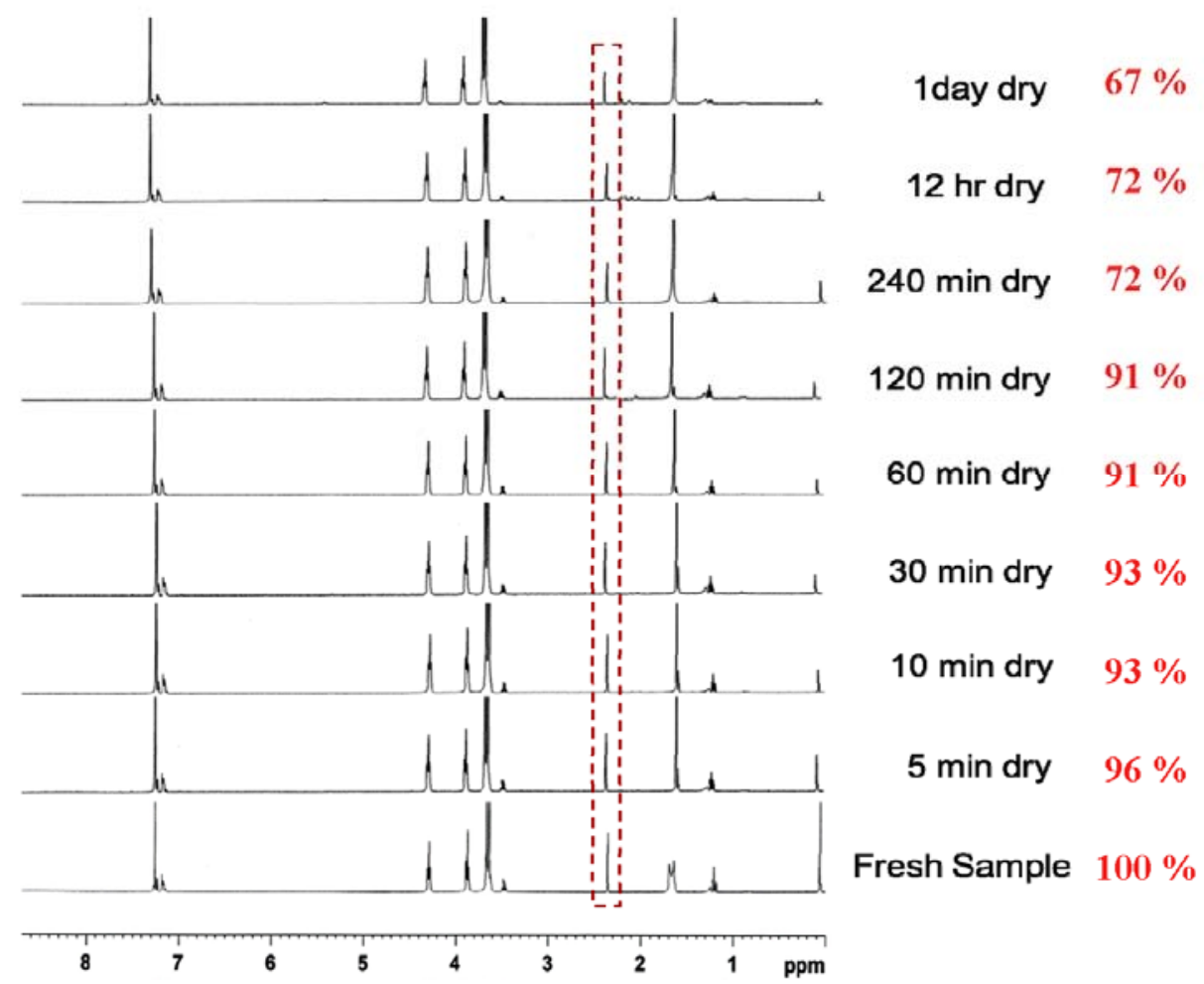

Figure S10. ${ }^{1} \mathrm{H}$ NMR spectra for $2 \cdot 1.5$ toluene while exposed to air up to $24 \mathrm{hr}$ : $\delta(\mathrm{ppm}) 2.93\left(\mathrm{~s}, 4.5 \mathrm{H}, \mathrm{CH}_{3} \mathrm{C}_{6} \mathrm{H}_{5}\right)$, 7.14-7.26 (m, 7.5H, $\left.\mathrm{CH}_{3} \mathrm{C}_{6} \mathrm{H}_{5}\right)$. 


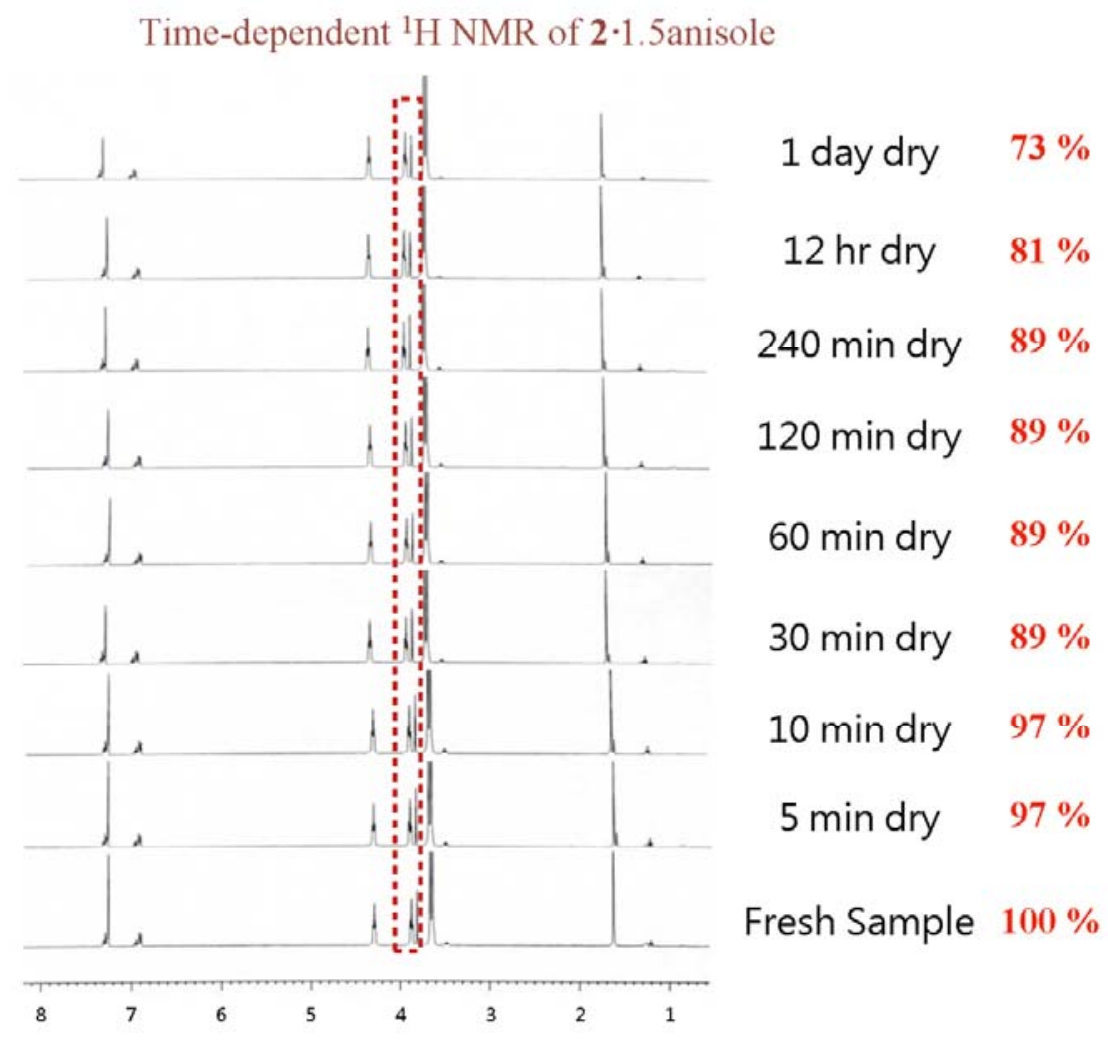

Figure S11. ${ }^{1} \mathrm{H}$ NMR spectra for $2 \cdot 1.5$ anisole while exposed to air up to 24 $\mathrm{hr}: \delta(\mathrm{ppm}) 3.73\left(\mathrm{~s}, 4.5 \mathrm{H}, \mathrm{CH}_{3} \mathrm{OC}_{6} \mathrm{H}_{5}\right), \delta 6.91-7.3\left(\mathrm{~m}, 7.5 \mathrm{H}_{,} \mathrm{CH}_{3} \mathrm{OC}_{6} \mathbf{H}_{5}\right)$. 


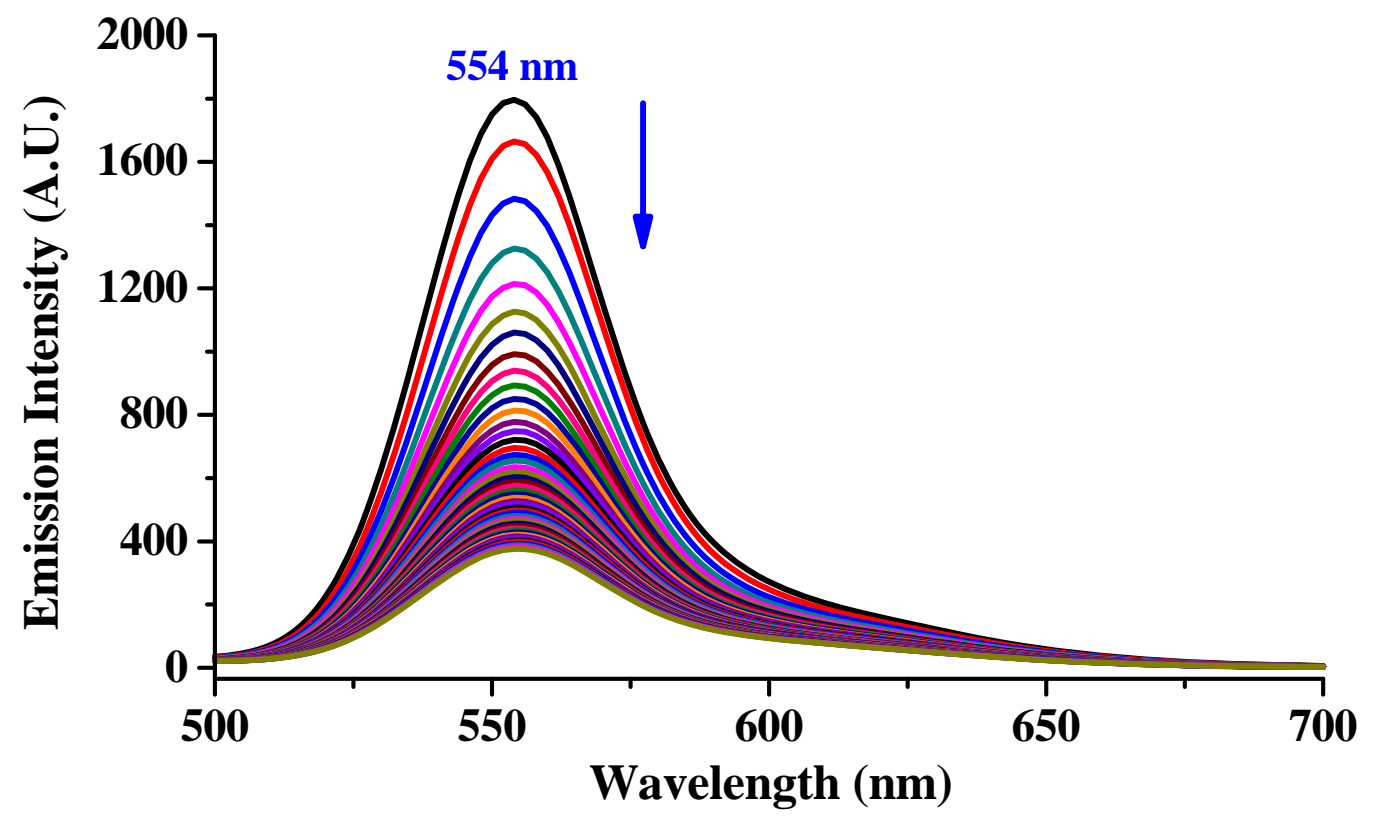

Figure S12. The luminescence spectra of the crystalline samples for 2.tert-butylbenzene $\cdot \mathrm{H}_{2} \mathrm{O}$ exposed in air with total time of $4 \mathrm{~h}$ (time interval : $5 \mathrm{~min}$ ). The excitation wavelength is $380 \mathrm{~nm}$. 


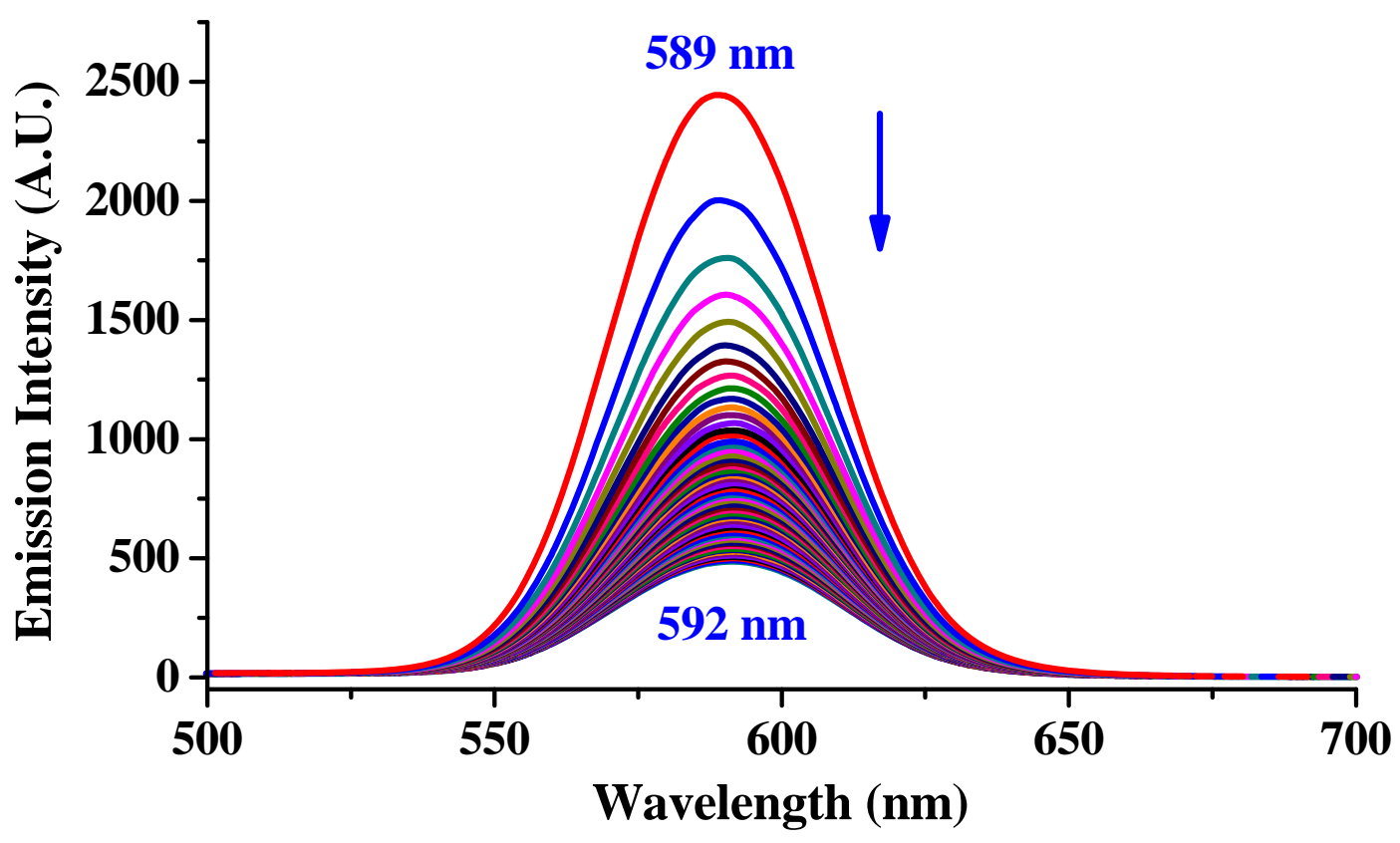

Figure S13. The luminescence spectra of the crystalline samples for 2.DMF exposed in air with total time of $4 \mathrm{~h}$ (time interval : $5 \mathrm{~min}$ ). The excitation wavelength is $380 \mathrm{~nm}$. 


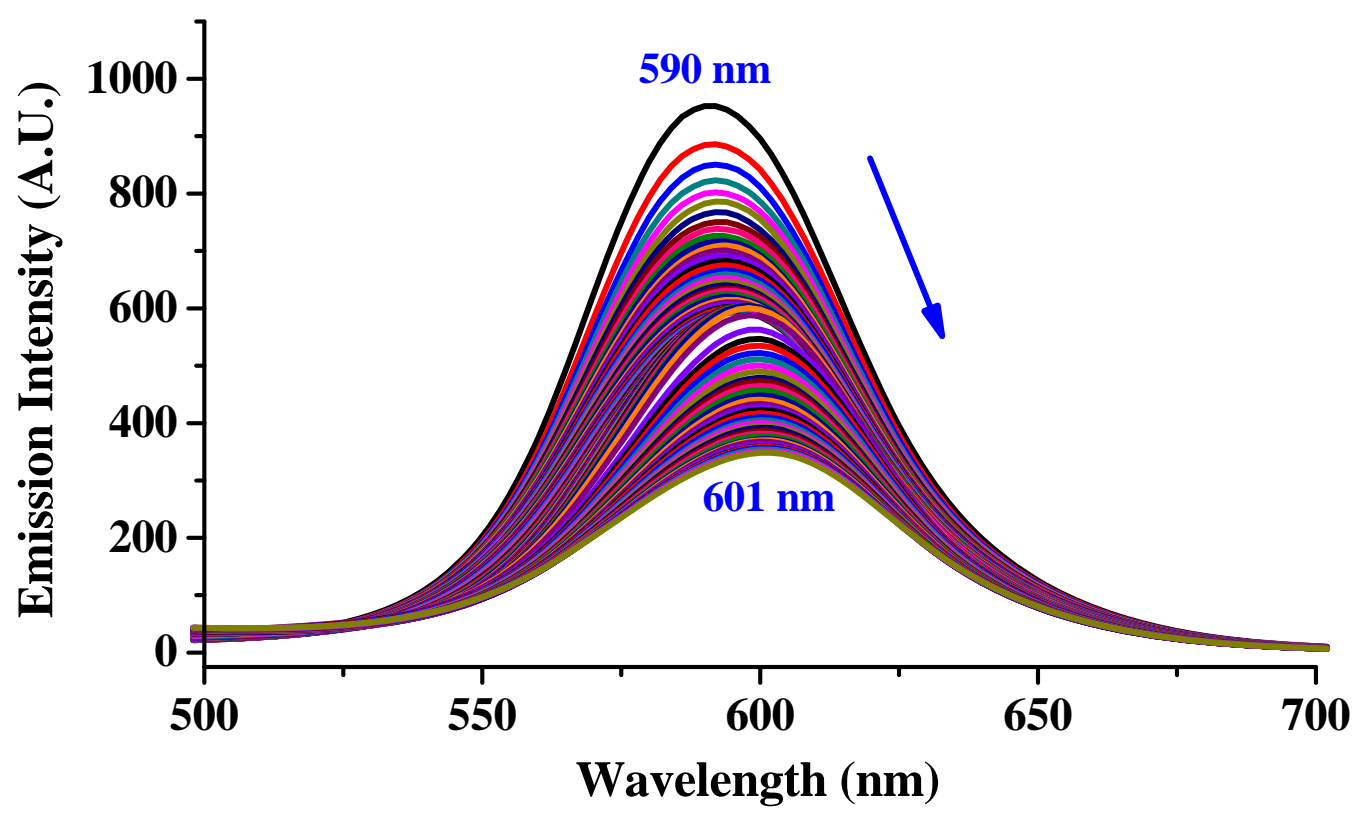

Figure S14. The luminescence spectra of the crystalline samples for $2 \cdot 0.5 \mathrm{~m}$ xylene exposed in air with total time of $4 \mathrm{~h}$ (time interval : $5 \mathrm{~min}$ ). The excitation wavelength is $380 \mathrm{~nm}$. 


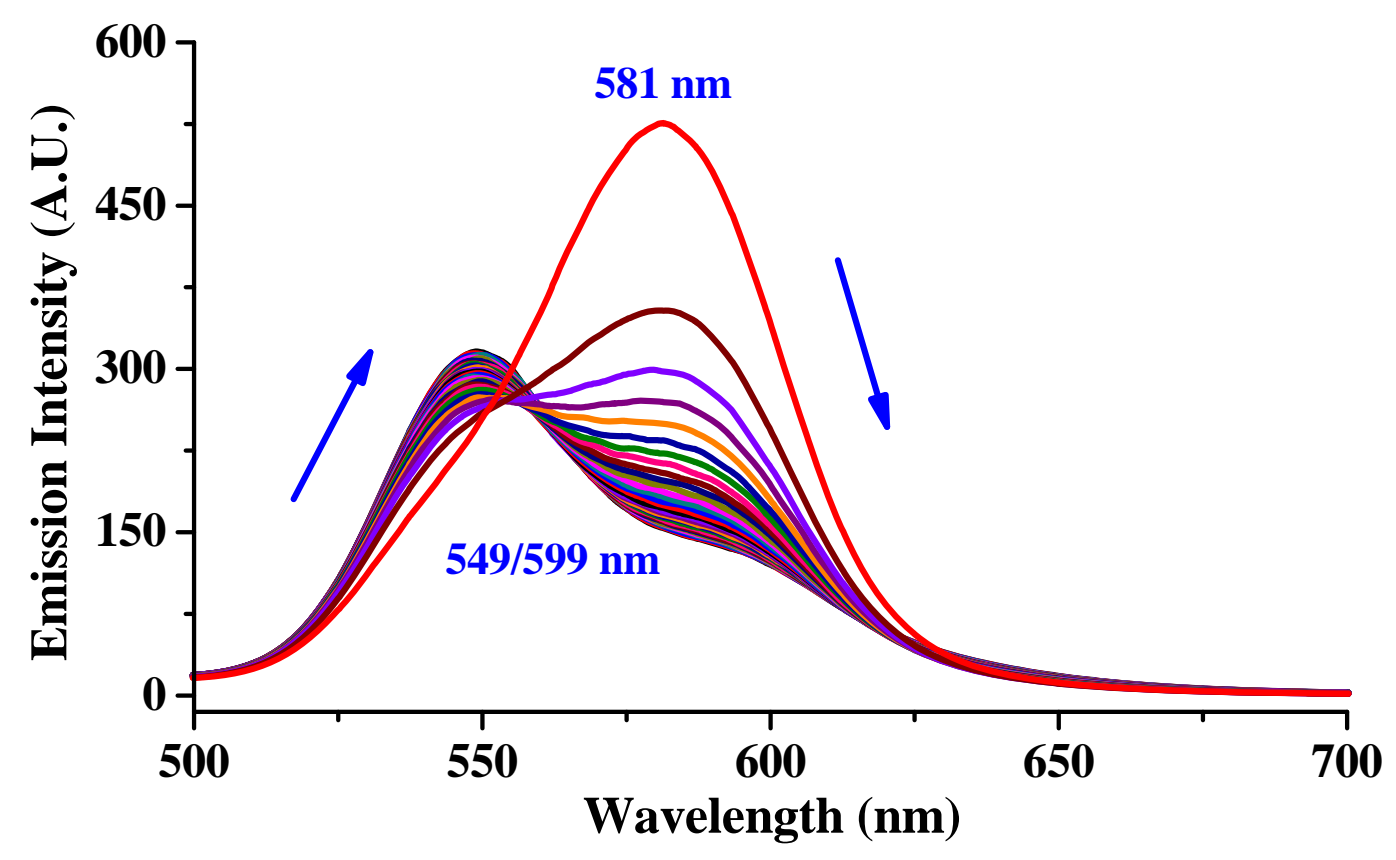

Figure S15. The luminescence spectra of the crystalline samples for 2.2THF exposed in air with total time of $4 \mathrm{~h}$ (time interval : $5 \mathrm{~min}$ ). The excitation wavelength is $380 \mathrm{~nm}$. 


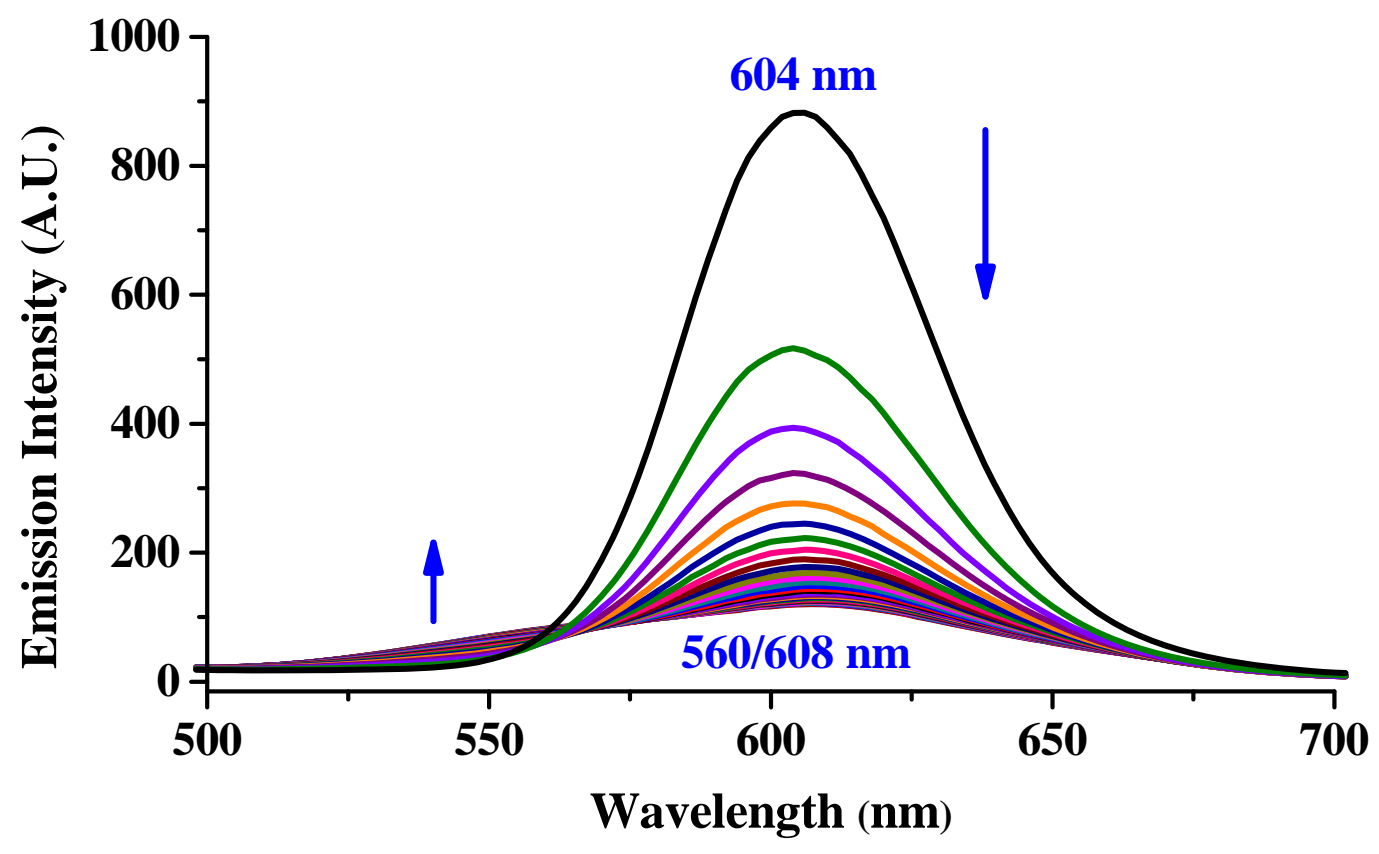

Figure S16. The luminescence spectra of the crystalline samples for 2.1.5toluene exposed in air with total time of $4 \mathrm{~h}$ (time interval $: 5 \mathrm{~min}$ ). The excitation wavelength is $380 \mathrm{~nm}$. 
Figure S17. HOMO and LUMO of 2· solvates $S_{0}$ state obtained by B3L YP/LanL2DZ calculations for (a) Auz complex, (b) two Au complexes, (c) three $\mathrm{Au}_{2}$ complexes.

(a)

\section{Toluene}

$\left(\mathrm{S}_{0}, \mathrm{Au}-\mathrm{Au}_{\mathrm{intra}}=2.717\right)$

LUMO (181, Au 20\%, S 16\%, C 42\%, N 17\%, isovalue = 0.02) $\quad-0.04025$ hartree

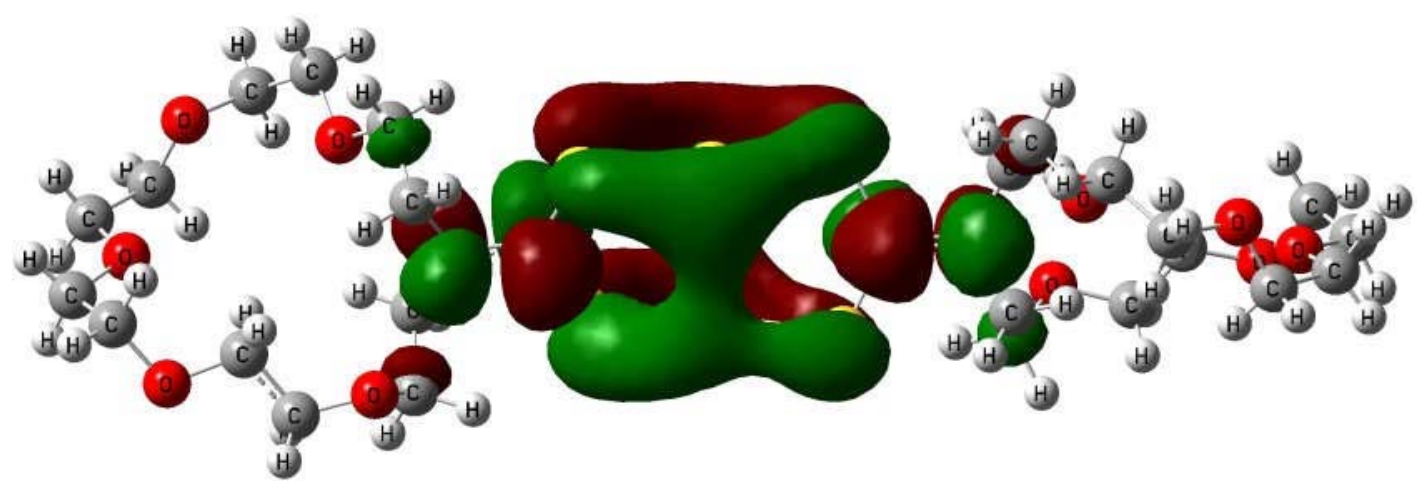

HOMO (180, Au 52\%, S 44\%, C 0\%, N 2\%, isovalue = 0.02) -0.20168 hartree

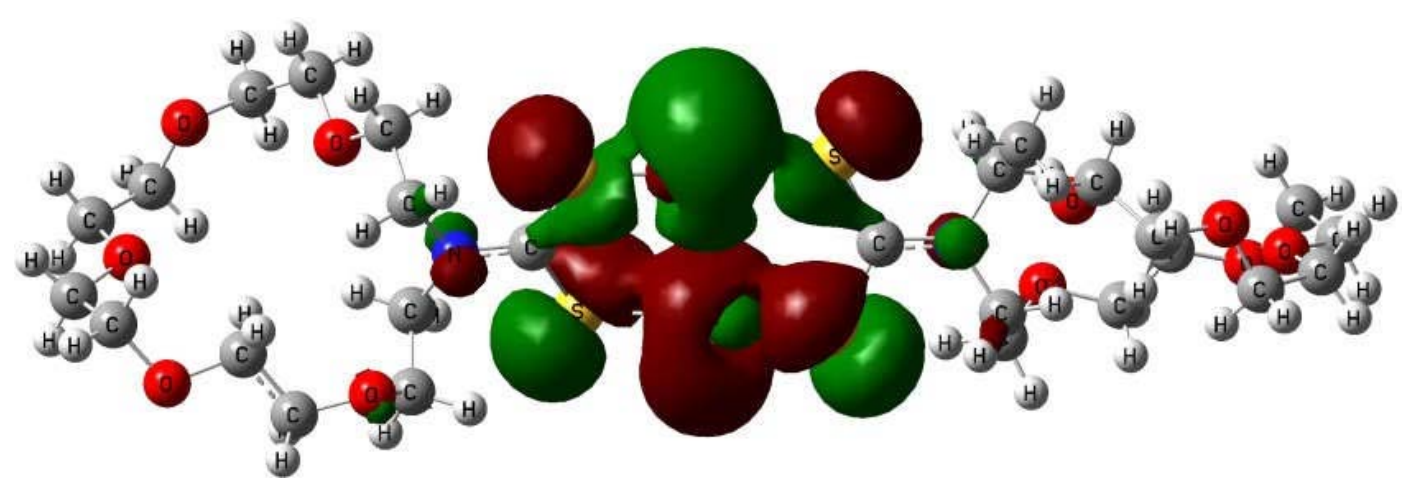




\section{Toluene}

$\left(\mathrm{S}_{0}, \mathrm{Au}-\mathrm{Au}_{\mathrm{intra}}=2.728\right)$

LUMO (181, Au 22\%, S 14\%, C 41\%, N 18\%, isovalue = 0.02) $\quad-0.03382$ hartree

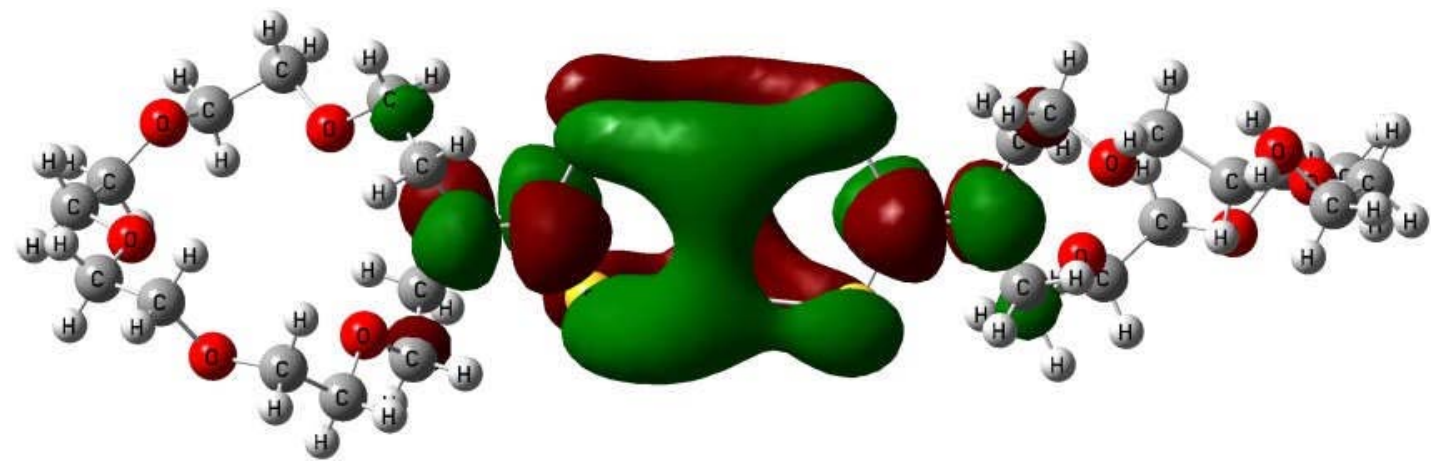

HOMO (180, Au 45\%, S 53\%, C 0\%, N 1\%, isovalue = 0.02) -0.19564 hartree

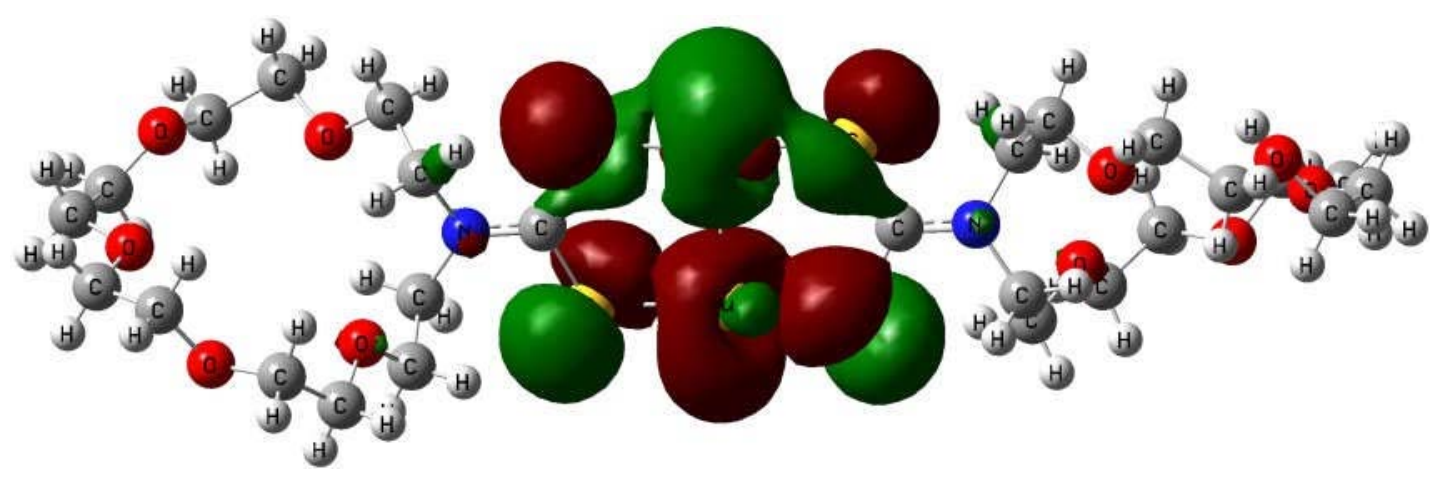




\section{Acetonitrile}

$\left(\mathrm{S}_{0}, \mathrm{Au}-\mathrm{Au}_{\mathrm{intra}}=2.719\right)$

LUMO (181, Au 24\%, S 13\%, C 41\%, N 18\%, isovalue = 0.02) $\quad-\mathbf{0 . 0 2 8 1 9}$ hartree

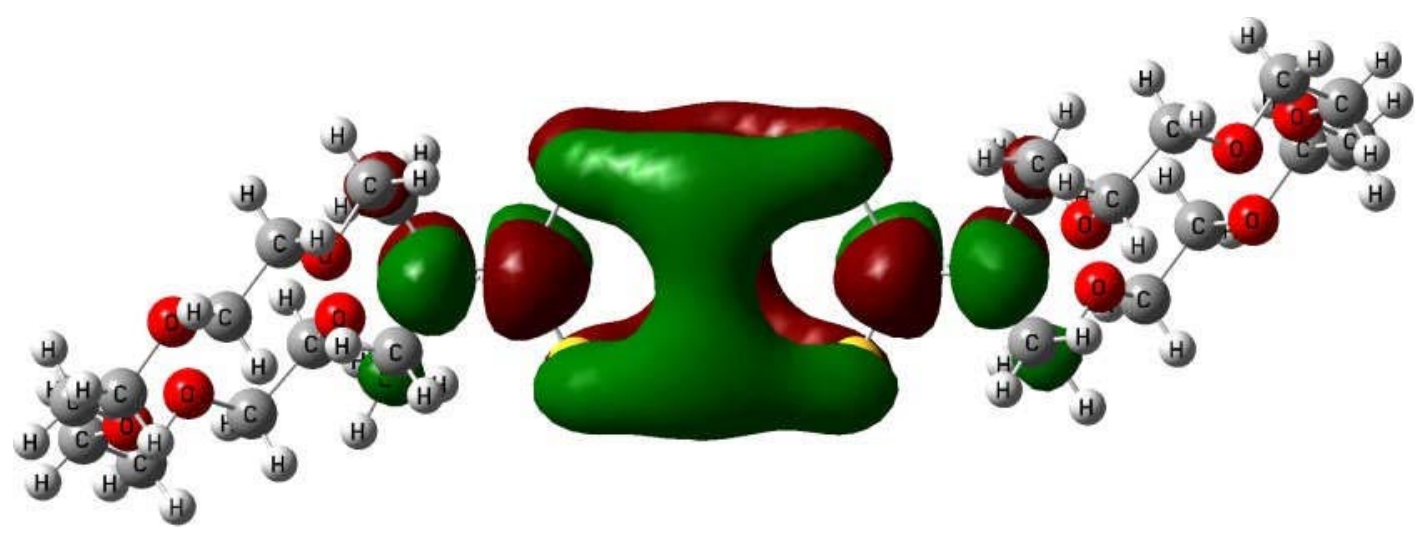

HOMO (180, Au 55\%, S 44\%, C 0\%, N 0\%, isovalue = 0.02) $\quad-0.19194$ hartree

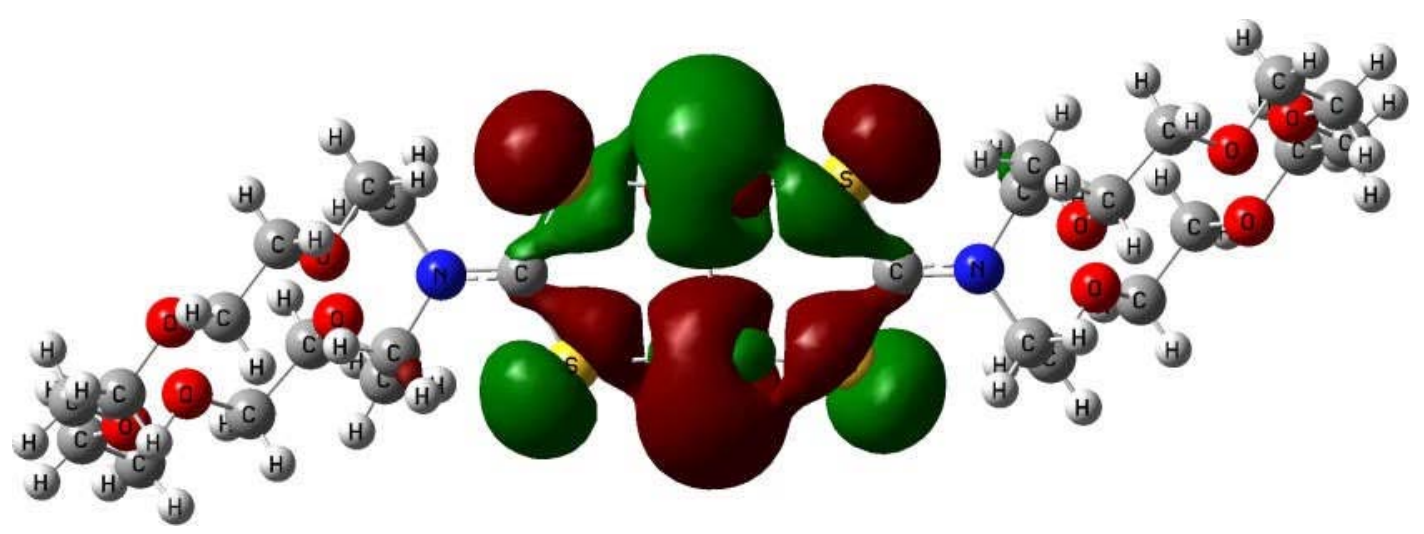




\section{Acetonitrile}

$\left(\mathrm{S}_{0}, \mathrm{Au}-\mathrm{Au}_{\mathrm{intra}}=2.725\right)$

LUMO (181, Au 23\%, S 14\%, C 41\%, N 18\%, isovalue = 0.02) $\quad-0.03592$ hartree

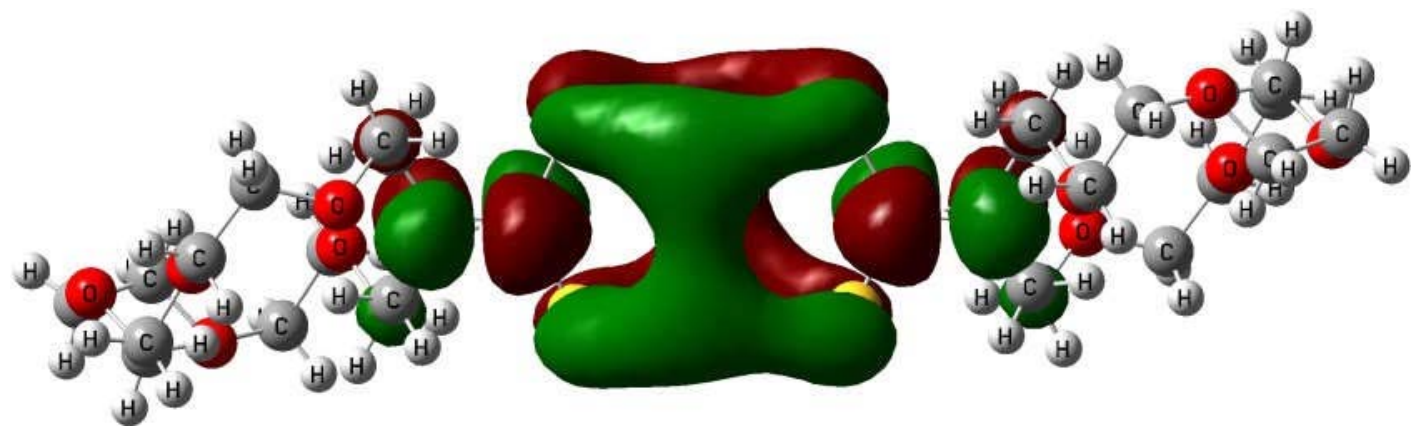

HOMO (180, Au 46\%, S 53\%, C 0\%, N 0\%, isovalue = 0.02) $\quad-0.19809$ hartree

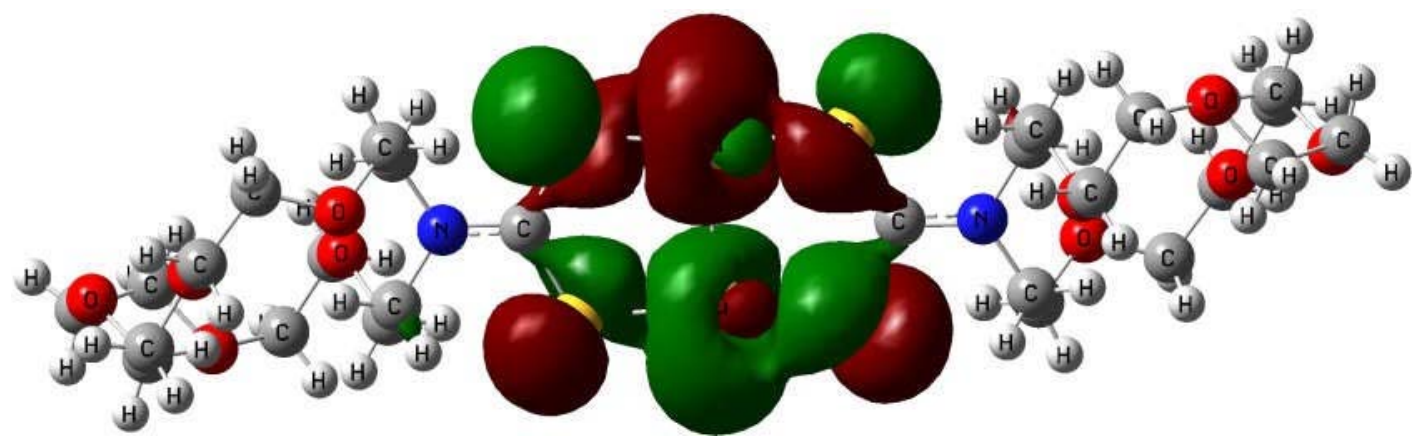




\section{Anisole}

$\left(\mathrm{S}_{0}, \mathrm{Au}-\mathrm{Au}_{\mathrm{intra}}=\mathbf{2 . 7 2 8}\right)$

LUMO (181, Au 22\%, S 15\%, C 42\%, N 18\%, isovalue = 0.02) $\quad-0.03506$ hartree

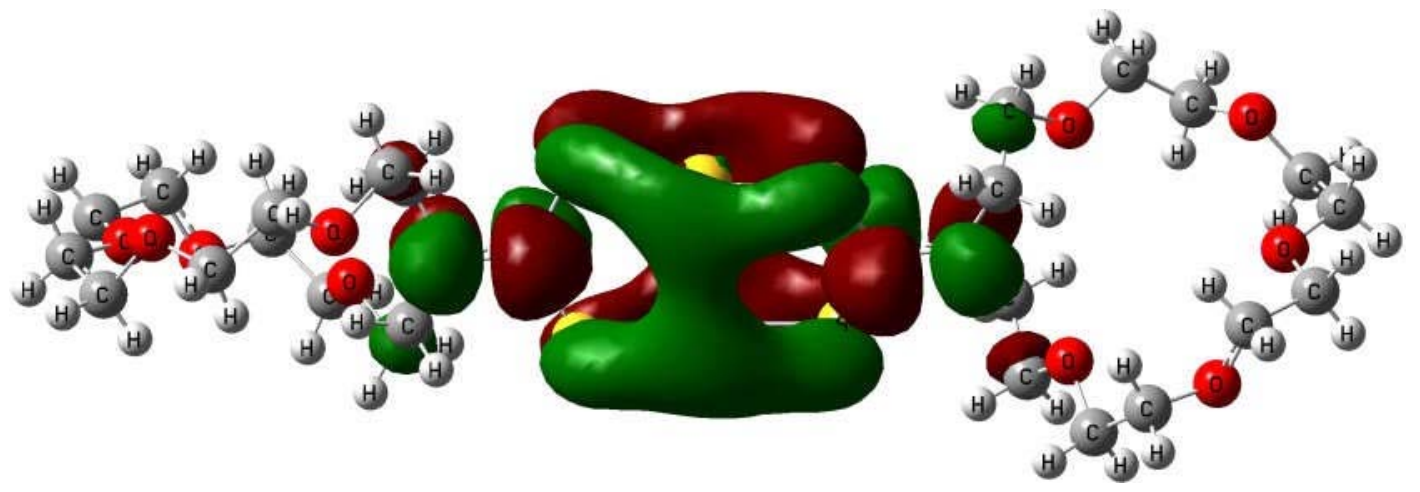

HOMO (180, Au 51\%, S 45\%, C 0\%, N 1\%, isovalue = 0.02) $\quad-0.19722$ hartree

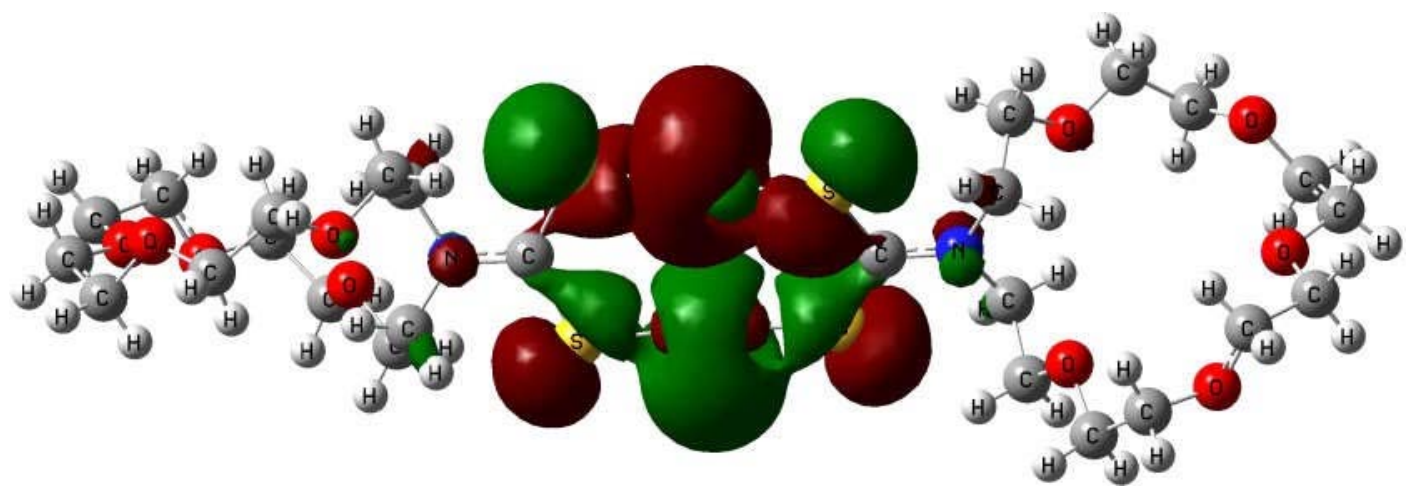




\section{Anisole}

$\left(\mathrm{S}_{0}, \mathrm{Au}-\mathrm{Au}_{\mathrm{intra}}=2.733\right)$

LUMO (181, Au 23\%, S 14\%, C 41\%, N 18\%, isovalue = 0.02) $\quad-0.03503$ hartree

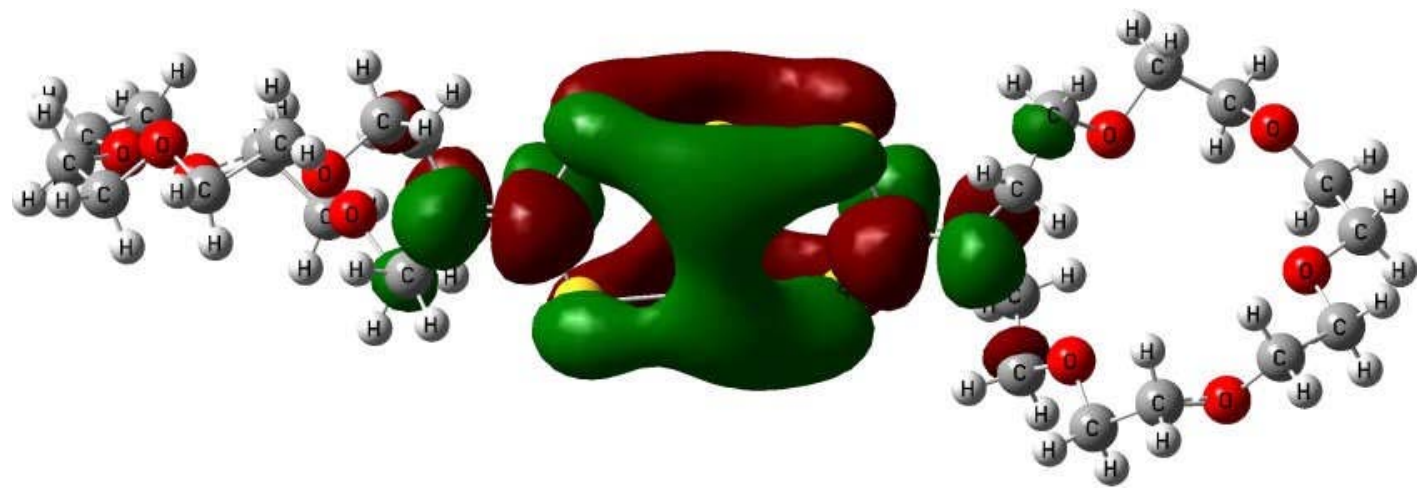

HOMO (180, Au 44\%, S 53\%, C 0\%, N 1\%, isovalue = 0.02) -0.19601 hartree

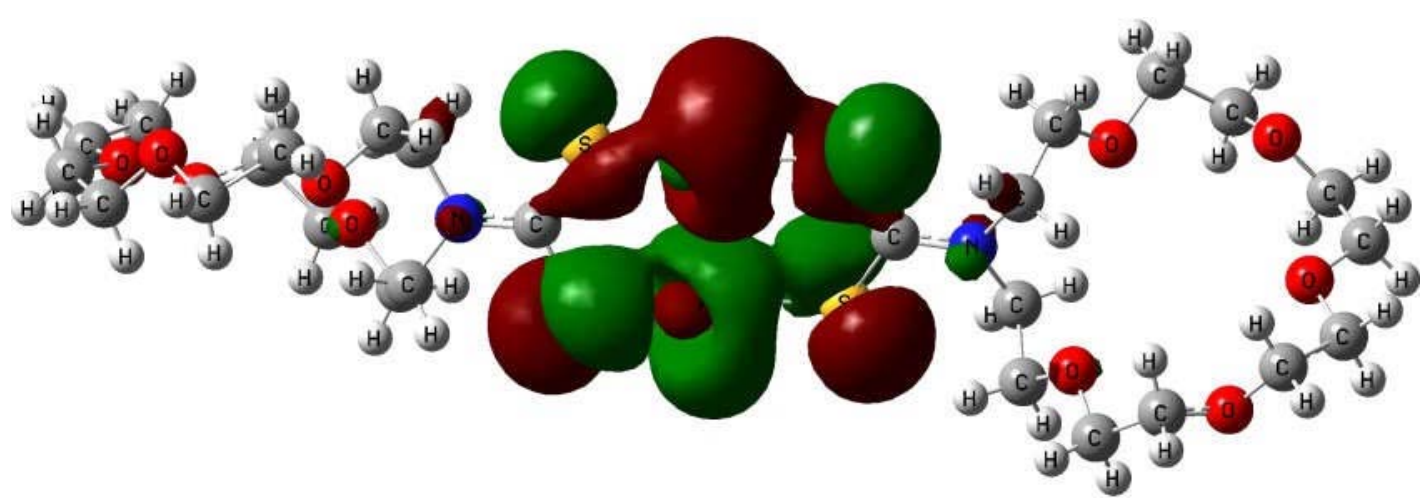




\section{THF}

$\left(\mathrm{S}_{0}, \mathrm{Au}-\mathrm{Au}_{\text {inter }}=2.733\right)$

LUMO (181, Au 24\%, S 13\%, C 41\%, N 18\%, isovalue = 0.02) $\quad-\mathbf{0 . 0 3 2 4 2}$ hartree

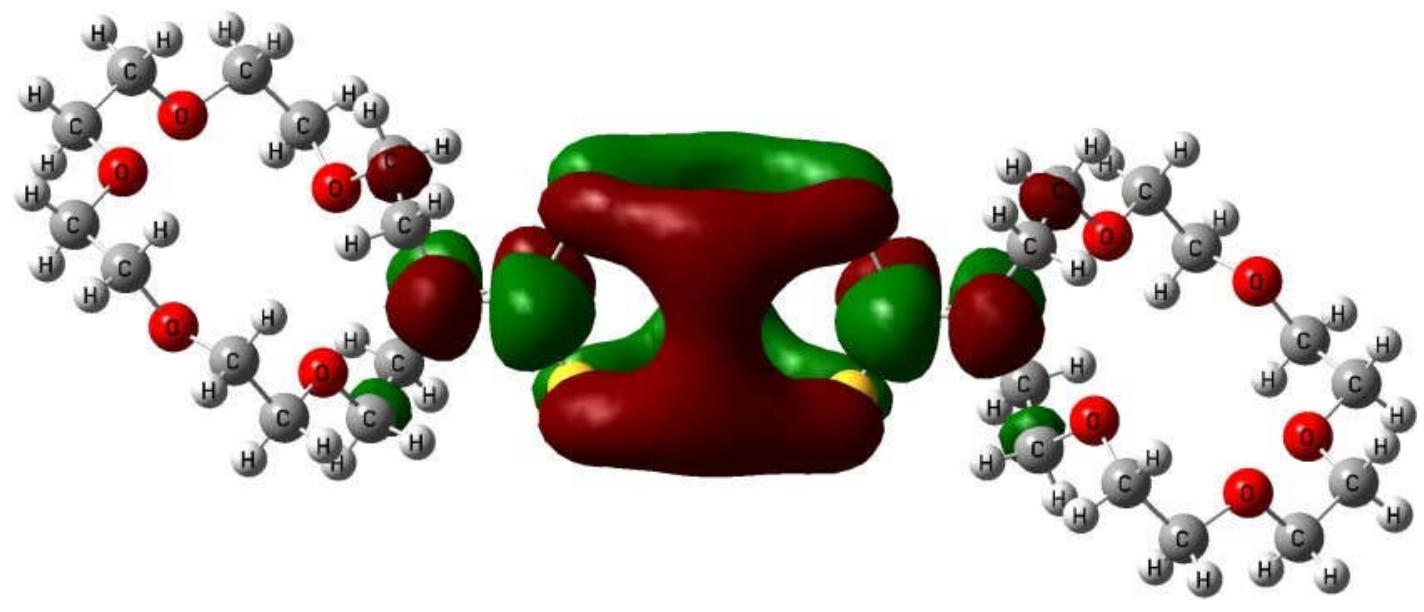

HOMO (180, Au 56\%, S 42\%, C 0\%, N 0\%, isovalue = 0.02) $\quad-0.19584$ hartree

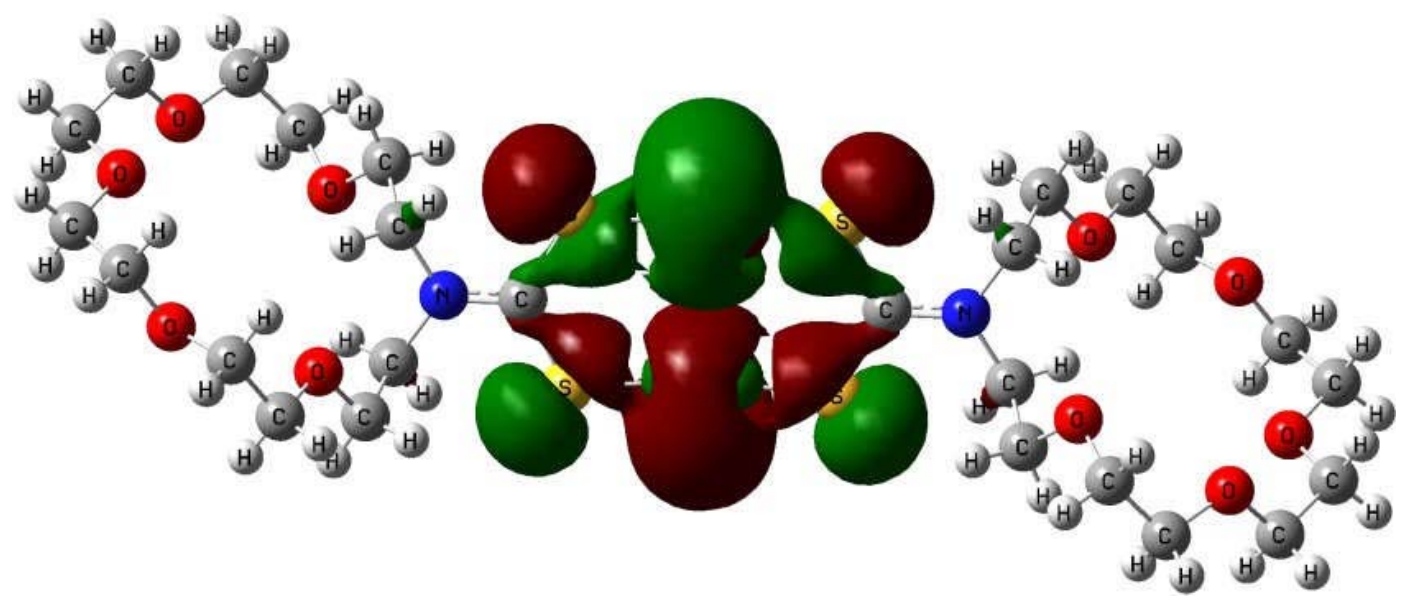




\section{THF}

$\left(\mathrm{S}_{0}, \mathrm{Au}-\mathrm{Au}_{\mathrm{inter}}=2.735\right)$

LUMO (181, Au 23\%, S 14\%, C 41\%, N 18\%, isovalue = 0.02 ) $\quad-\mathbf{0 . 0 3 6 8 7}$ hartree

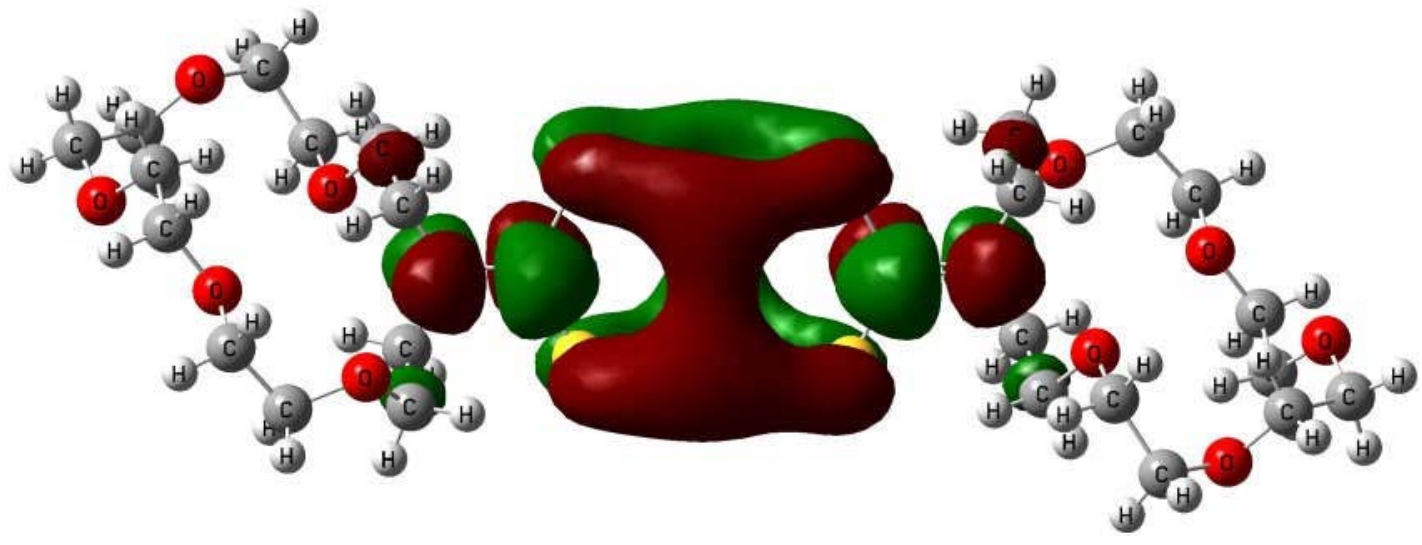

HOMO (180, Au 47\%, S 52\%, C 0\%, N 0\%, isovalue = 0.02) - 0.19945 hartree

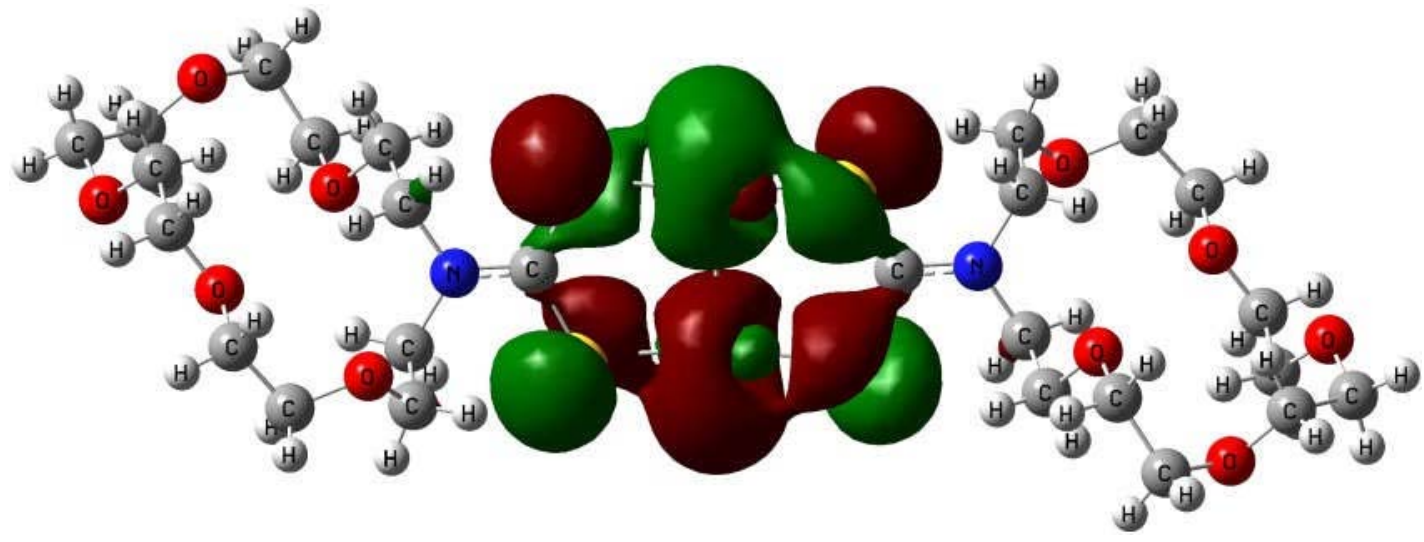




\section{Acetone}

$\left(\mathrm{S}_{0}, \mathrm{Au}-\mathrm{Au}_{\mathrm{intra}}=2.735\right)$

LUMO (181, Au 24\%, S 14\%, C 41\%, N 18\%, isovalue = 0.02) $\quad-0.03374$ hartree

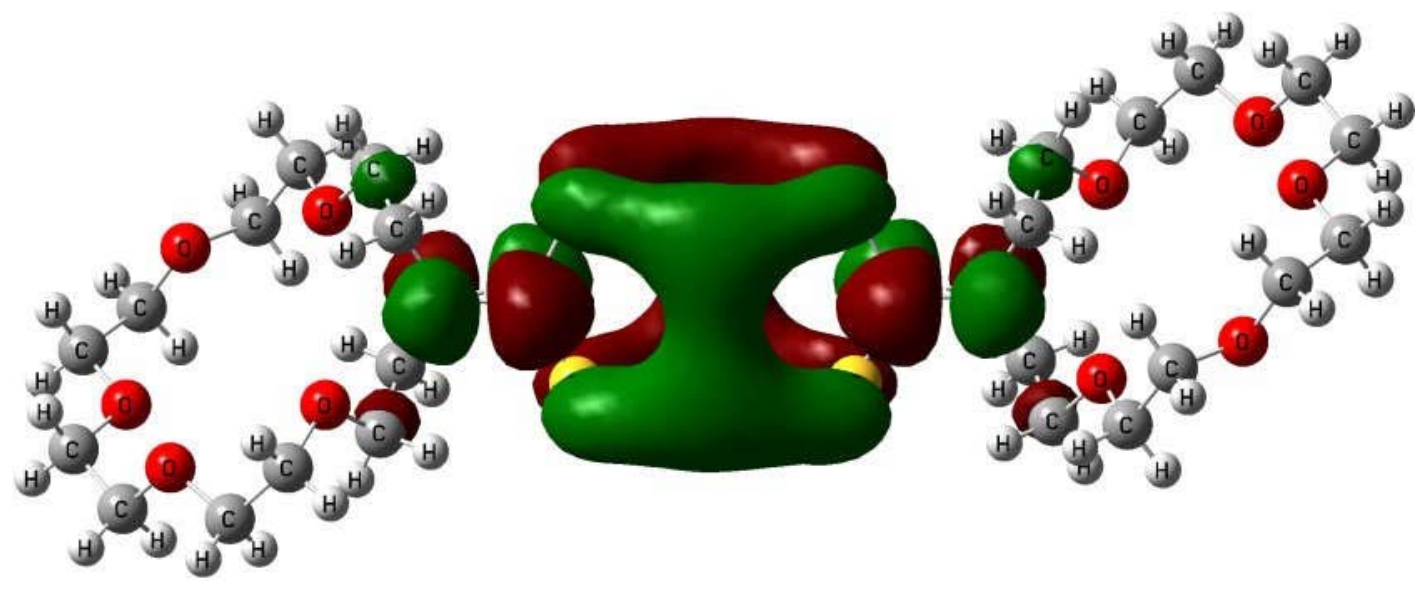

HOMO (180, Au 55\%, S 44\%, C 0\%, N 0\%, isovalue = 0.02) $\quad-0.19684$ hartree

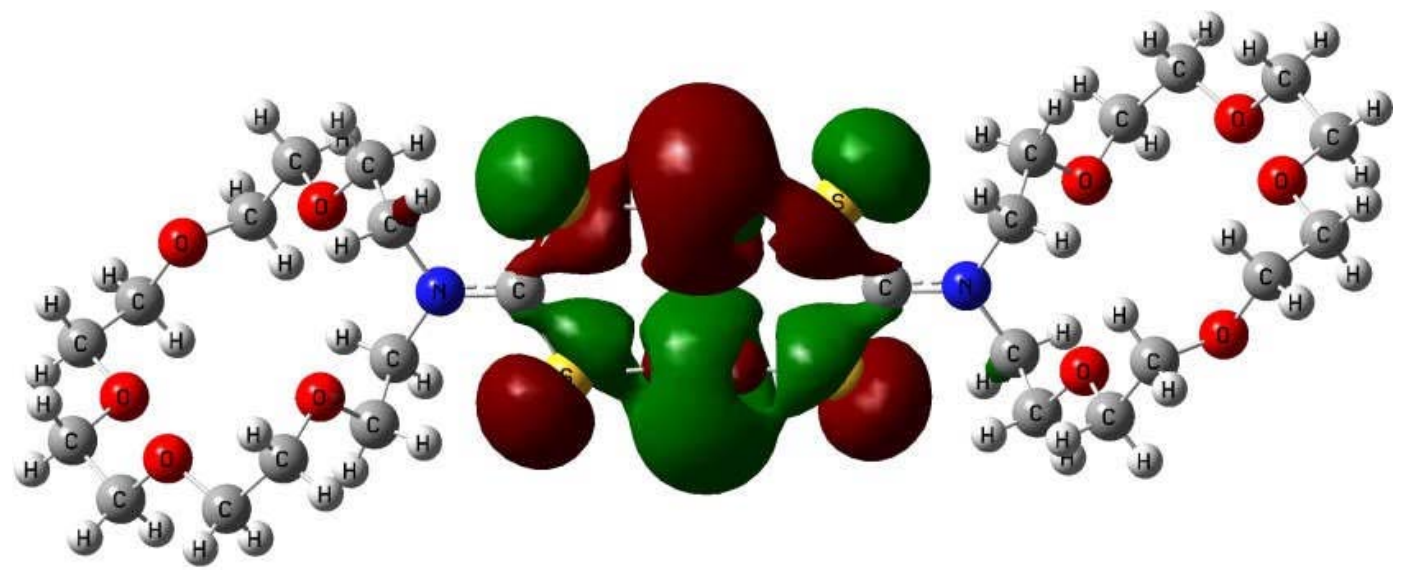




\section{Acetone}

$\left(\mathrm{S}_{0}, \mathrm{Au}-\mathrm{Au}_{\mathrm{intra}}=2.738\right)$

LUMO (181, Au 23\%, S 14\%, C 41\%, N 18\%, isovalue = 0.02) $\quad-0.03593$ hartree

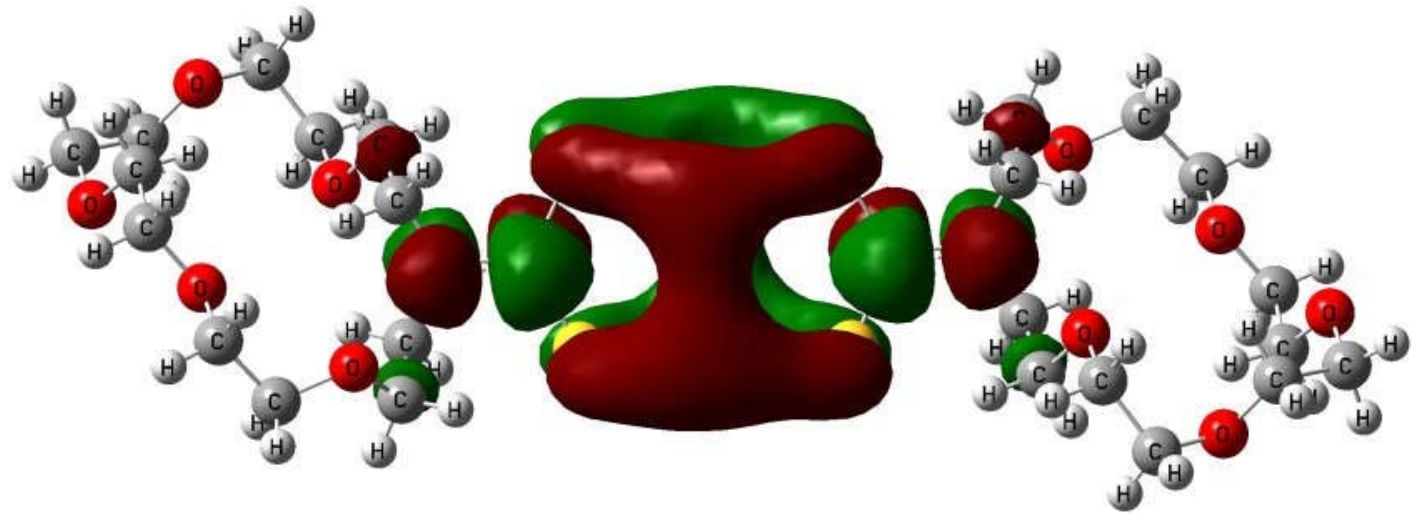

HOMO (180, Au 50\%, S 49\%, C 0\%, N 0\%, isovalue = 0.02) $\quad-0.19909$ hartree

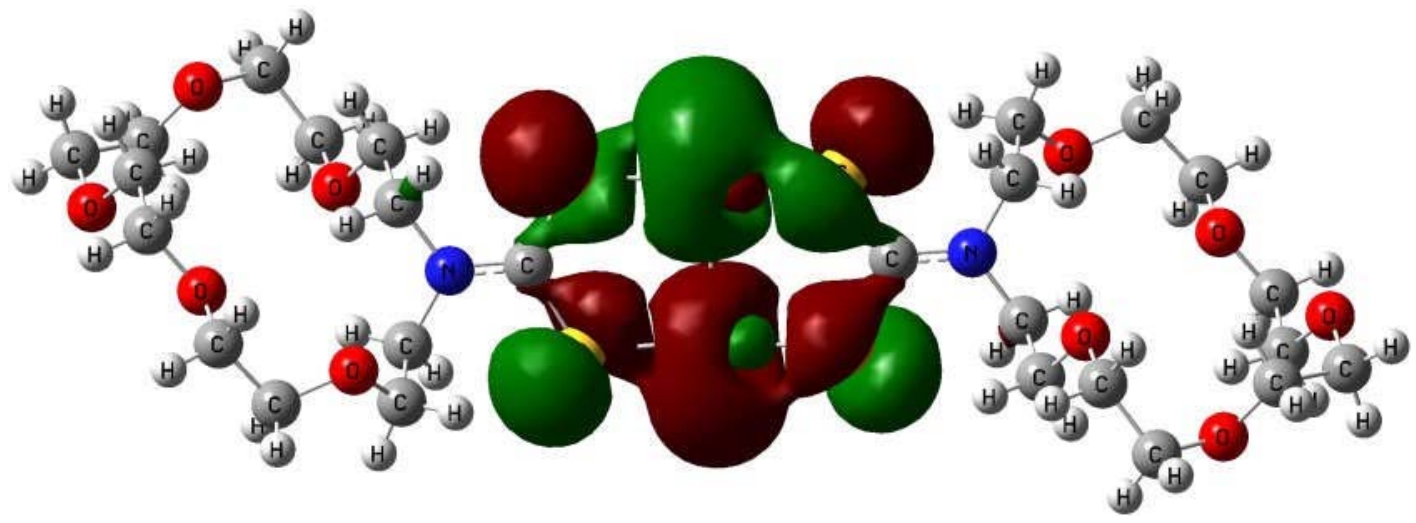




\section{DMSO}

$\left(\mathrm{S}_{0}, \mathrm{Au}-\mathrm{Au}_{\text {inter }}=2.729\right)$

LUMO (181, Au 24\%, S 14\%, C 40\%, N 18\%, isovalue = 0.02) $\quad-0.03355$ hartree

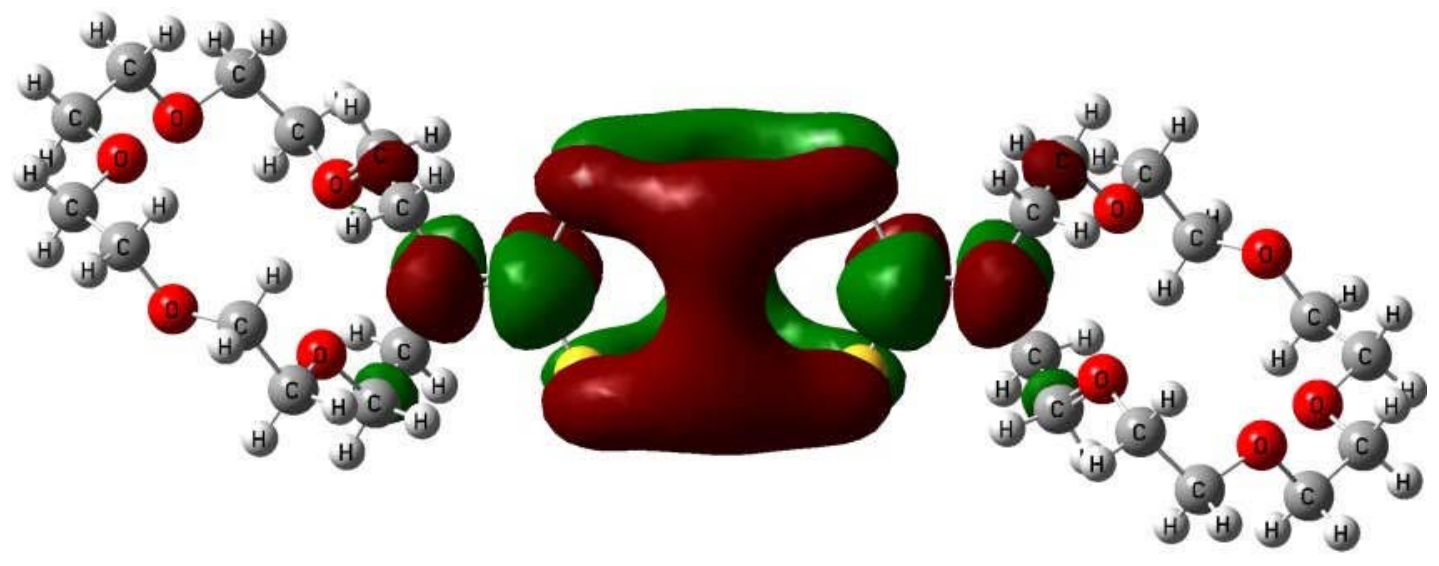

HOMO (180, Au 52\%, S 47\%, C 0\%, N 0\%, isovalue = 0.02) -0.19550 hartree

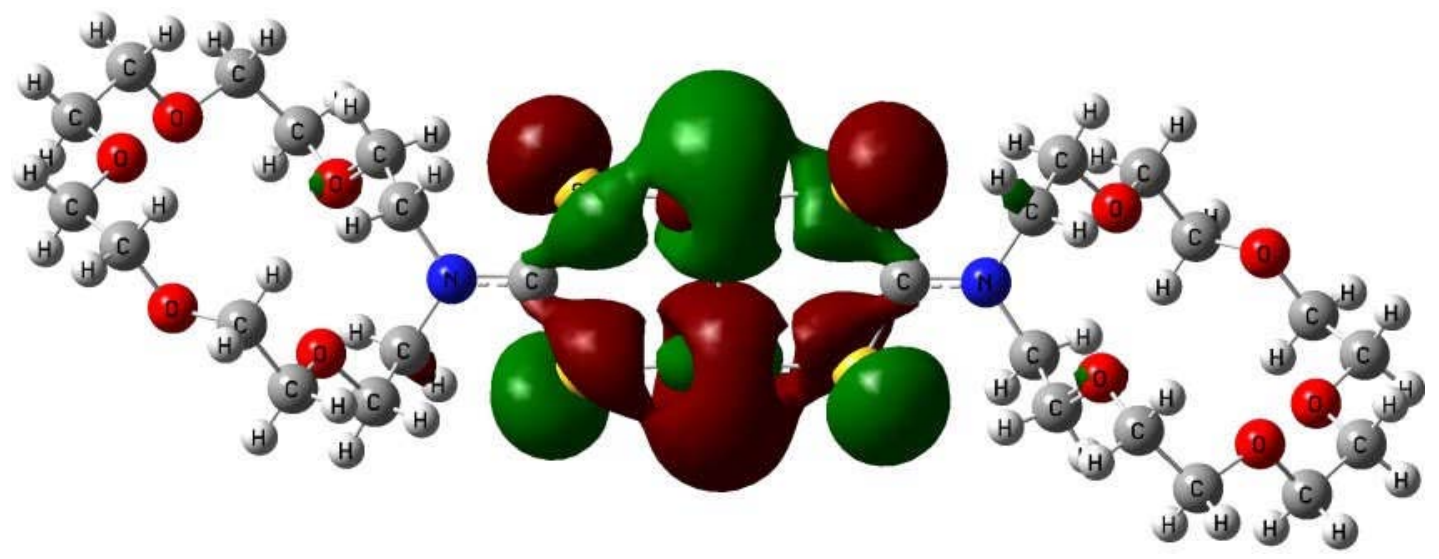




\section{DMSO}

$\left(\mathrm{S}_{0}, \mathrm{Au}-\mathrm{Au}_{\text {inter }}=2.739\right)$

LUMO (181, Au 24\%, S 13\%, C 41\%, N 18\%, isovalue = 0.02 ) $\quad-0.03500$ hartree

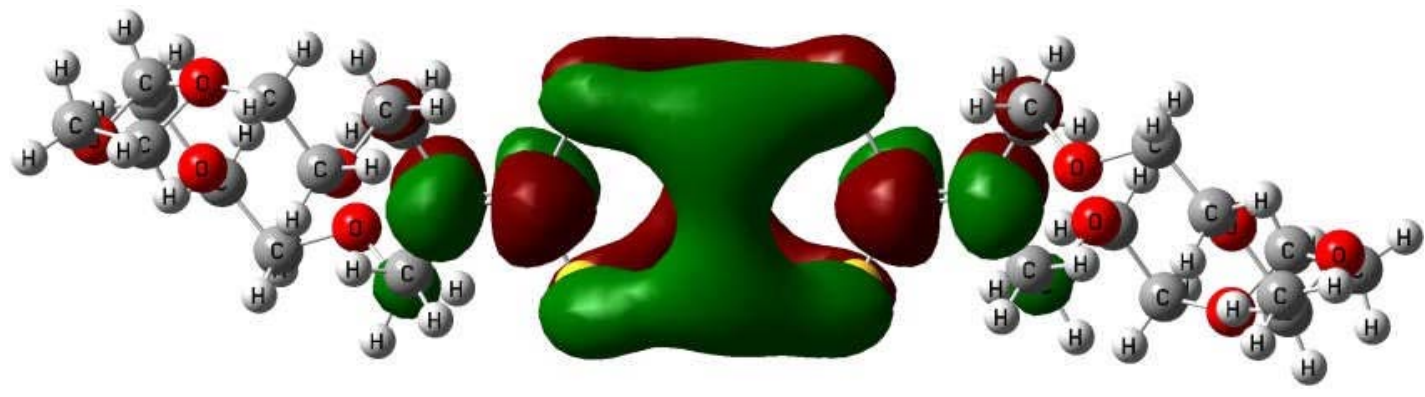

HOMO (180, Au 47\%, S 51\%, C 0\%, N 0\%, isovalue = 0.02) $\quad-0.19865$ hartree

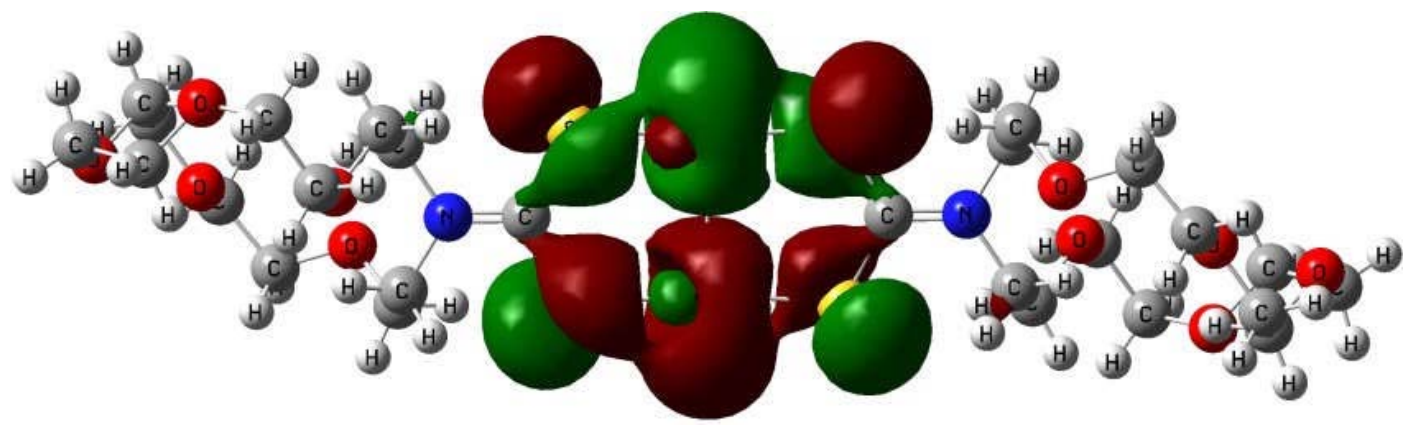




\section{m-Xylene}

$$
\left(\mathrm{S}_{0}, \mathrm{Au}-\mathrm{Au}_{\mathrm{intra}}=2.755\right)
$$

LUMO (181, Au 22\%, S 14\%, C 42\%, N 18\%, isovalue = 0.02) - 0.03319 hartree

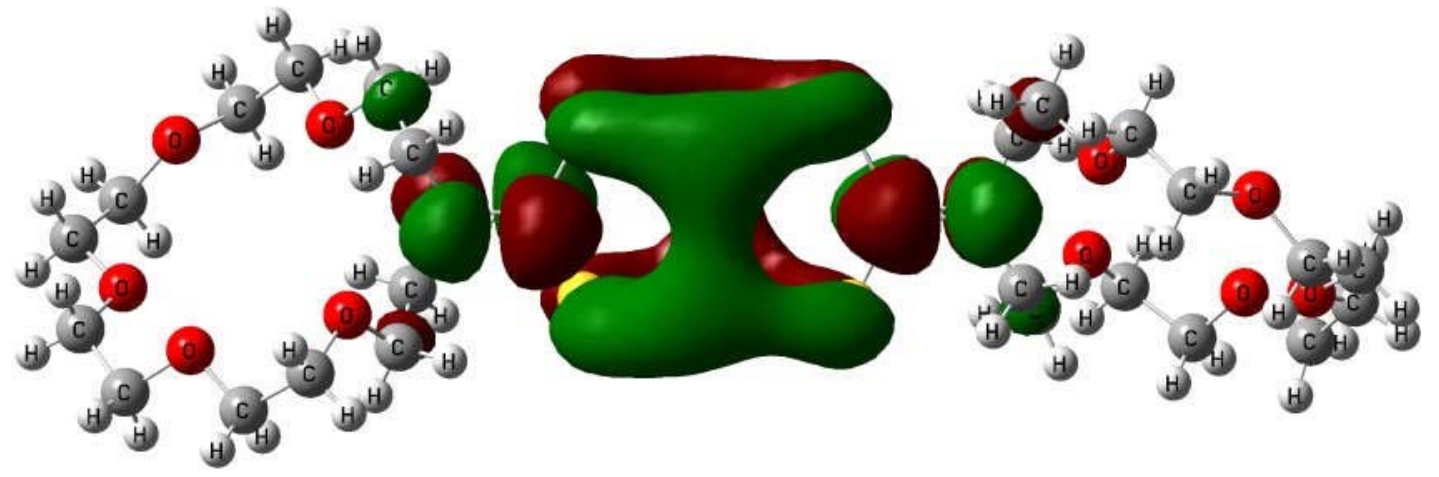

HOMO (180, Au 51\%, S 46\%, C 0\%, N 1\%, isovalue = 0.02) - 0.19669 hartree

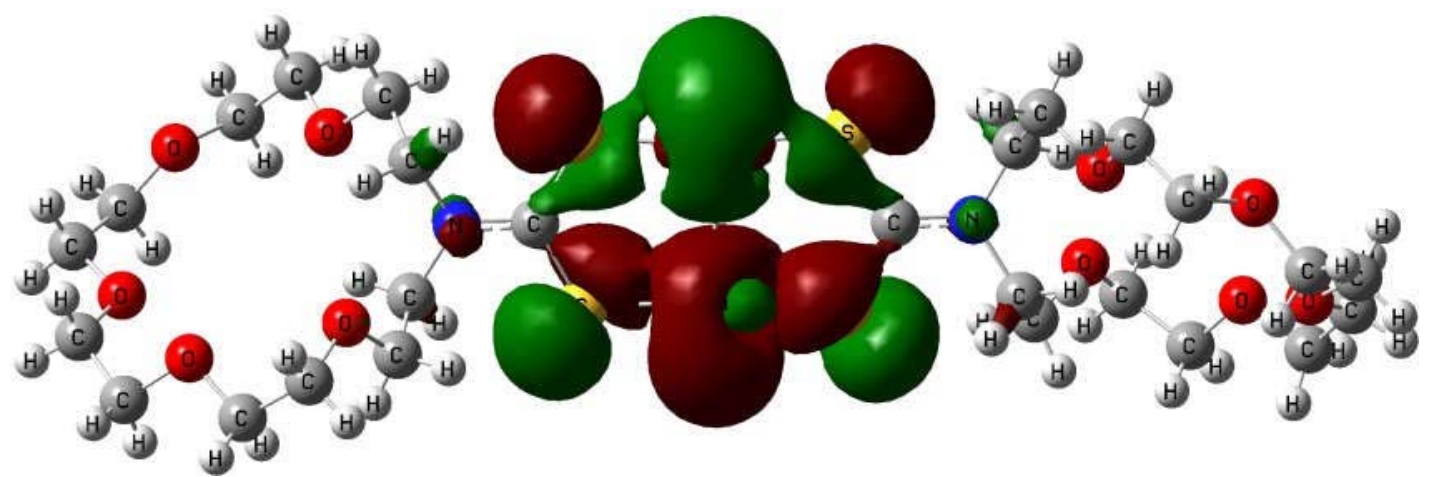




\section{m-Xylene}

$\left(\mathrm{S}_{0}, \mathrm{Au}-\mathrm{Au}_{\mathrm{intra}}=\mathbf{2 . 7 6 4}\right)$

LUMO (181, Au 19\%, S 16\%, C 43\%, N 18\%, isovalue = 0.02) $\quad-\mathbf{0 . 0 4 5 0 1}$ hartree

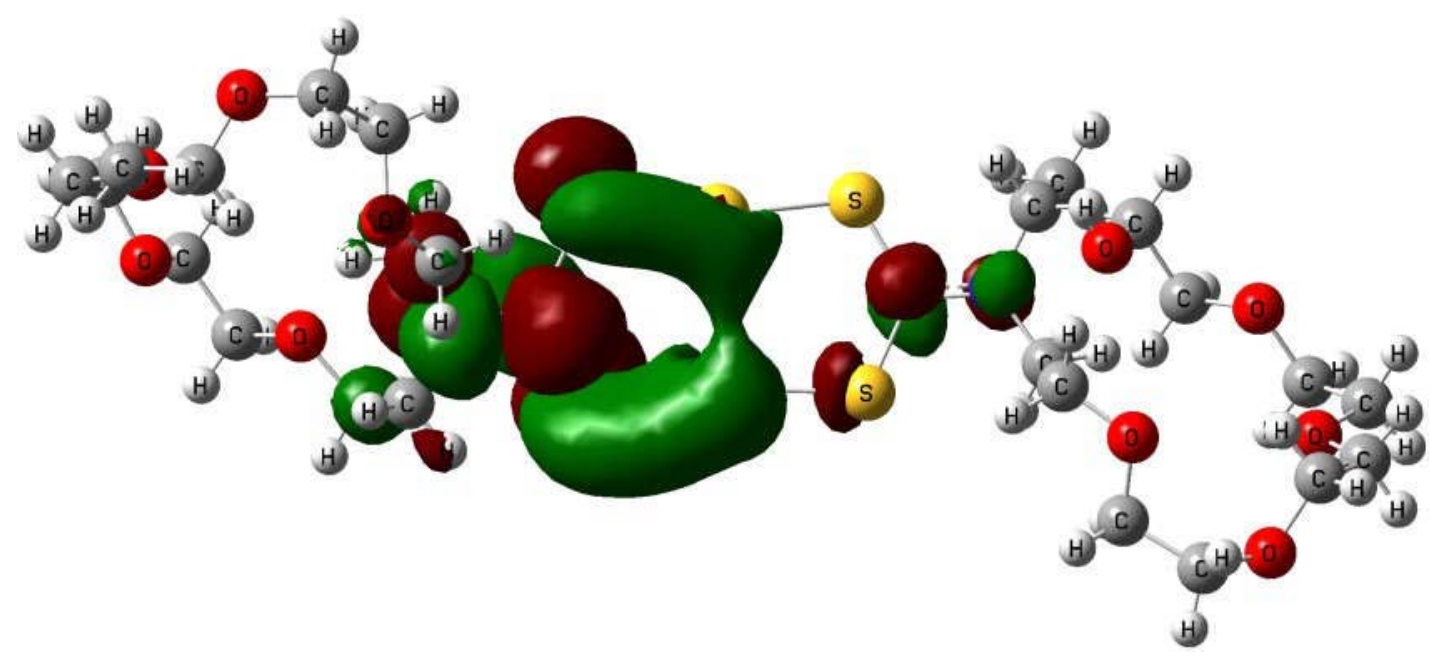

HOMO (180, Au 55\%, S 44\%, C 0\%, N 0\%, isovalue = 0.02) $\quad-0.20610$ hartree

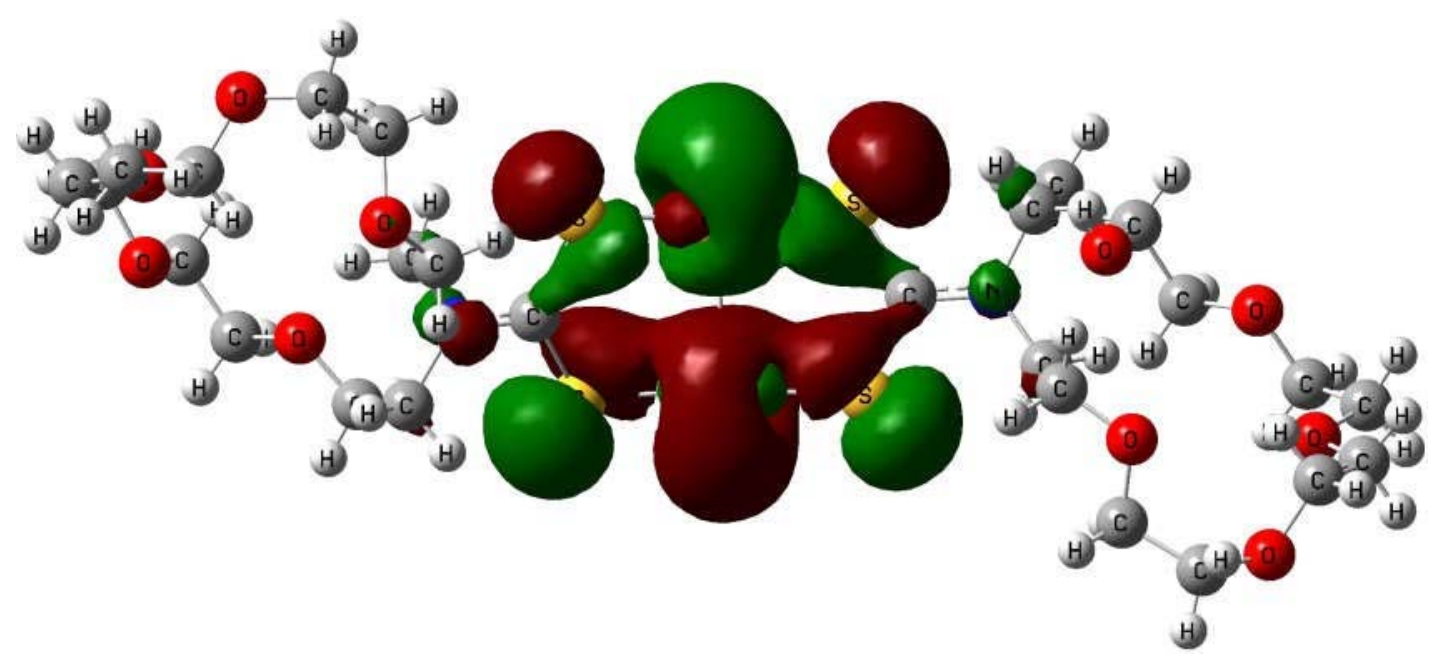




\section{m-Xylene}

$$
\left(\mathrm{S}_{0}, \mathrm{Au}-\mathrm{Au}_{\mathrm{intra}}=2.755\right)
$$

\footnotetext{
LUMO (181, Au 24\%, S 14\%, C 41\%, N 18\%, isovalue = 0.02) $\quad-0.03398$ hartree
}

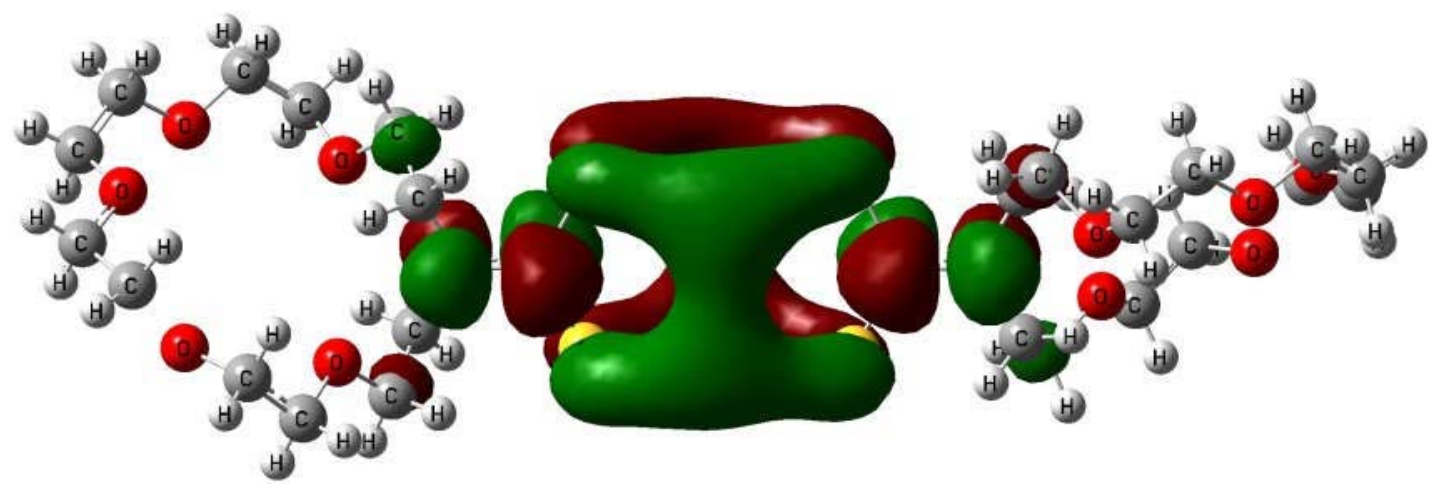

HOMO (180, Au 56\%, S 42\%, C 0\%, N 1\%, isovalue = 0.02) - 0.19756 hartree

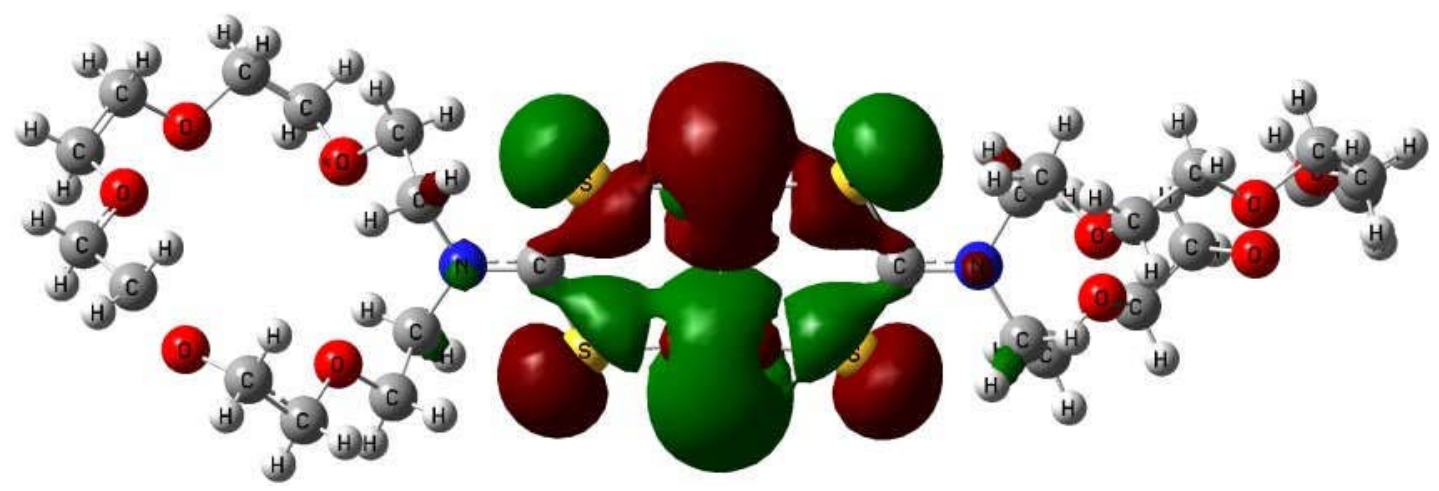




\section{DMF}

$\left(\mathrm{S}_{0}, \mathrm{Au}-\mathrm{Au}_{\text {inter }}=2.741\right)$

LUMO (181, Au 24\%, S 14\%, C 40\%, N 18\%, isovalue = 0.02) $\quad-\mathbf{0 . 0 3 3 6 0}$ hartree

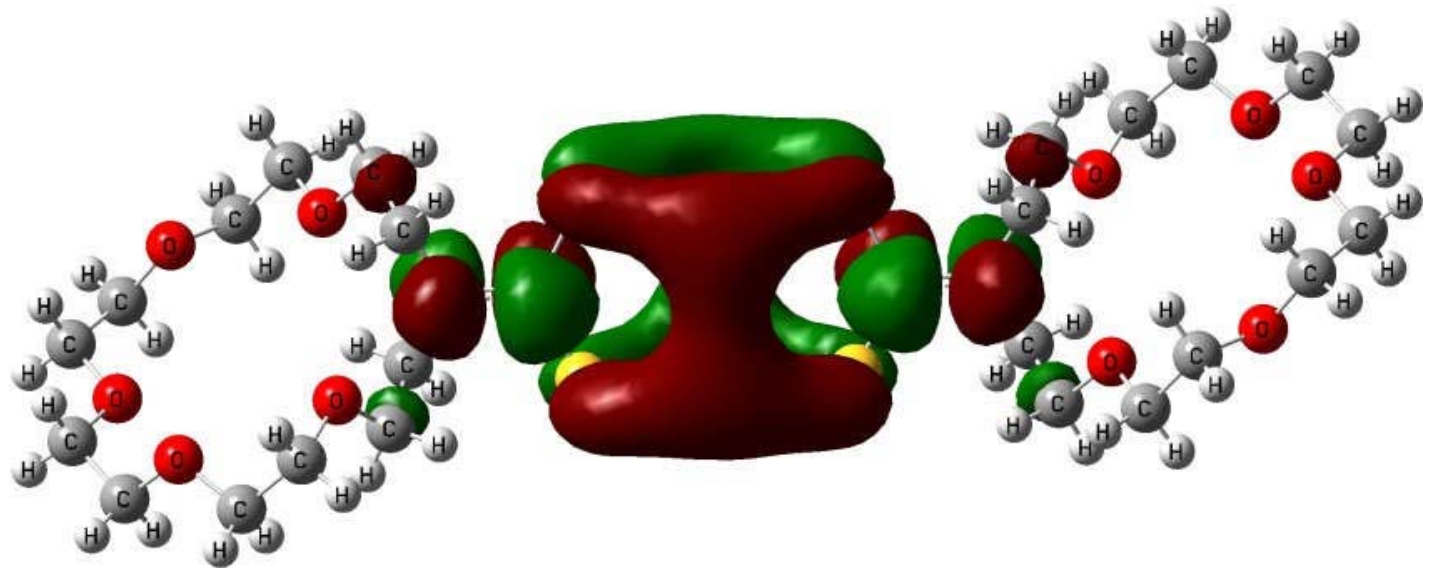

HOMO (180, Au 57\%, S 41\%, C 0\%, N 0\%, isovalue = 0.02) $\quad-0.19727$ hartree

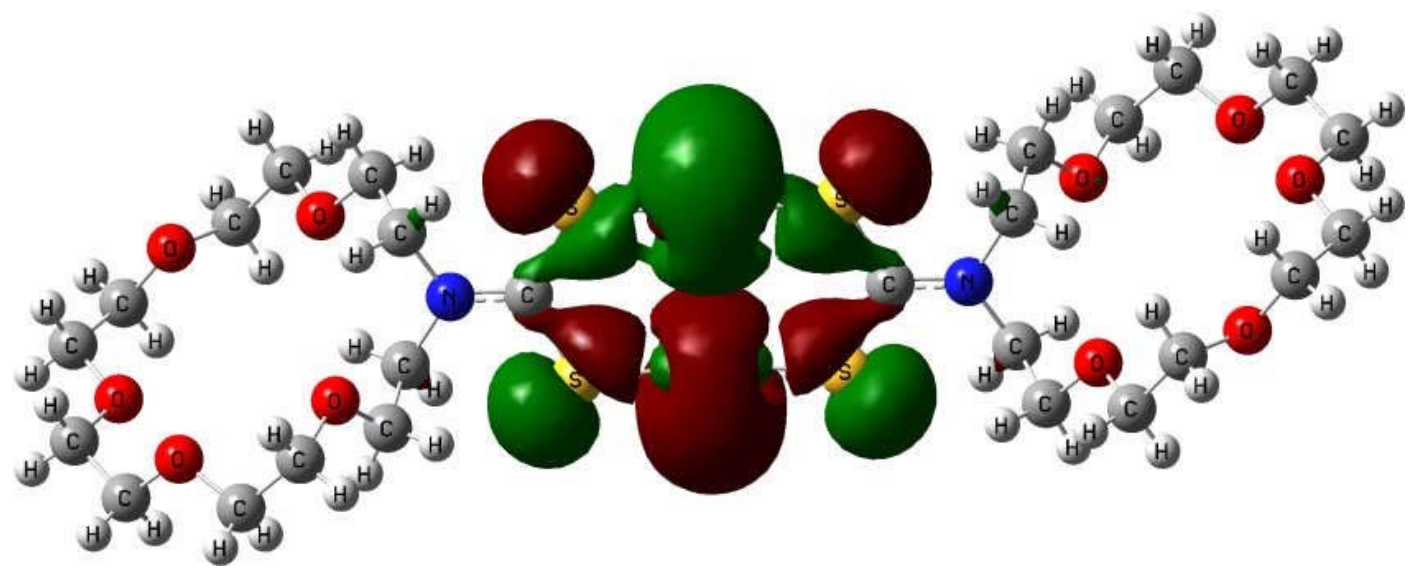




\section{DMF}

$\left(\mathrm{S}_{0}, \mathrm{Au}-\mathrm{Au}_{\text {inter }}=2.746\right)$

LUMO (181, Au 23\%, S 14\%, C 41\%, N 18\%, isovalue = 0.02) $\quad-0.03787$ hartree

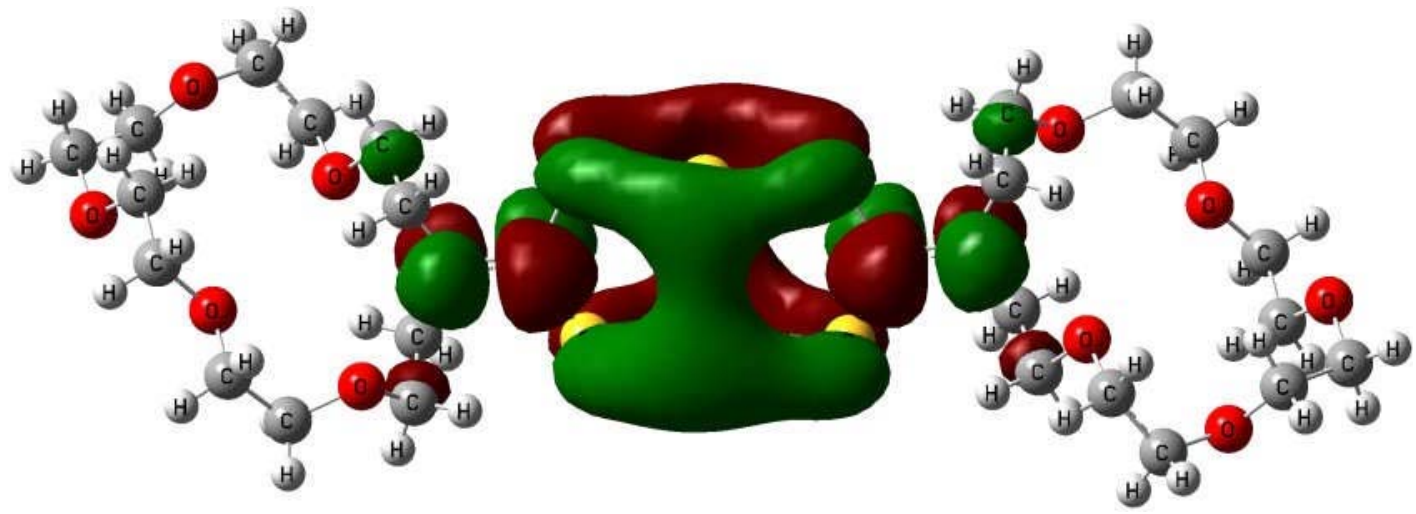

HOMO (180, Au 45\%, S 54\%, C 0\%, N 0\%, isovalue = 0.02) -0.20011 hartree

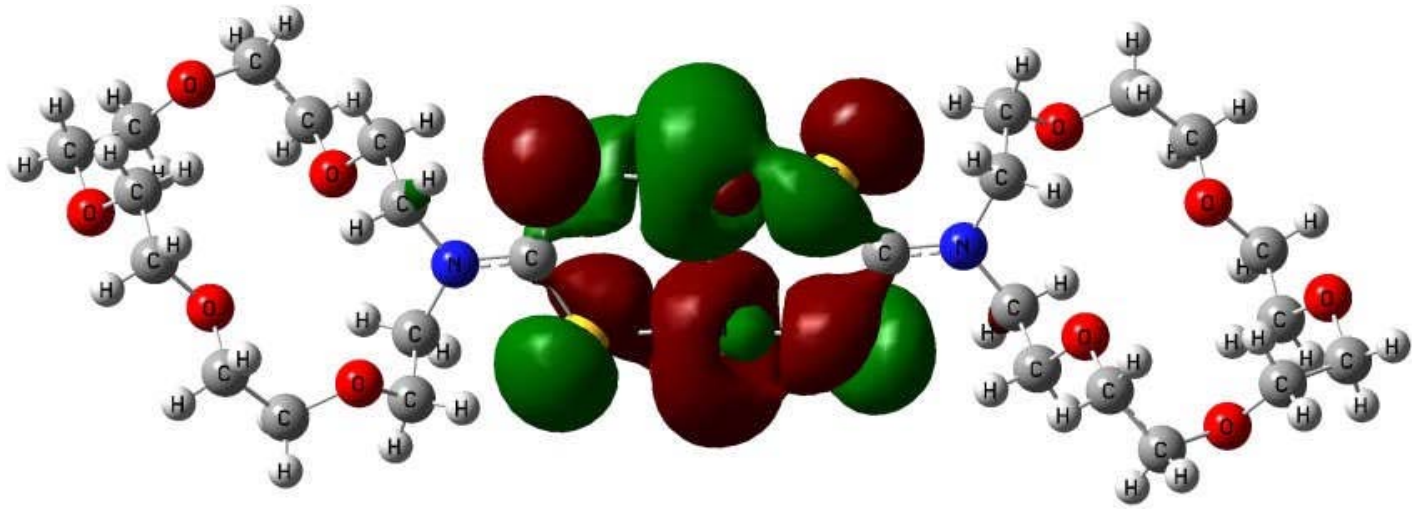




\title{
tert-Butylbenzene $\cdot \mathrm{H}_{2} \mathrm{O}$
}

$\left(\mathrm{S}_{0}, \mathrm{Au}-\mathrm{Au}_{\text {intra }}=2.771\right)$

\begin{abstract}
LUMO (181, Au 21\%, S 15\%, C 42\%, N 18\%, isovalue = 0.02) $\quad-0.03809$ hartree
\end{abstract}

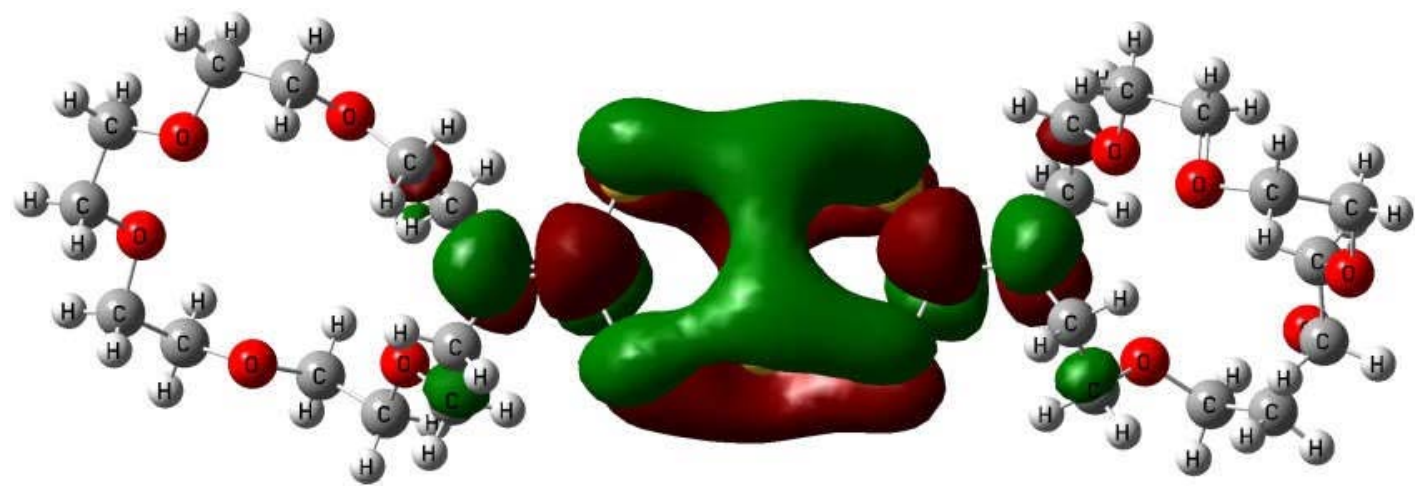

HOMO (180, Au 42\%, S 56\%, C 0\%, N 0\%, isovalue = 0.02) -0.20052 hartree

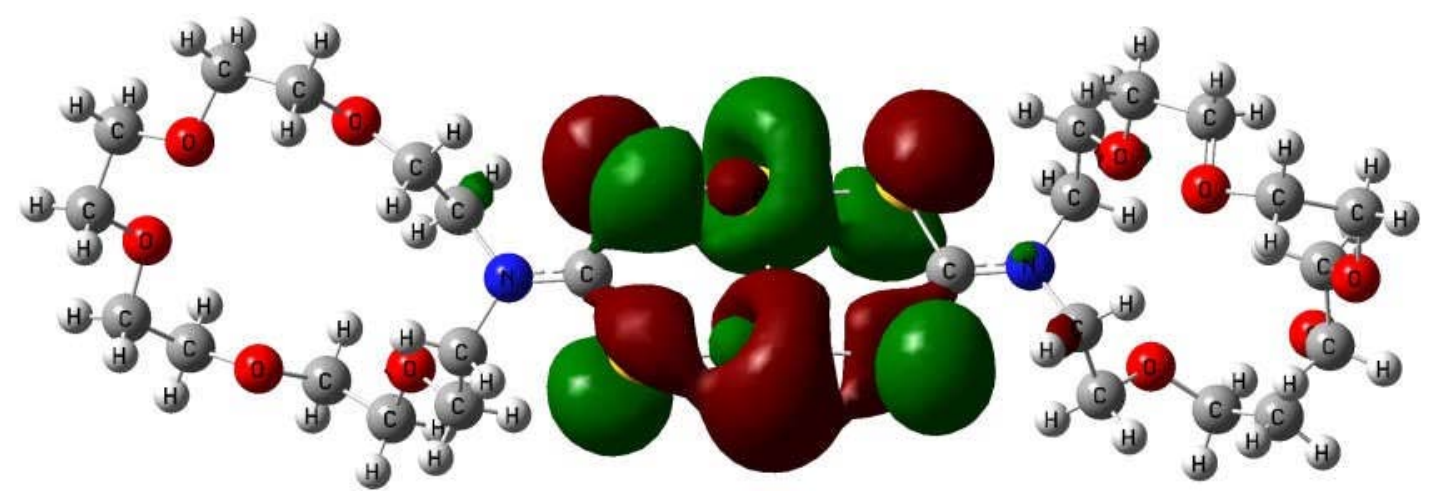


(b)

\section{Toluene}

$\left(\mathrm{S}_{0}, \mathrm{Au}-\mathrm{Au}_{\mathrm{intra}}=(2.717,2.728), \mathrm{Au}-\mathrm{Au} \mathrm{u}_{\text {inter }}=\right.$

LUMO (361, Au 23\%, S 14\%, C 41\%, N 17\%, isovalue = 0.02) $\quad-\mathbf{0 . 0 3 0 4 1}$ hartree

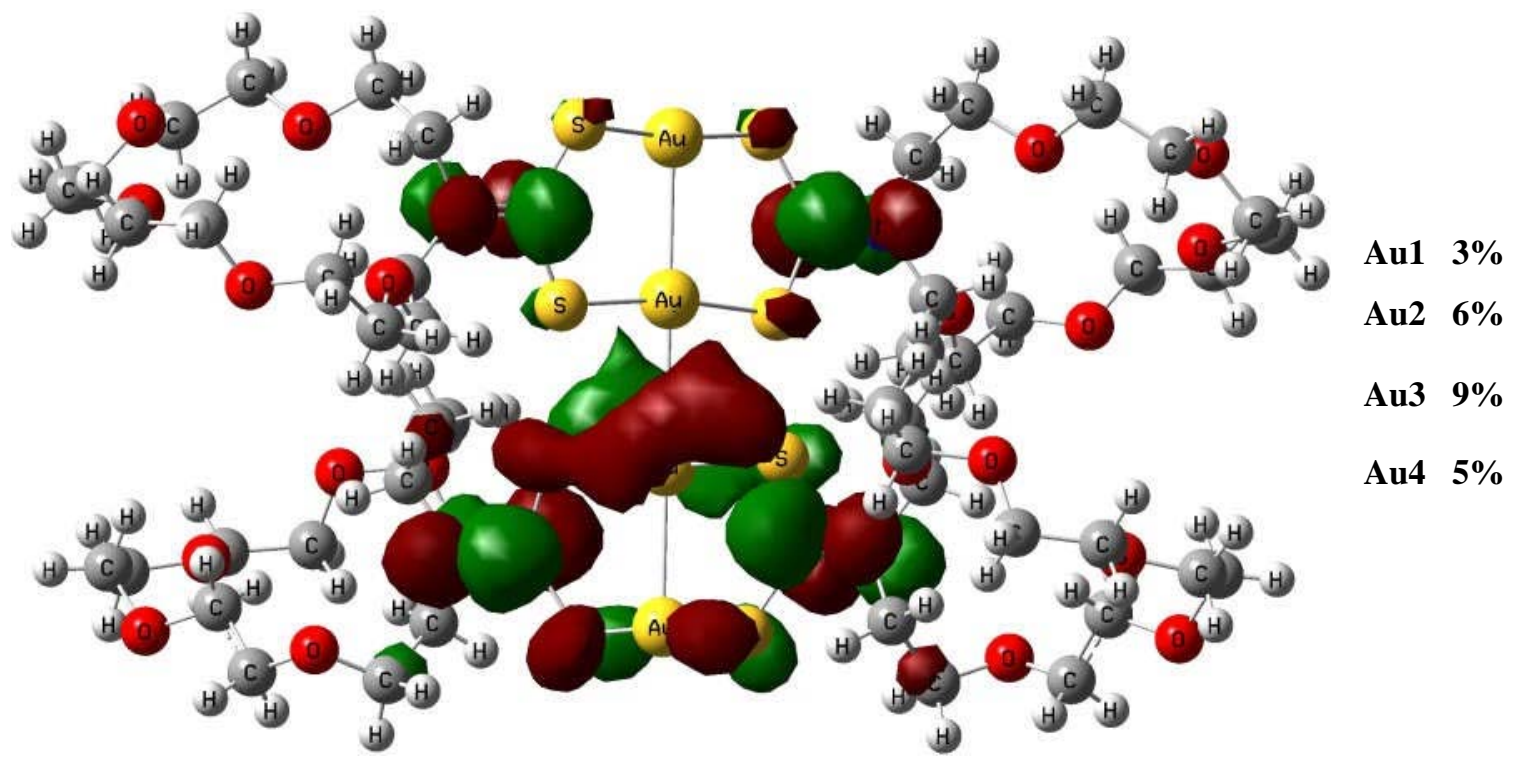

HOMO (360, Au 60\%, S 39\%, C 0\%, N 0\%, isovalue = 0.02) $\quad-0.16290$ hartree

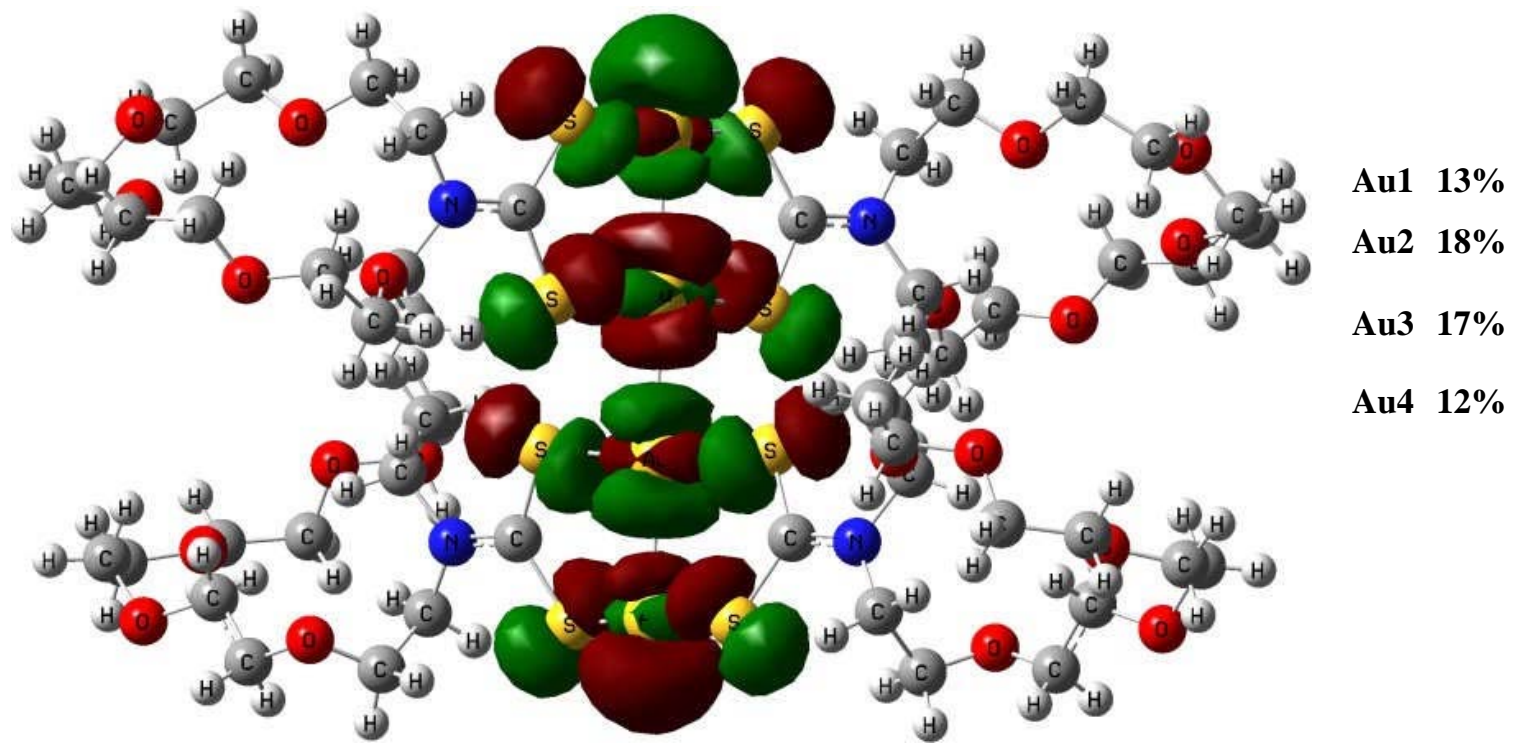




\section{Toluene}

$\left(\mathrm{S}_{0}, \mathrm{Au}-\mathrm{Au}_{\mathrm{intra}}=(2.717,2.728), \mathrm{Au}-\mathrm{Au}_{\mathrm{inter}}=2.829\right)$

LUMO (361, Au 20\%, S 16\%, C 43\%, N 17\%, isovalue = 0.02) $\quad-\mathbf{0 . 0 3 0 5 0}$ hartree

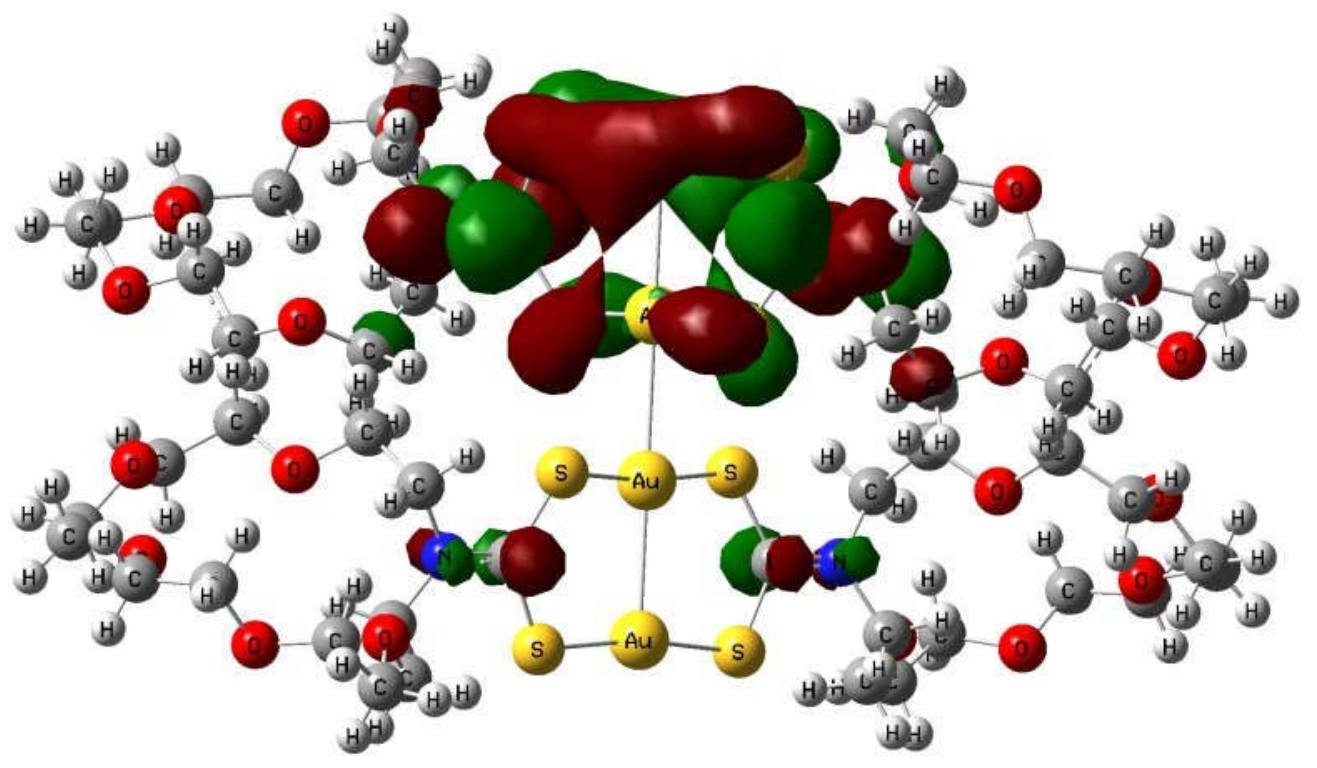

Au1 9\%

Au2 8\%

Au3 2\%

Au4 1\%

HOMO (360, Au 62\%, S 37\%, C 0\%, N 0\%, isovalue = 0.02) $\quad-0.16402$ hartree

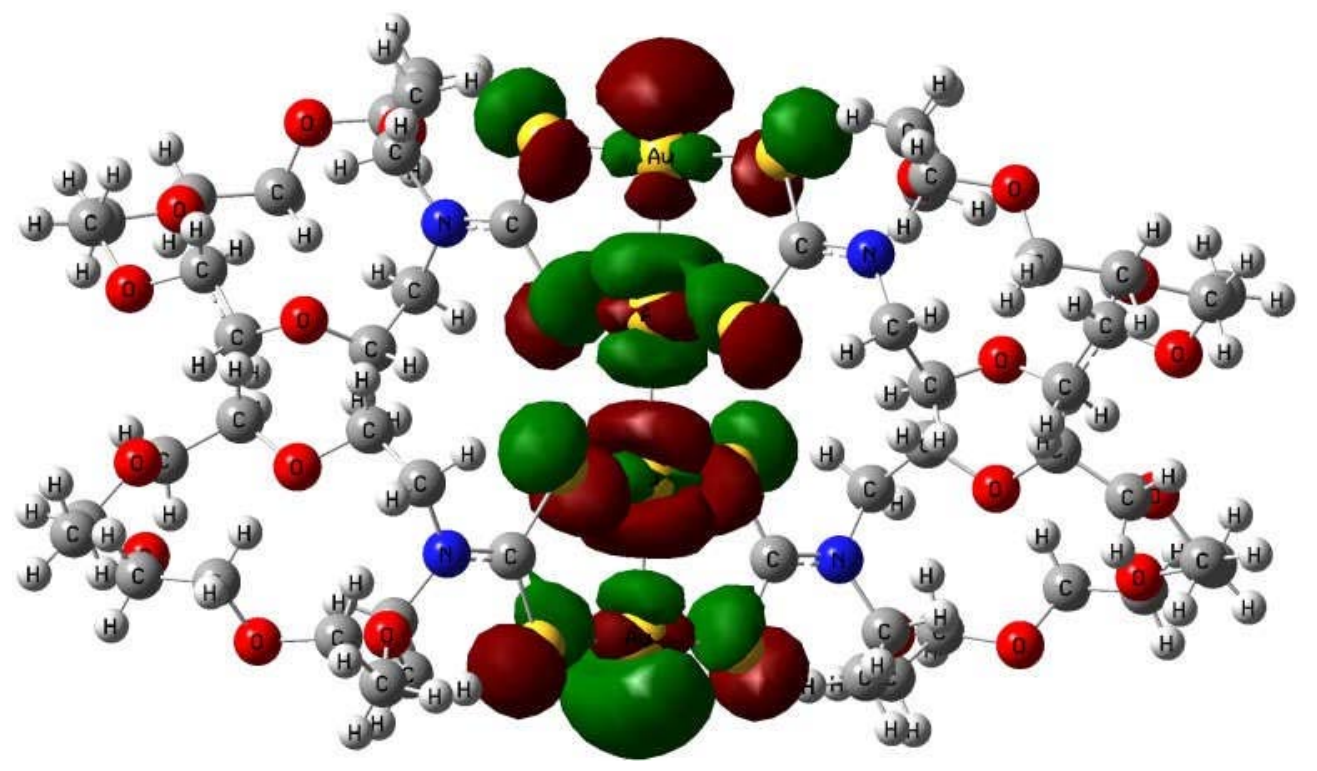

Au1 11\%

Au2 17\%

Au3 19\%

Au4 15\% 


\section{Acetonitrile}

$\left(\mathrm{S}_{0}, \mathrm{Au}-\mathrm{Au}_{\mathrm{intra}}=(2.719,2.725), \mathrm{Au}-\mathrm{Au}_{\mathrm{inter}}=2.836\right)$

LUMO (361, Au 23\%, S 15\%, C 41\%, N 17\%, isovalue = 0.02) $\quad-0.02264$ hartree

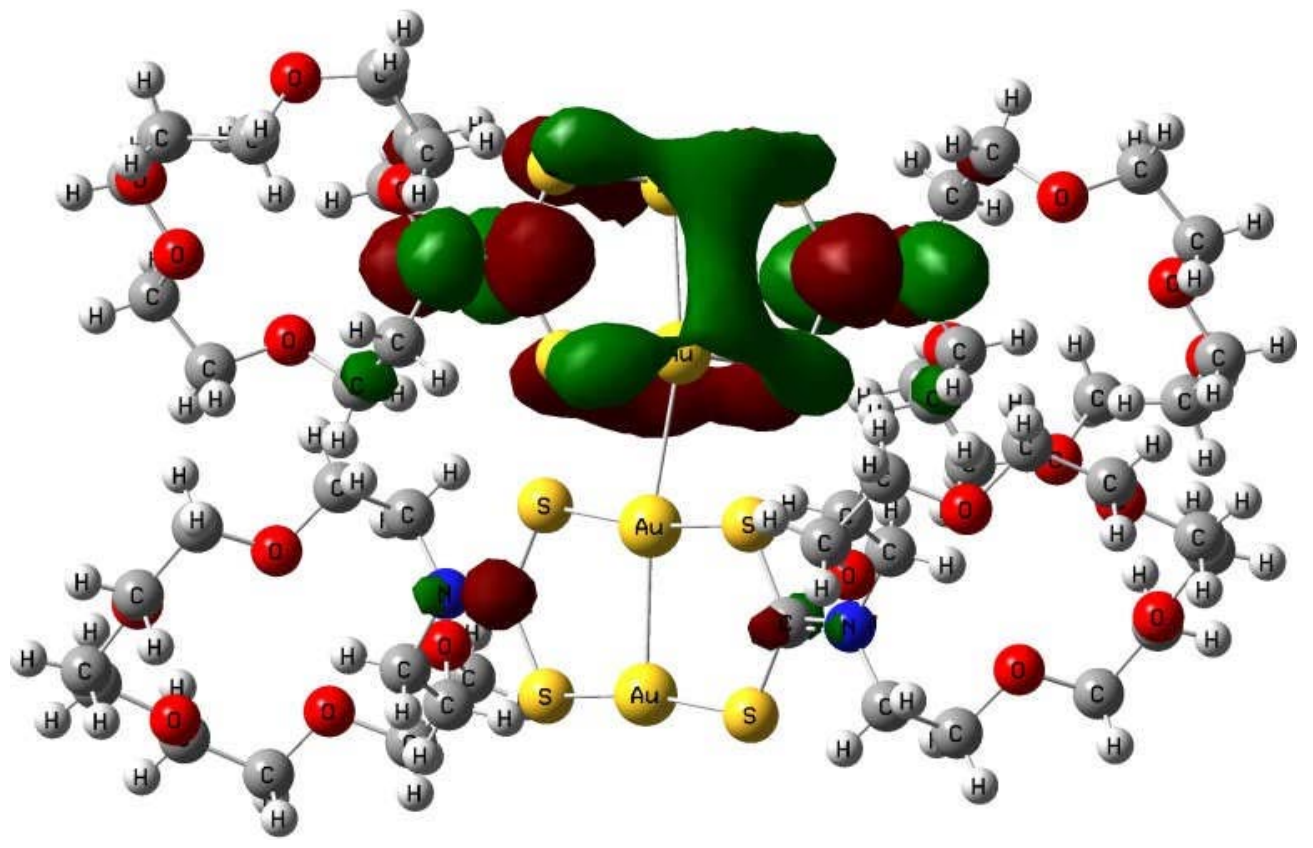

Au1 11\%

Au2 11\%

Au3 1\%

Au4 0\%

HOMO (360, Au 62\%, S 36\%, C 0\%, N 0\%, isovalue = 0.02) $\quad-0.15960$ hartree

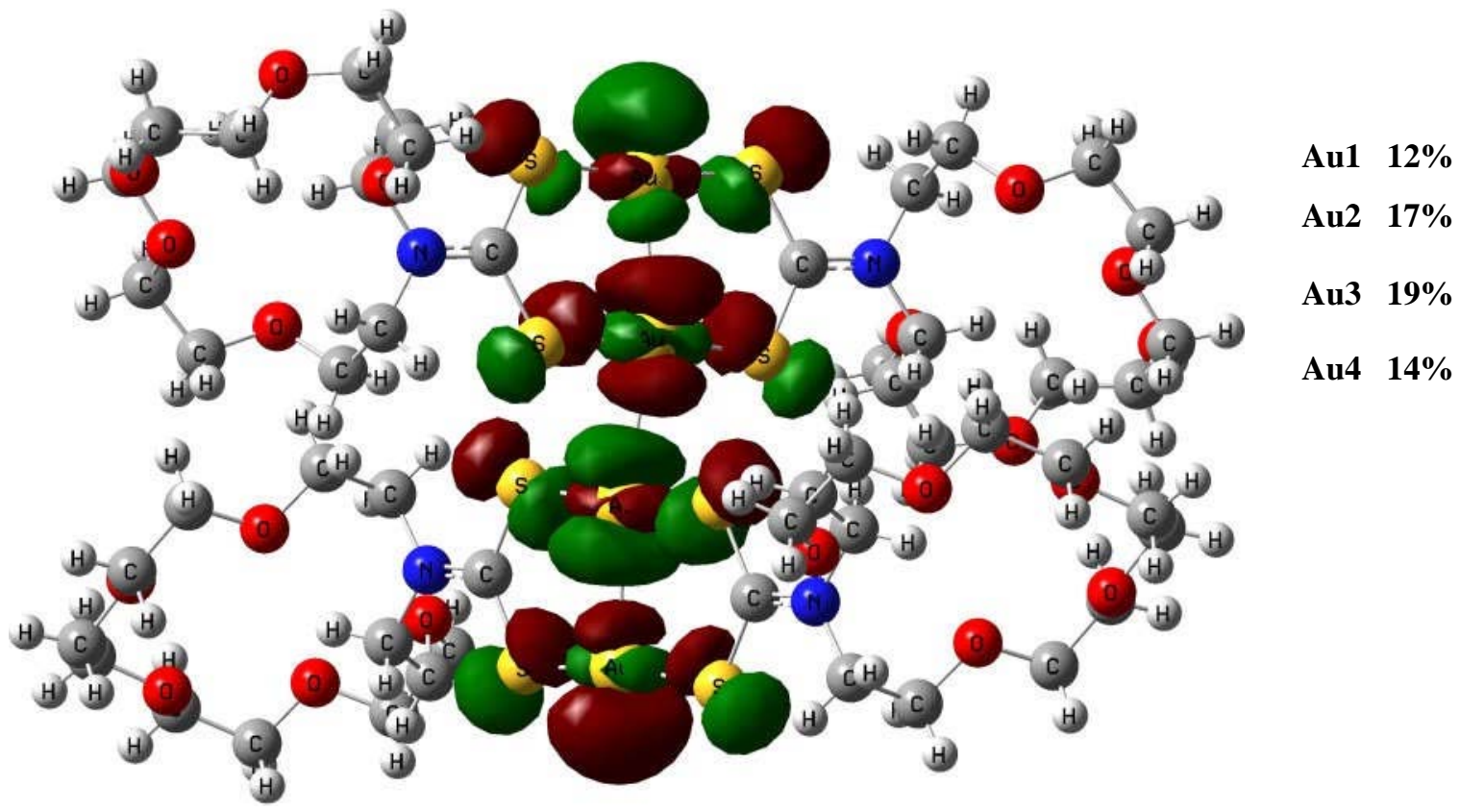




\section{Anisole}

$\left(\mathrm{S}_{0}, \mathrm{Au}-\mathrm{Au}_{\mathrm{intra}}=(2.728,2.733), \mathrm{Au}-\mathrm{Au}_{\mathrm{inter}}=2.854\right)$

LUMO (361, Au 22\%, S 14\%, C 42\%, N 17\%, isovalue = 0.02) $\quad-0.02664$ hartree

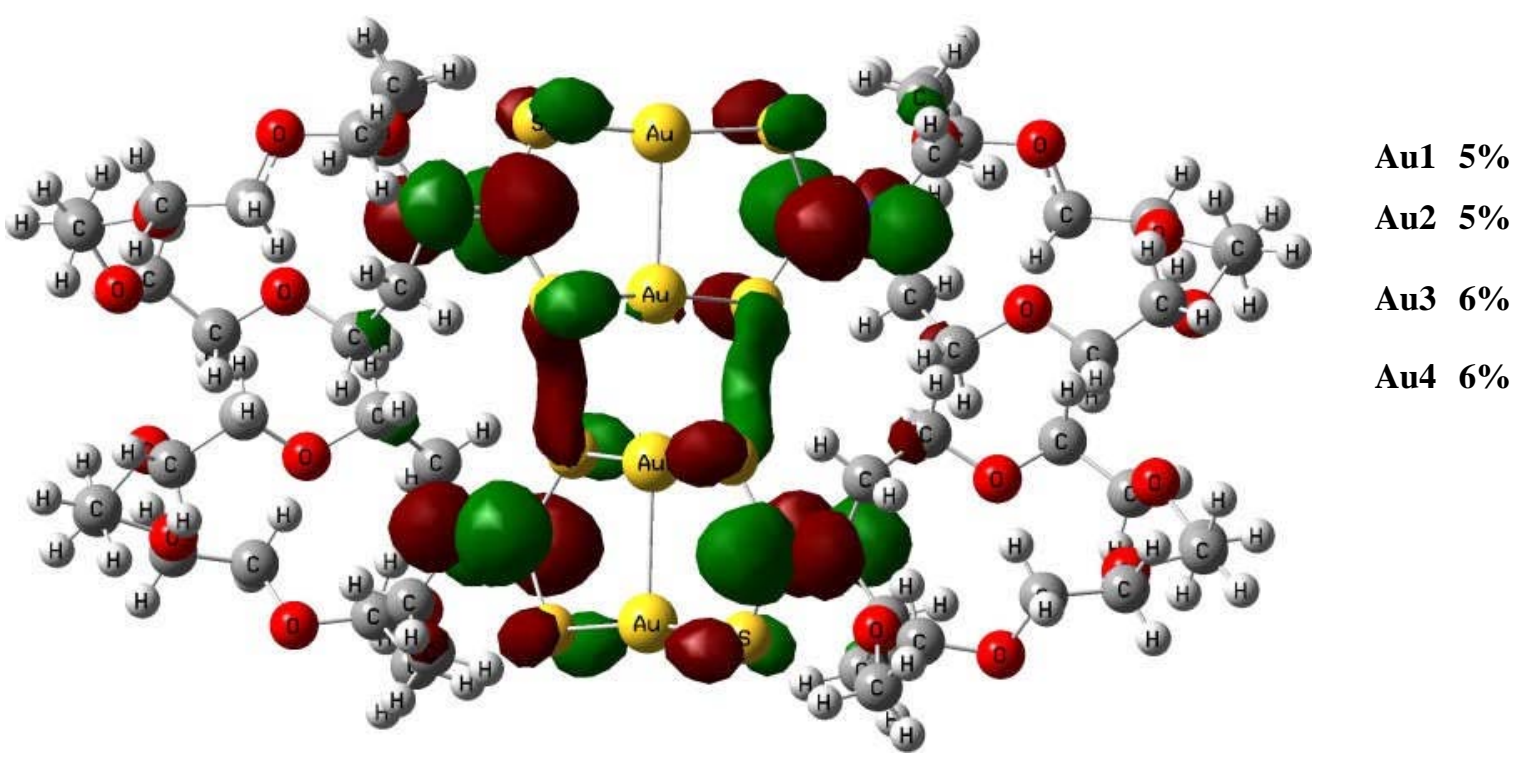

HOMO (360, Au 62\%, S 37\%, C 0\%, N 0\%, isovalue = 0.02) $\quad-0.16366$ hartree

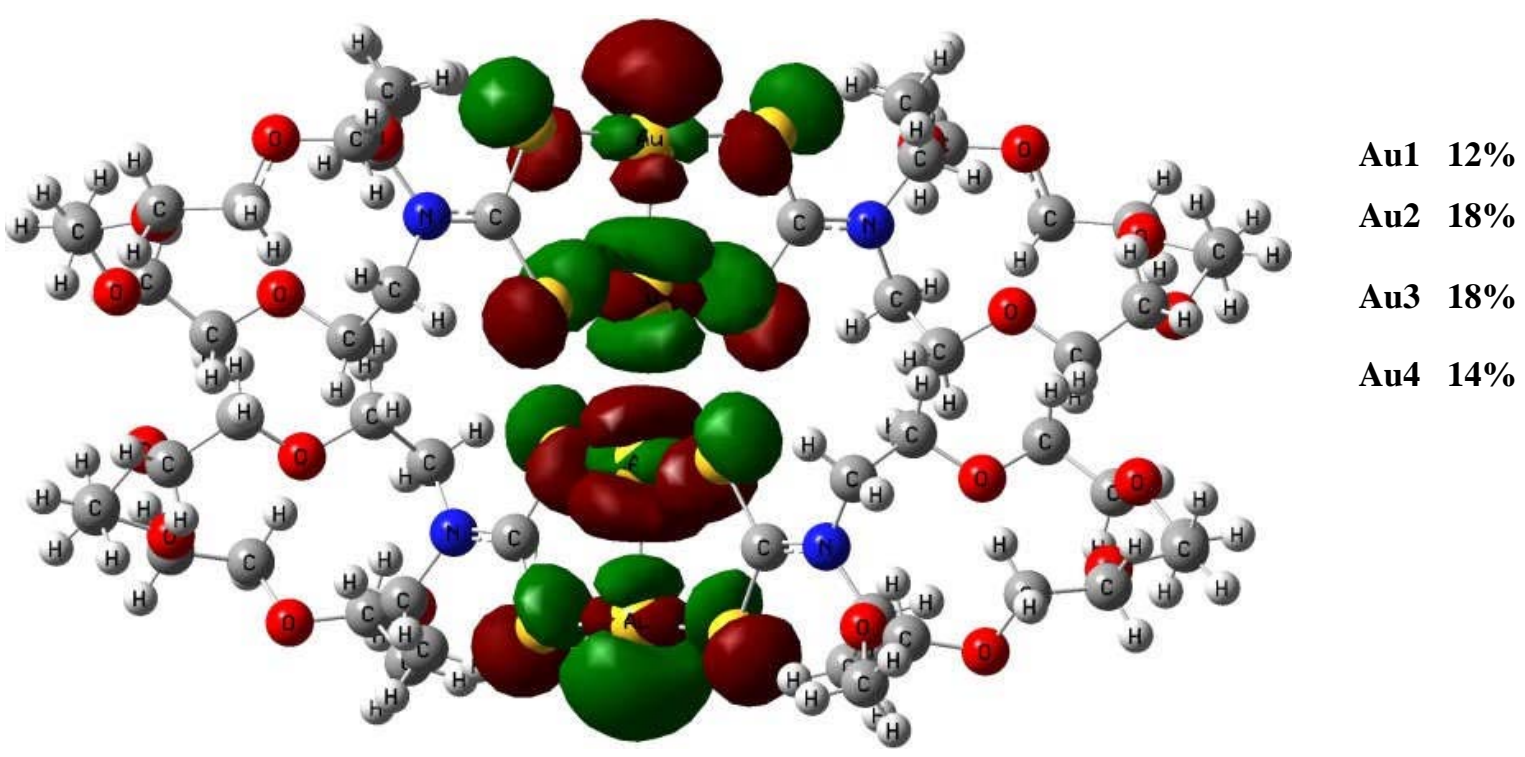




\section{Anisole}

$\left(\mathrm{S}_{0}, \mathrm{Au}-\mathrm{Au}_{\mathrm{intra}}=(2.728,2.733), \mathrm{Au}-\mathrm{Au}_{\mathrm{inter}}=2.856\right)$

LUMO (361, Au 25\%, S 13\%, C 41\%, N 17\%, isovalue = 0.02) $\quad-\mathbf{0 . 0 2 6 8 3}$ hartree

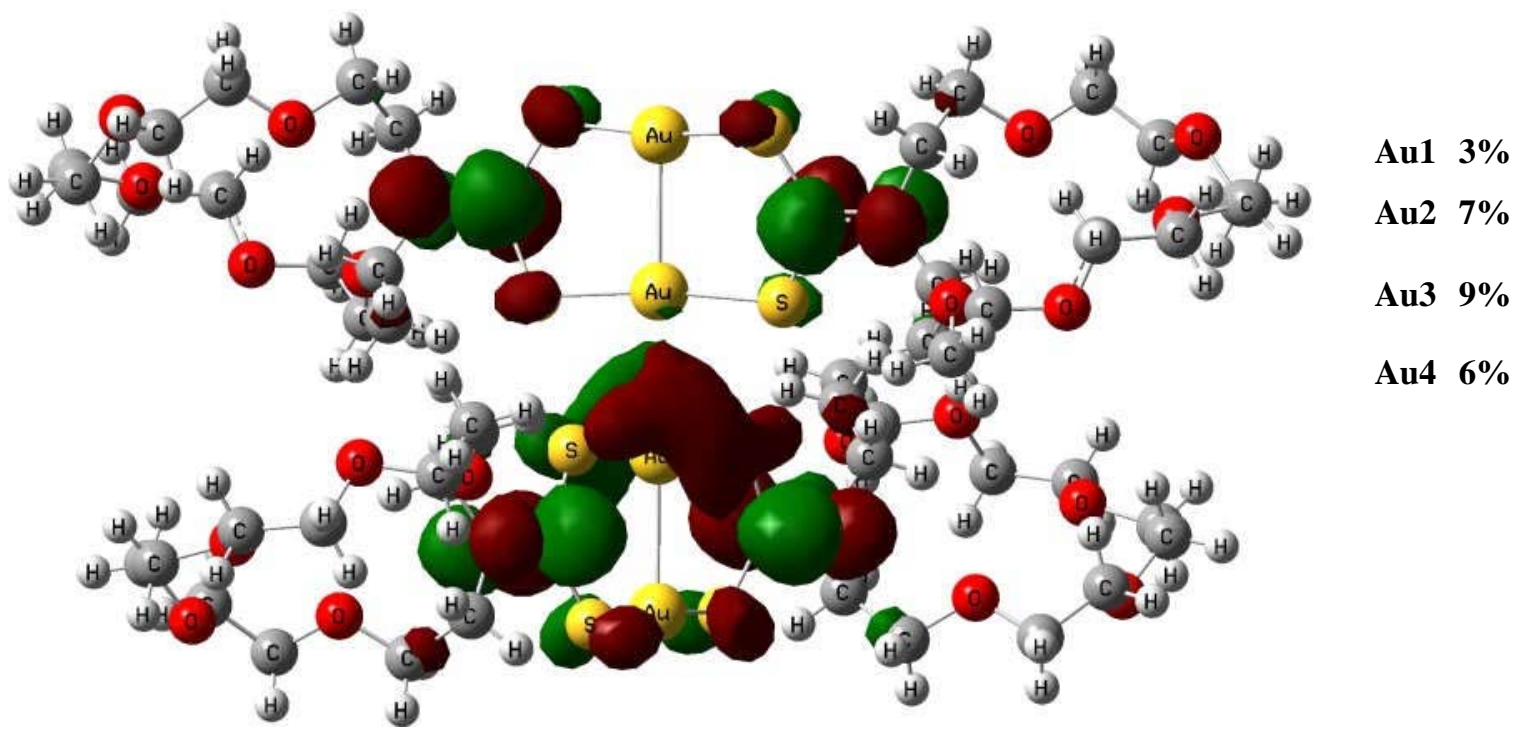

HOMO (360, Au 59\%, S 40\%, C 0\%, N 0\%, isovalue = 0.02) $\quad-0.16081$ hartree

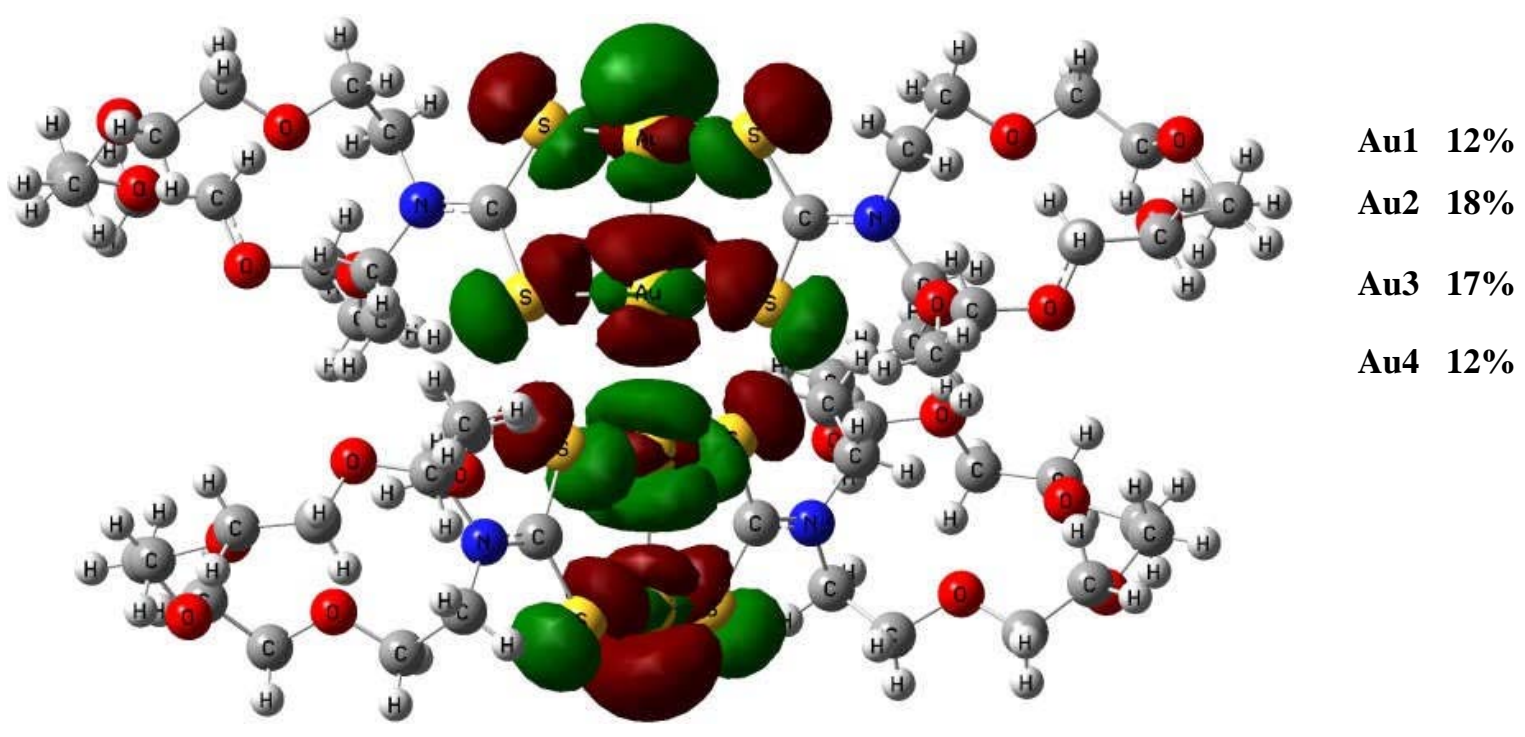




\section{THF}

$\left(S_{0}, A u-A u_{\text {intra }}=(2.733,2.735), A u-A u_{\text {inter }}=2.857\right)$

LUMO (361, Au 24\%, S 14\%, C 41\%, N 17\%, isovalue = 0.02) $\quad-0.02509$ hartree

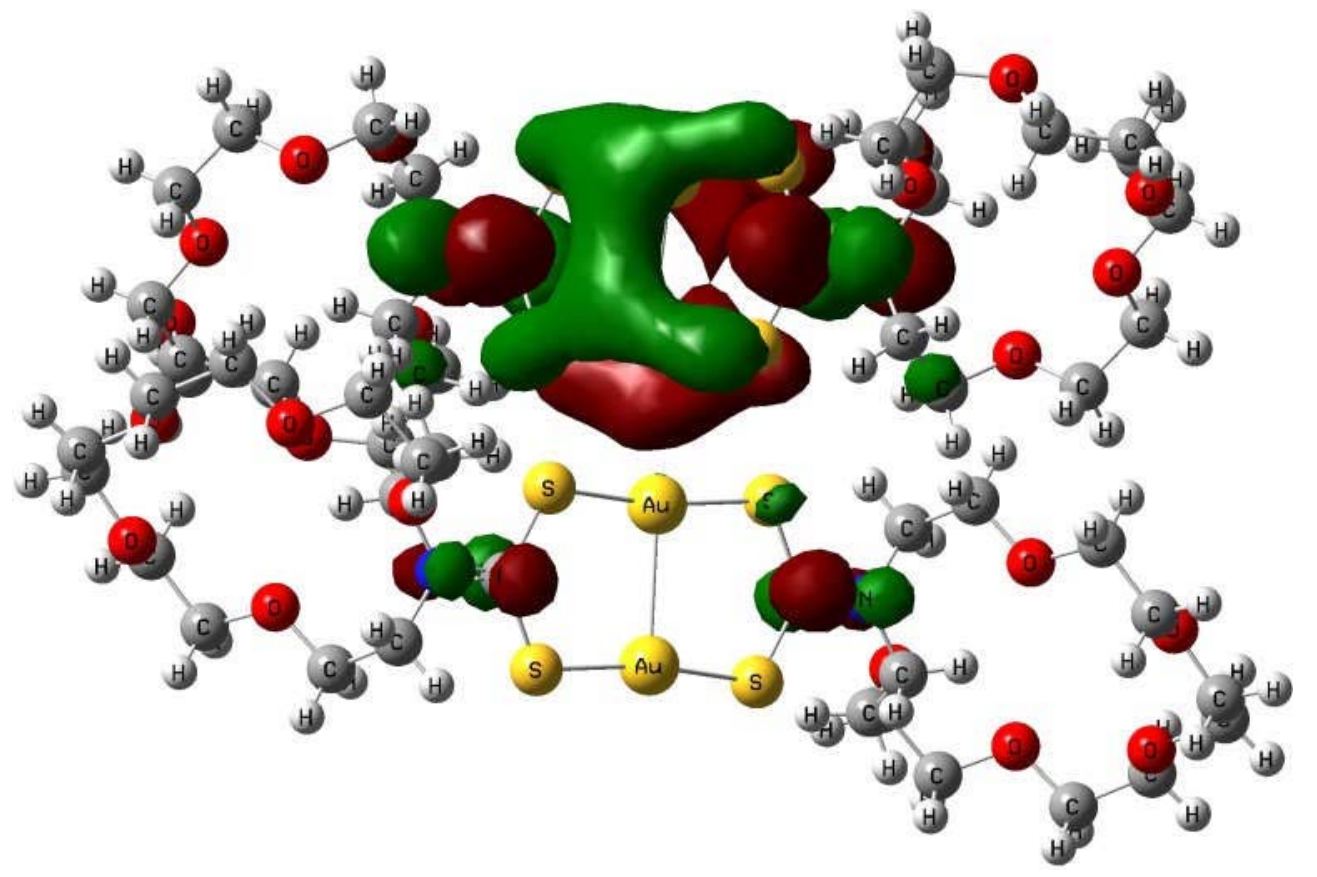

Au1 9\%

Au2 11\%

Au3 3\%

Au4 1\%

HOMO (360, Au 62\%, S 36\%, C 0\%, N 0\%, isovalue = 0.02) - 0.16291 hartree

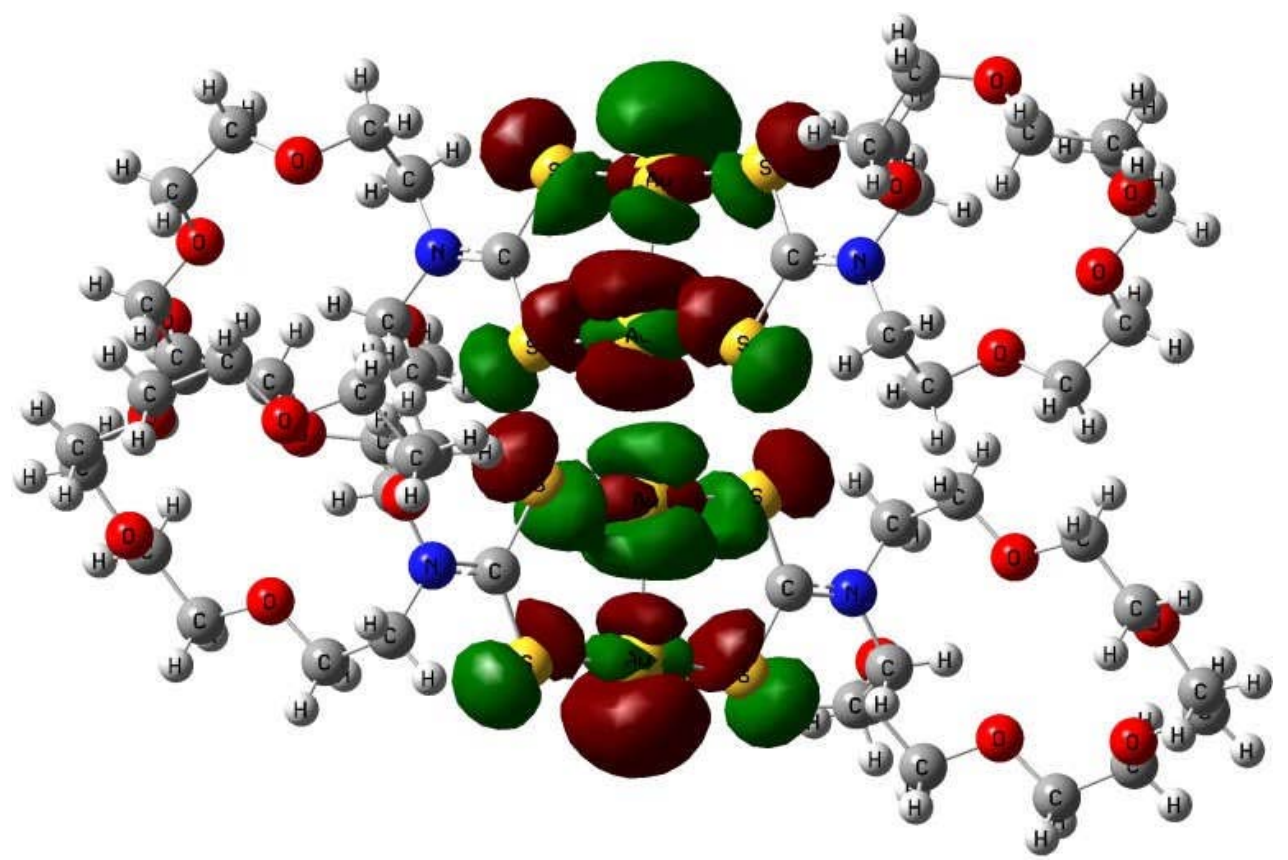

Au1 12\%

Au2 18\%

Au3 18\%

Au4 14\% 


\section{Acetone}

$\left(\mathrm{S}_{0}, \mathrm{Au}-\mathrm{Au}_{\mathrm{intra}}=(2.735,2.738), \mathrm{Au}-\mathrm{Au}_{\mathrm{inter}}=2.872\right)$

LUMO (361, Au 26\%, S 13\%, C 40\%, N 17\%, isovalue = 0.02) $\quad-0.02511$ hartree

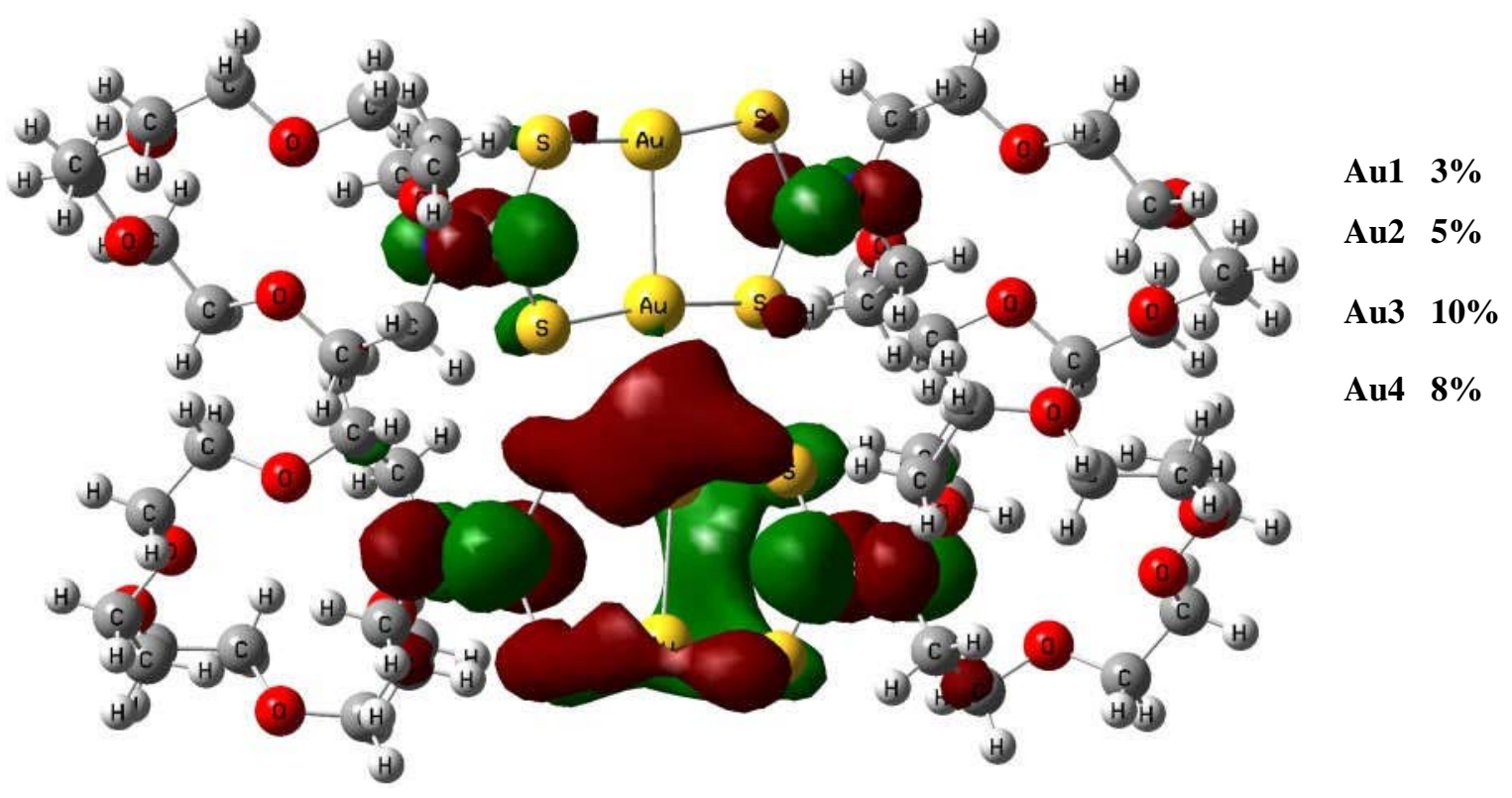

HOMO (360, Au 62\%, S 37\%, C 0\%, N 0\%, isovalue = 0.02) $\quad-0.16388$ hartree

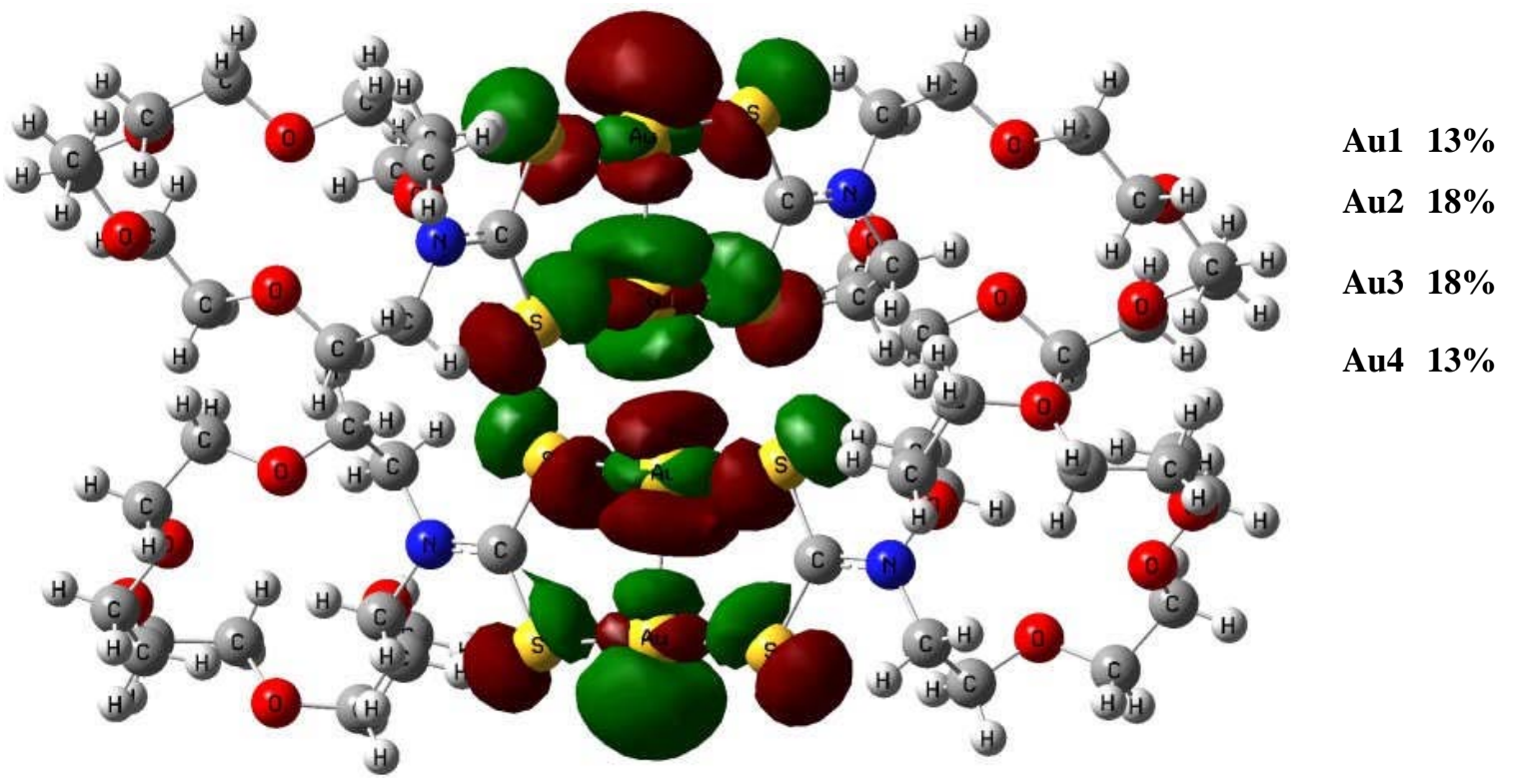




\section{DMSO}

$\left(\mathrm{S}_{0}, \mathrm{Au}-\mathrm{Au} \mathrm{u}_{\text {intra }}=(2.729,2.739), \mathrm{Au}-\mathrm{Au} \mathrm{u}_{\text {inter }}=2.875\right)$

LUMO (361, Au 26\%, S 13\%, C 40\%, N 17\%, isovalue = 0.02) $\quad-0.02432$ hartree

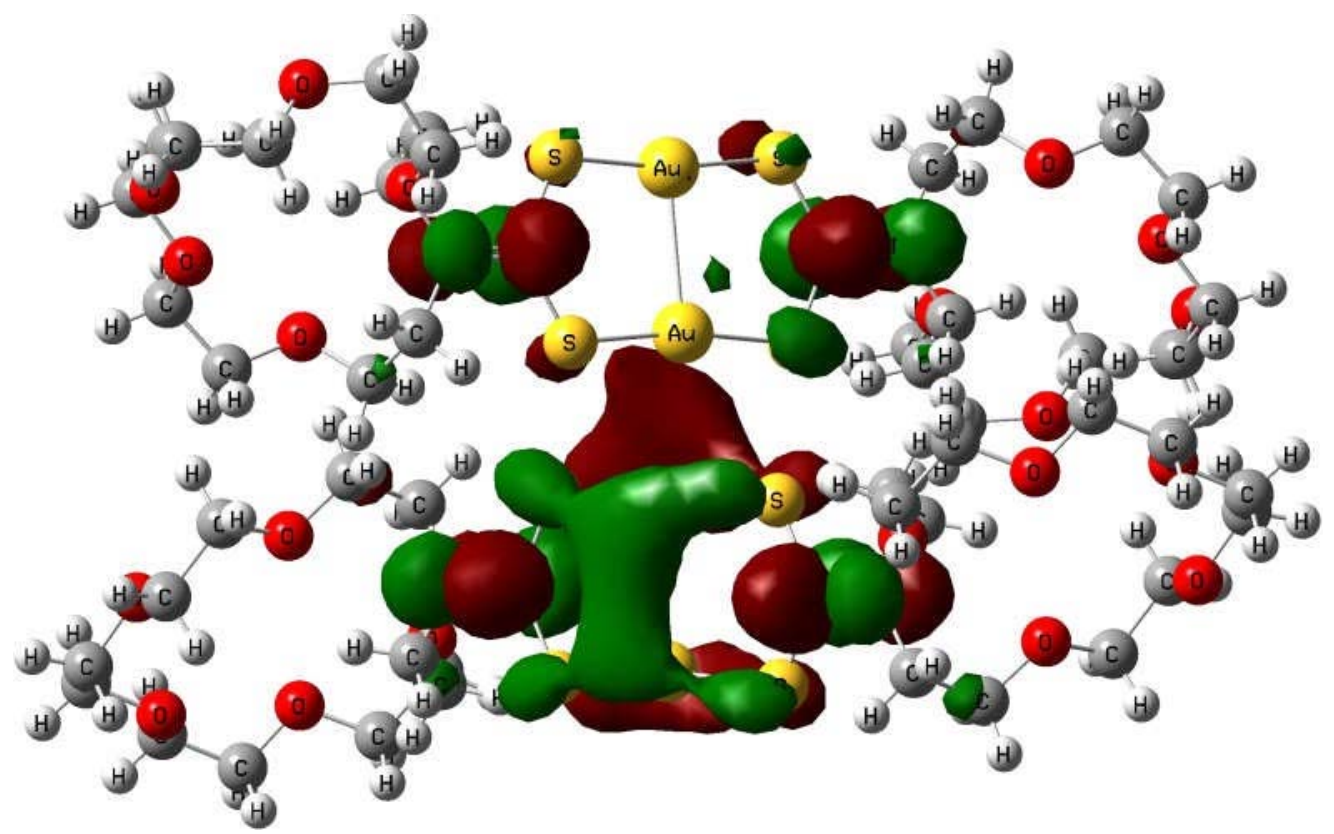

Au1 4\%

Au2 6\%

Au3 9\%

Au4 7\%

HOMO (360, Au 62\%, S 37\%, C 0\%, N 0\%, isovalue = 0.02) $\quad-0.16329$ hartree

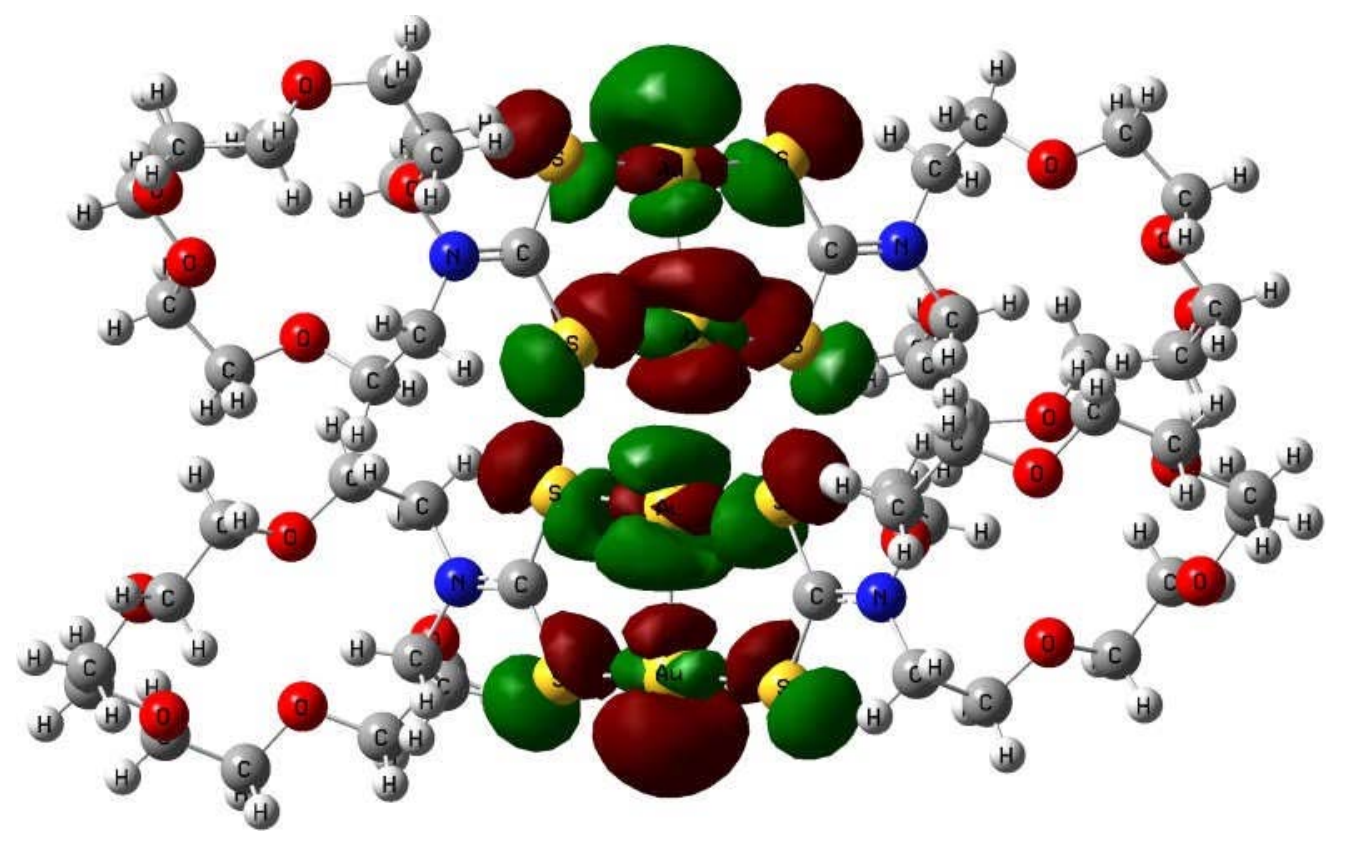

Au1 13\%

Au2 18\%

Au3 18\%

Au4 13\% 


\section{m-Xylene}

$\left(\mathrm{S}_{0}, \mathrm{Au}-\mathrm{Au}_{\text {intra }}=(2.755,2.755), \mathrm{Au}-\mathrm{Au}_{\text {inter }}=2.890\right)$

LUMO (361, Au 25\%, S 13\%, C 41\%, N 17\%, isovalue = 0.02) $\quad-0.02460$ hartree

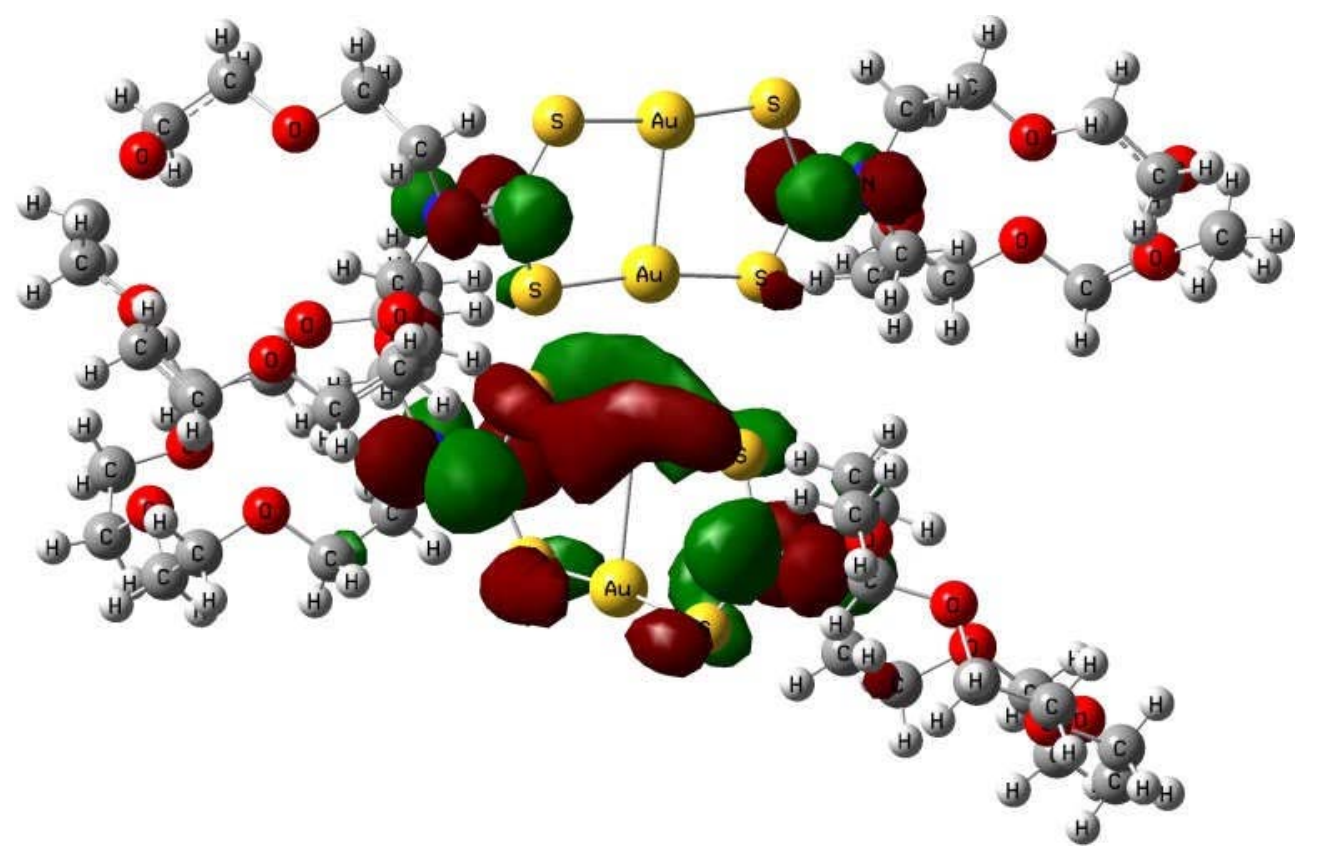

Au1 2\%

Au2 6\%

Au3 $10 \%$

Au4 7\%

HOMO (360, Au 61\%, S 38\%, C 0\%, N 0\%, isovalue = 0.02) - 0.16179 hartree

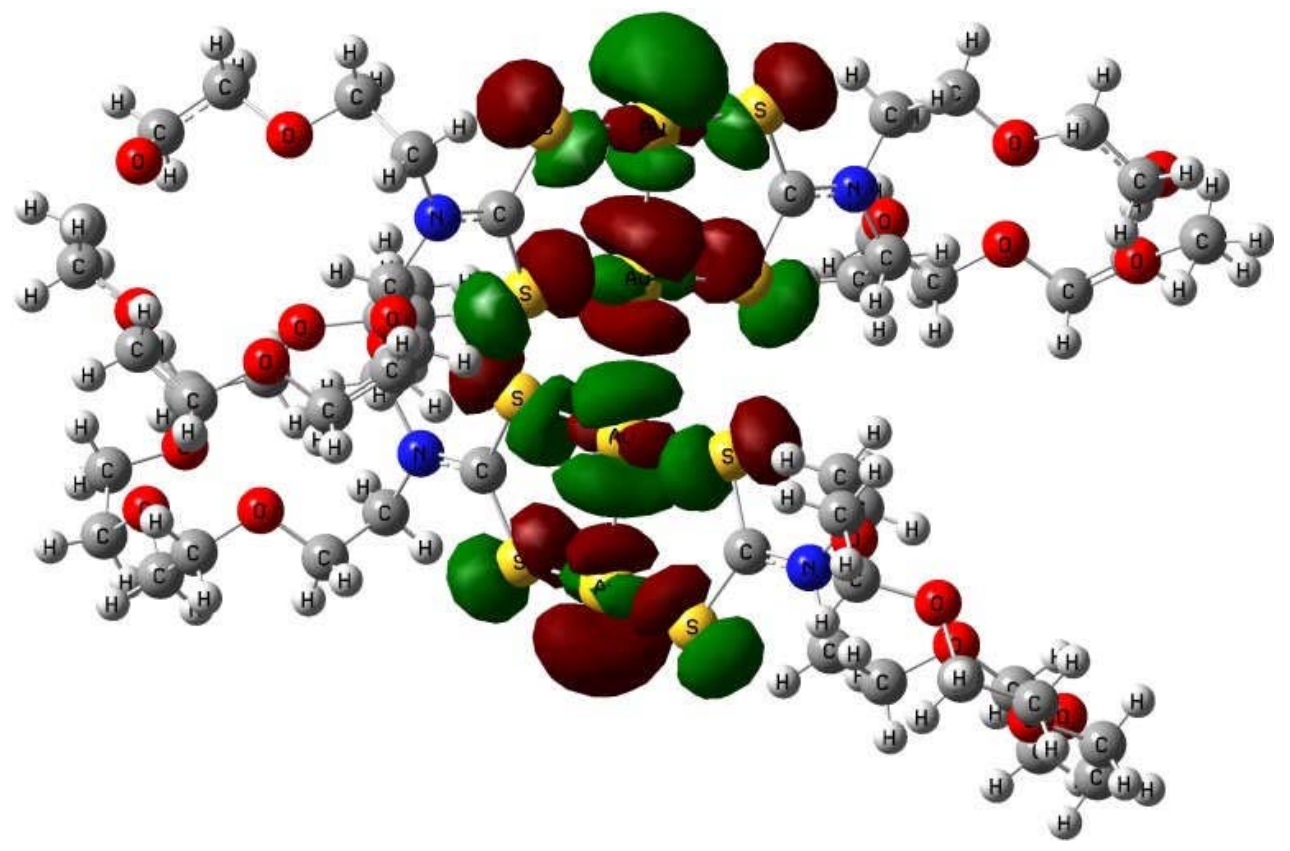

Au1 14\%

Au2 18\%

Au3 17\%

Au4 12\% 


\section{m-Xylene}

$\left(\mathrm{S}_{0}, \mathrm{Au}-\mathrm{Au}_{\text {intra }}=(2.764,2.764), \mathrm{Au}-\mathrm{Au}_{\text {inter }}=2.893\right)$

LUMO (361, Au 20\%, S 15\%, C 43\%, N 17\%, isovalue = 0.02) - 0.03958 hartree

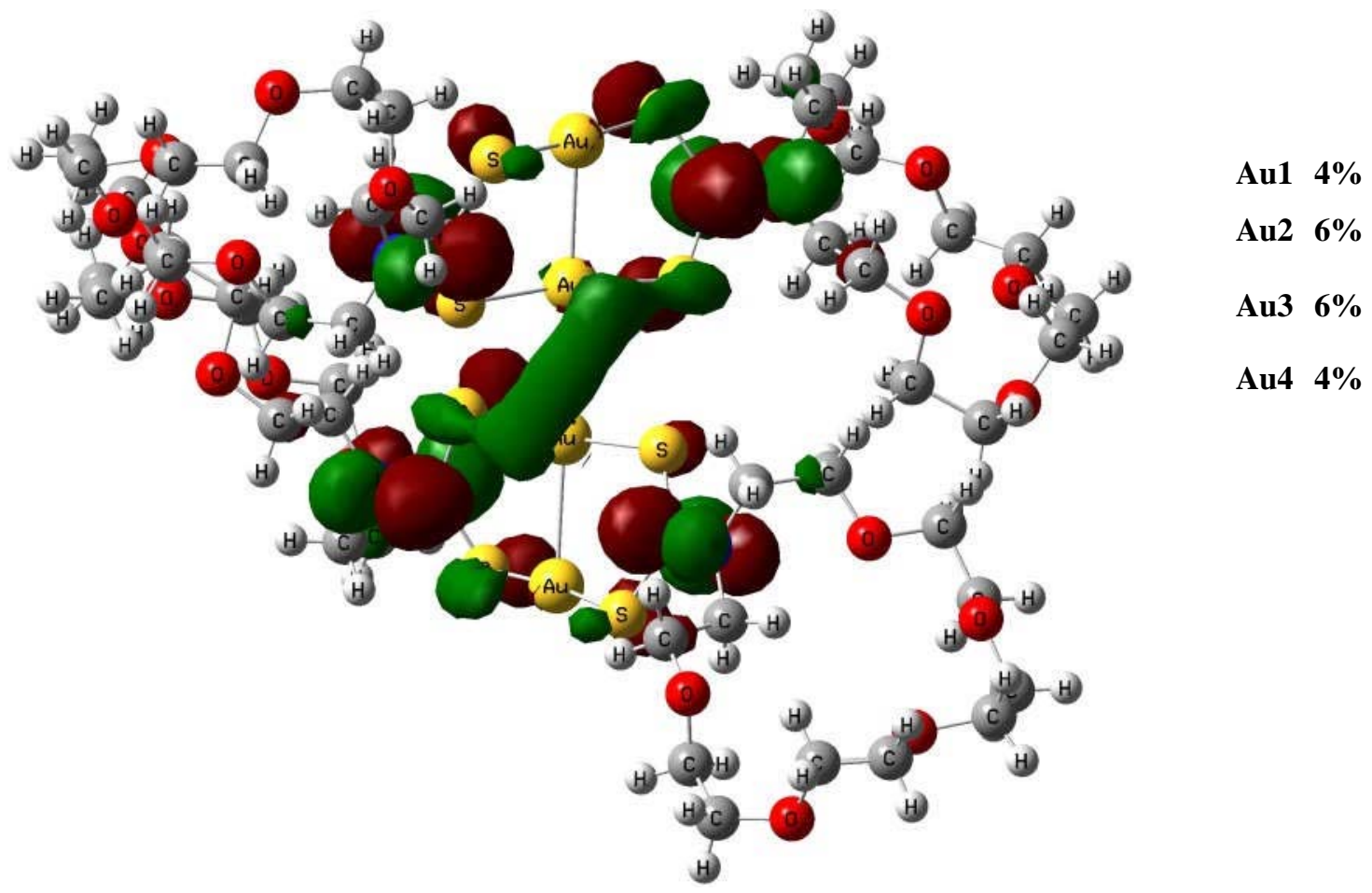

HOMO (360, Au 59\%, S 40\%, C 0\%, N 0\%, isovalue = 0.02) - 0.17232 hartree

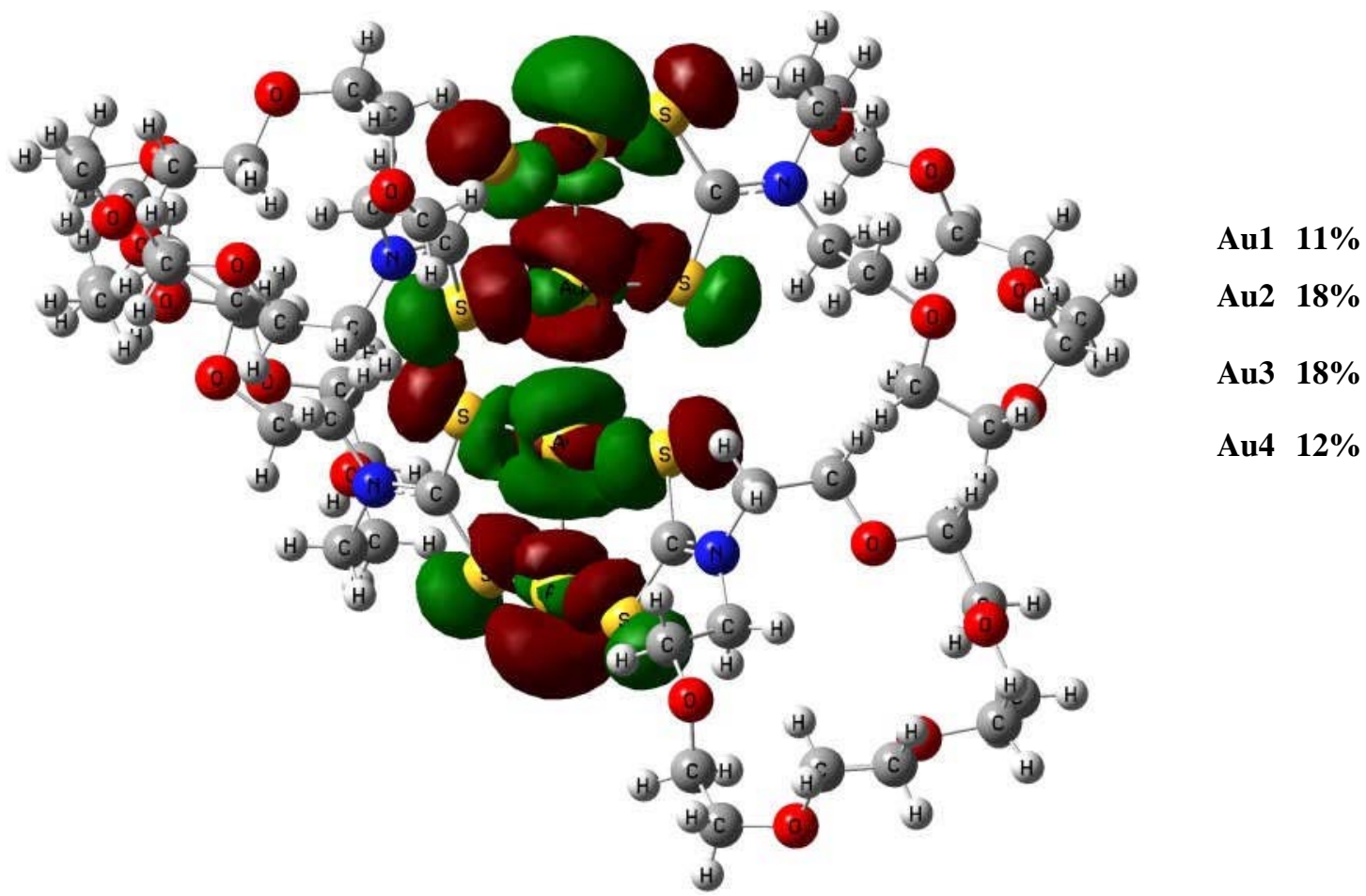




\section{m-Xylene}

$\left(\mathrm{S}_{0}, \mathrm{Au}-\mathrm{Au}_{\text {intra }}=(2.755,2.755), \mathrm{Au}-\mathrm{Au}_{\text {inter }}=2.902\right)$

LUMO (361, Au 22\%, S 14\%, C 42\%, N 17\%, isovalue = 0.02) $\quad-\mathbf{0 . 0 2 4 9 6}$ hartree

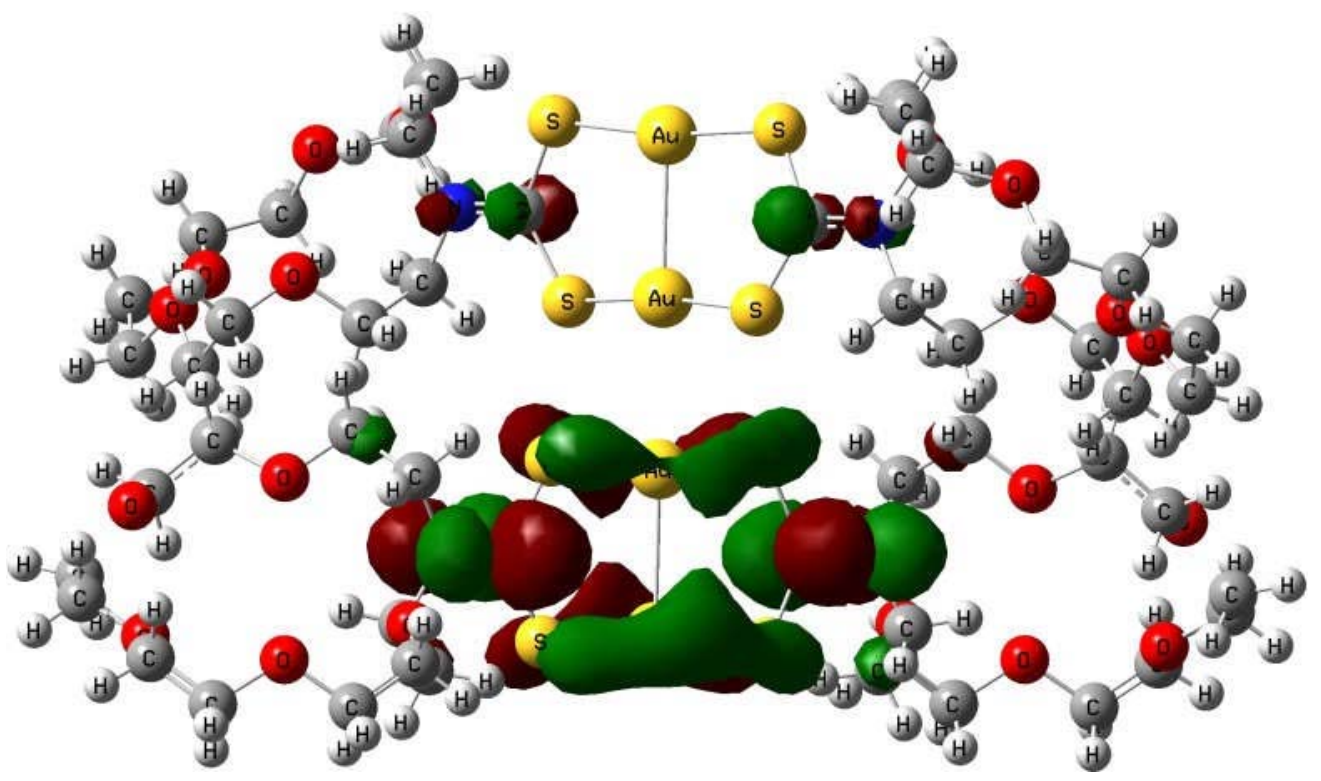

Au1 0\%

Au2 1\%

Au3 10\%

Au4 11\%

HOMO (360, Au 62\%, S 37\%, C 0\%, N 0\%, isovalue = 0.02) - 0.16429 hartree

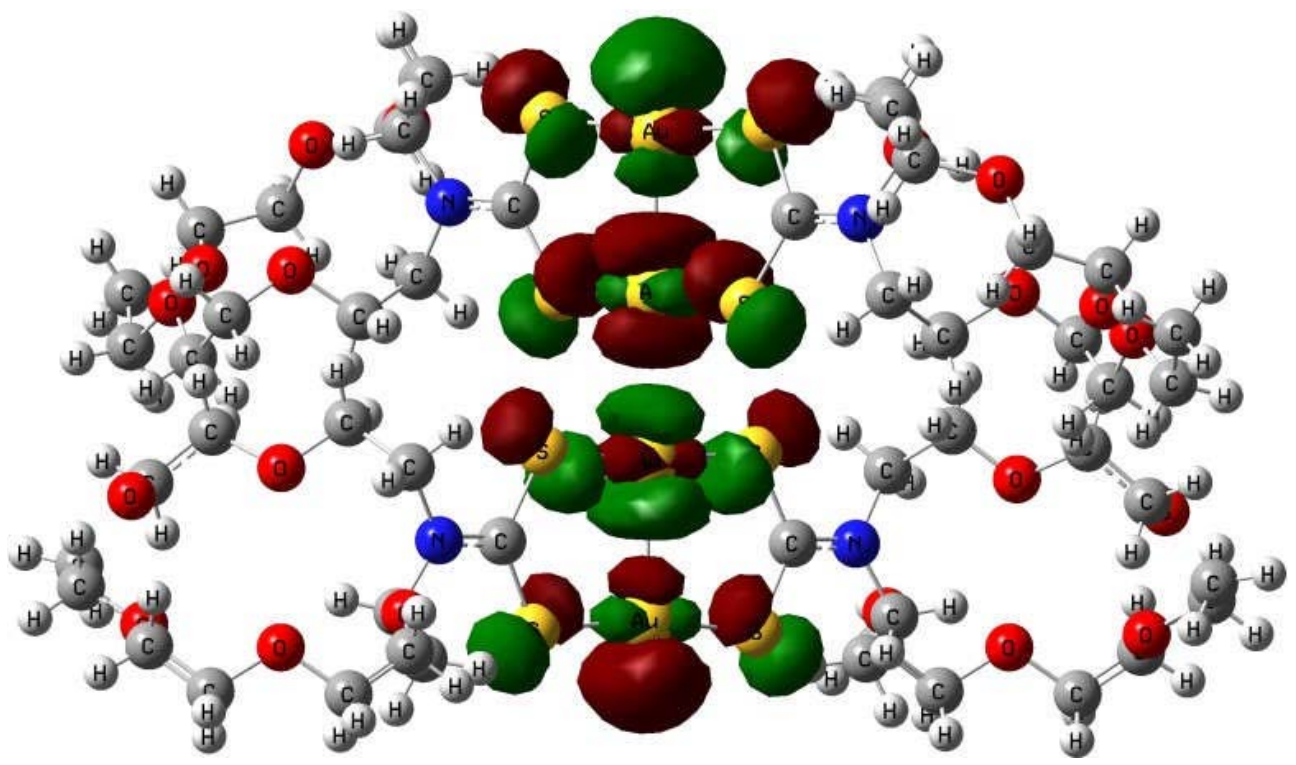

Au1 14\%

Au2 18\%

Au3 18\%

Au4 12\% 


\section{DMF}

$\left(\mathrm{S}_{0}, \mathrm{Au}-\mathrm{Au}_{\mathrm{intra}}=(2.741,2.746), \mathrm{Au}-\mathrm{Au}_{\text {inter }}=2.902\right)$

LUMO (361, Au 25\%, S 14\%, C 40\%, N 17\%, isovalue = 0.02) $\quad-0.02666$ hartree

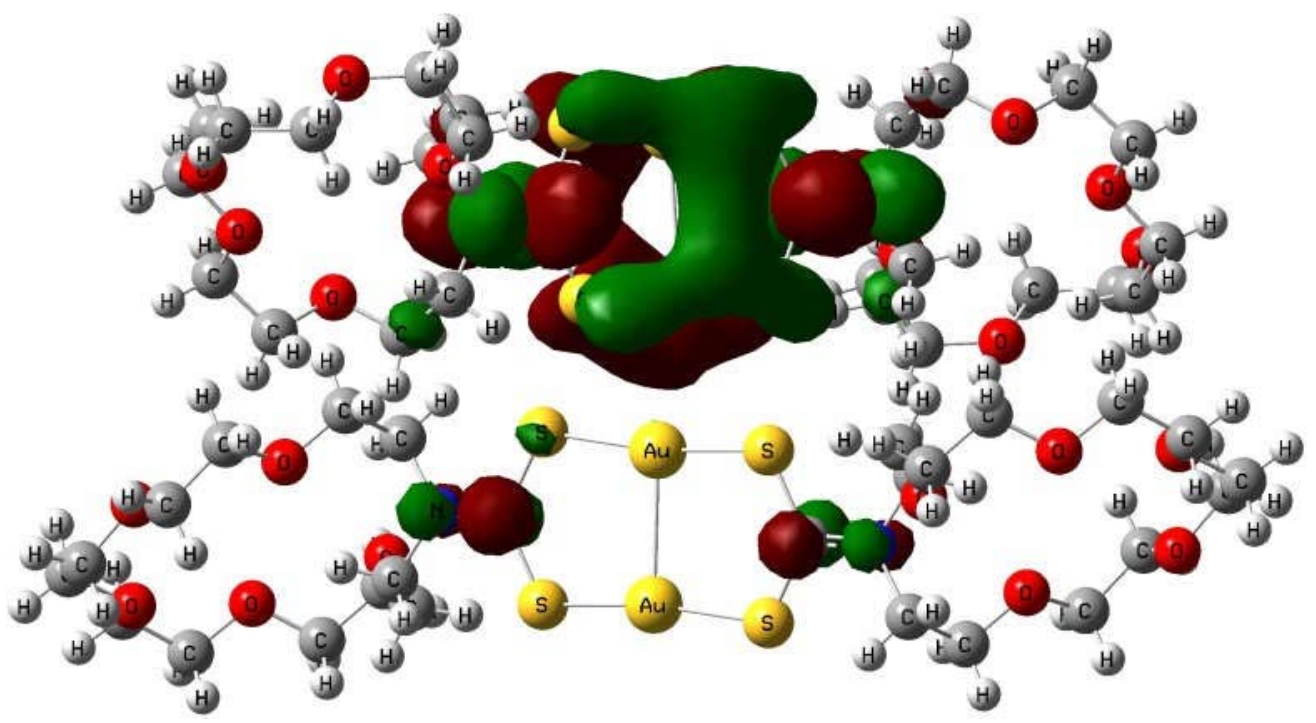

Au1 9\%

Au2 13\%

Au3 3\%

Au4 0\%

HOMO (360, Au 62\%, S 37\%, C 0\%, N 0\%, isovalue = 0.02) - -0.16592 hartree

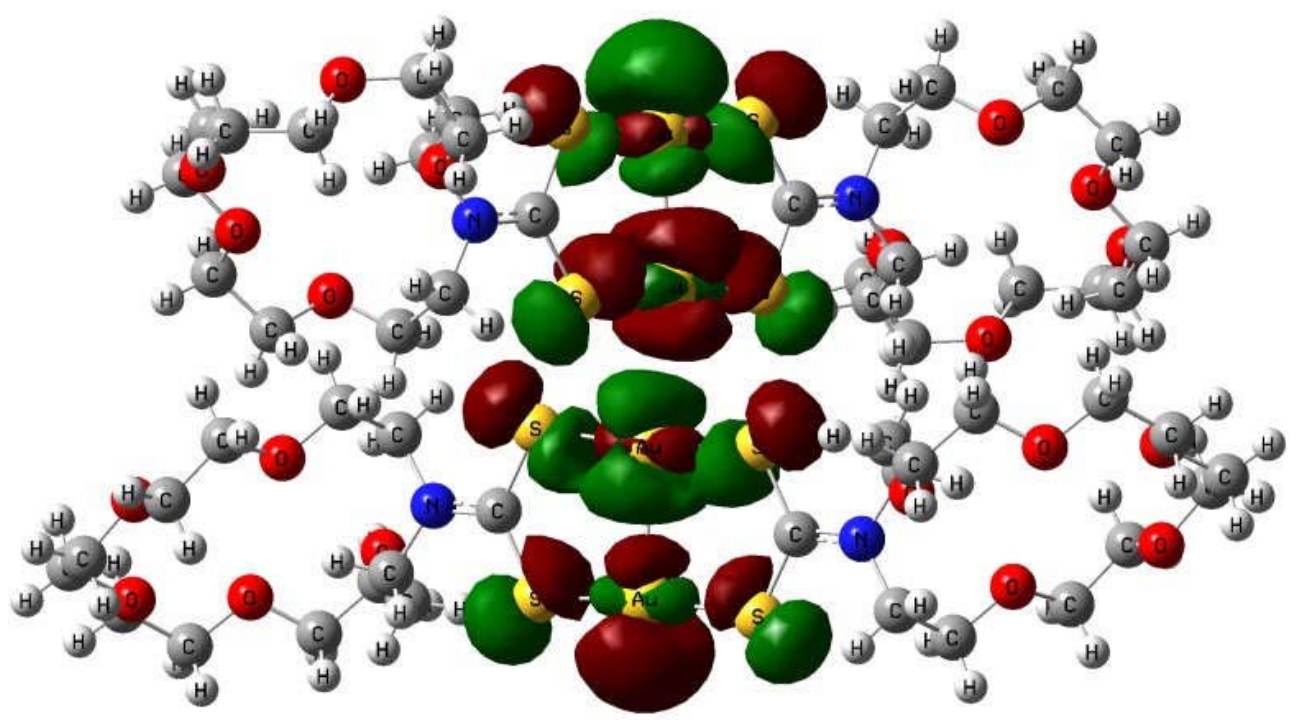

Au1 12\%

Au2 18\%

Au3 18\%

Au4 14\% 


\section{tert-Butylbenzene $\cdot \mathrm{H}_{2} \mathrm{O}$}

$\left(\mathrm{S}_{0}, \mathrm{Au}-\mathrm{Au}_{\mathrm{intra}}=(2.771,2.771), \mathrm{Au}-\mathrm{Au} \mathrm{u}_{\text {inter }}=2.942\right)$

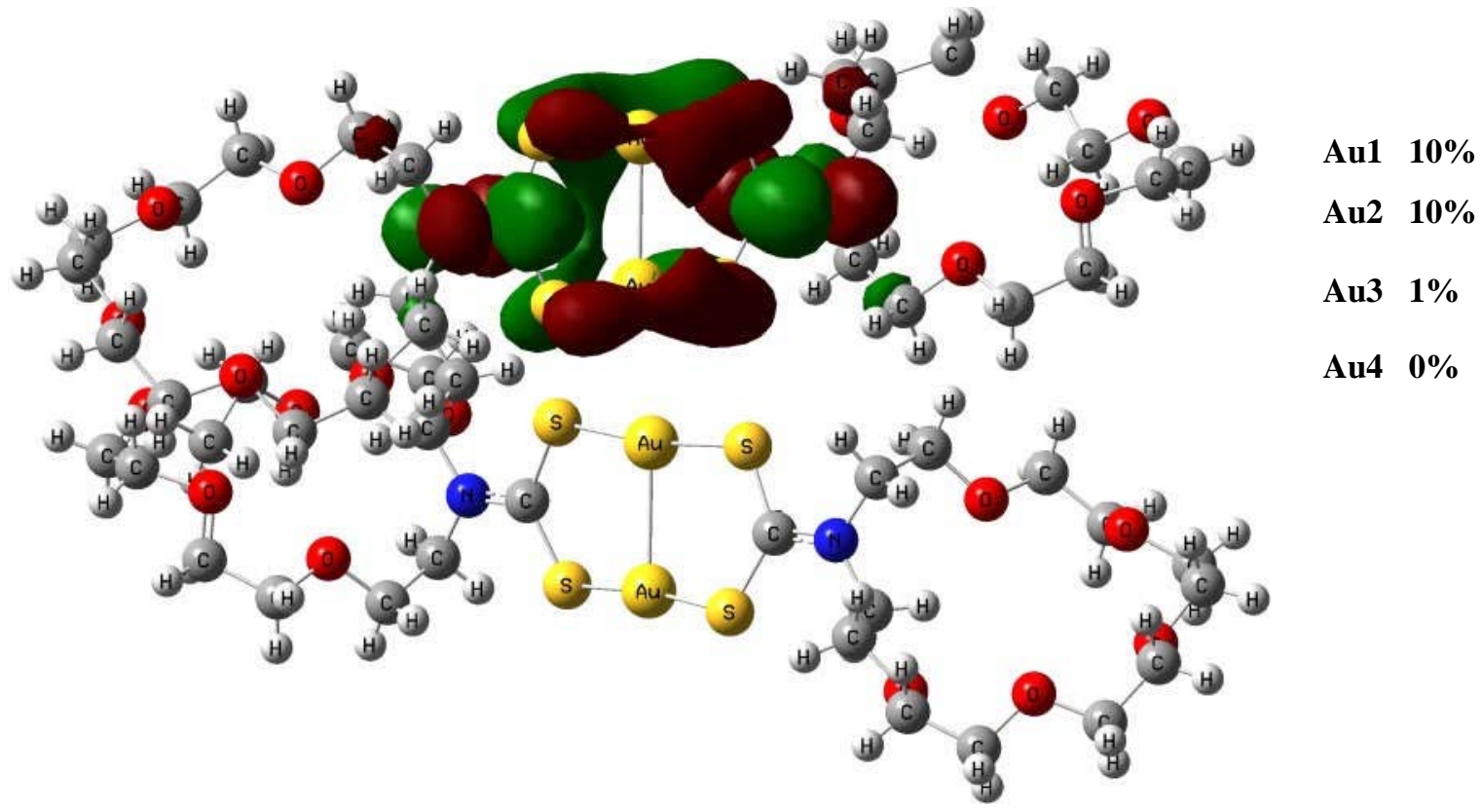

HOMO (360, Au 62\%, S 37\%, C 0\%, N 0\%, isovalue = 0.02) $\quad-0.17002$ hartree

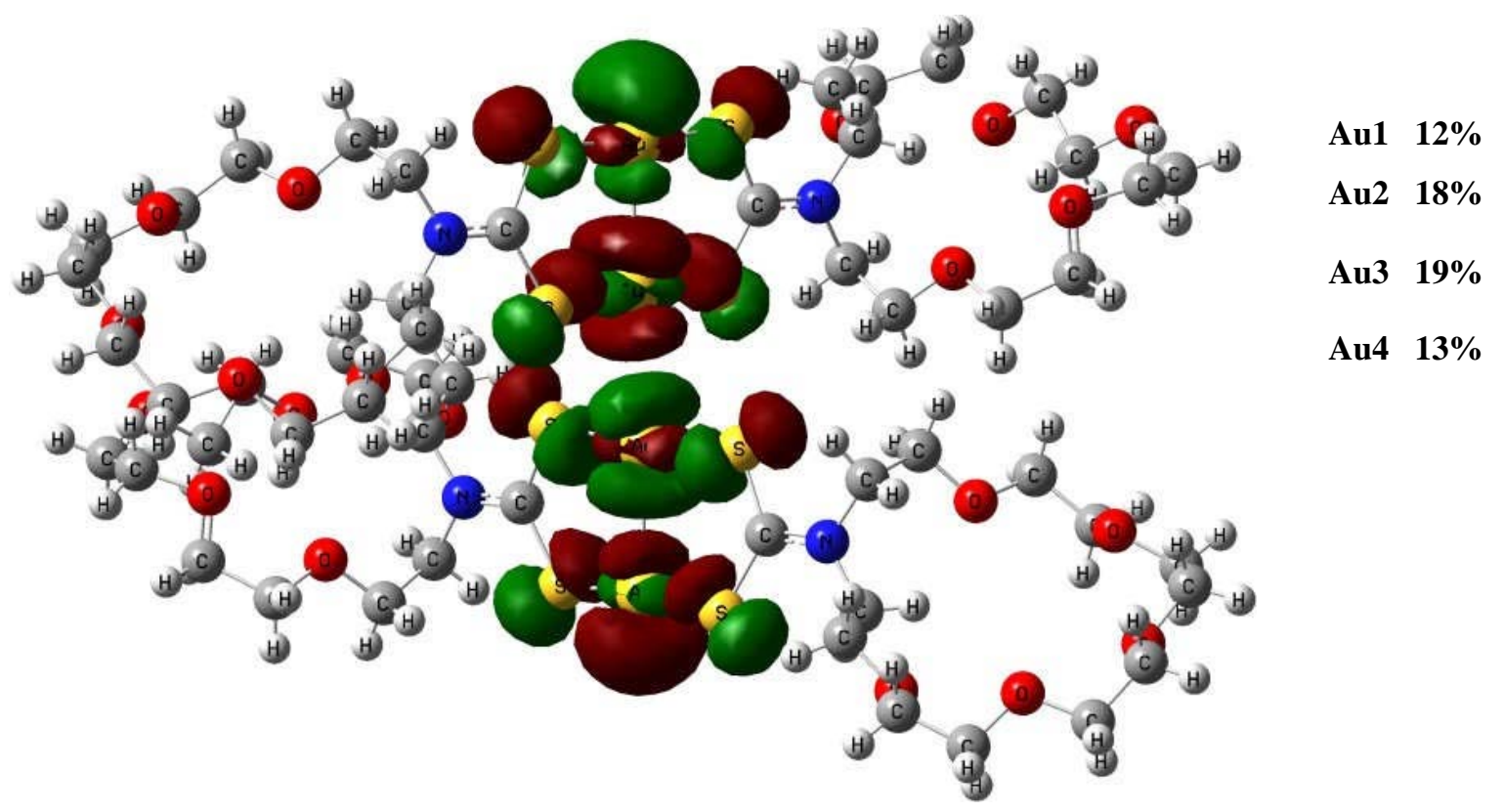


(c)

\section{Toluene}

$\left(\mathrm{S}_{0}, \mathrm{Au}-\mathrm{Au}_{\mathrm{intra}}=(2.717,2.728,2.717), \mathrm{Au}-\mathrm{Au} u_{\text {inter }}=(2.825,2.829)\right)$

LUMO (541, Au 19\%, S 16\%, C 43\%, N 17\%, isovalue = 0.02) $\quad-0.02864$ hartree

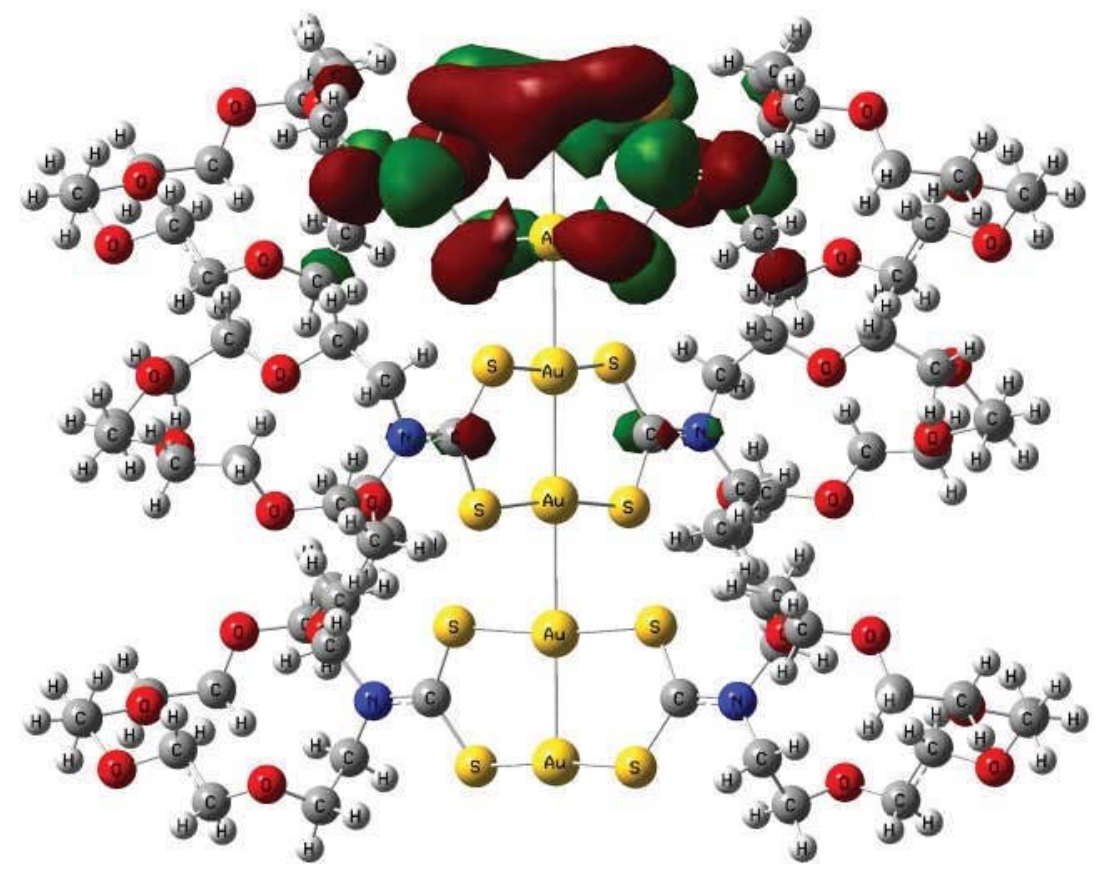

Au1 10\%

Au2 8\%

Au3 1\%

Au4 0\%

Au5 0\%

Au6 0\%

HOMO (540, Au 61\%, S 38\%, C 0\%, N 0\%, isovalue = 0.02) $\quad-0.14722$ hartree

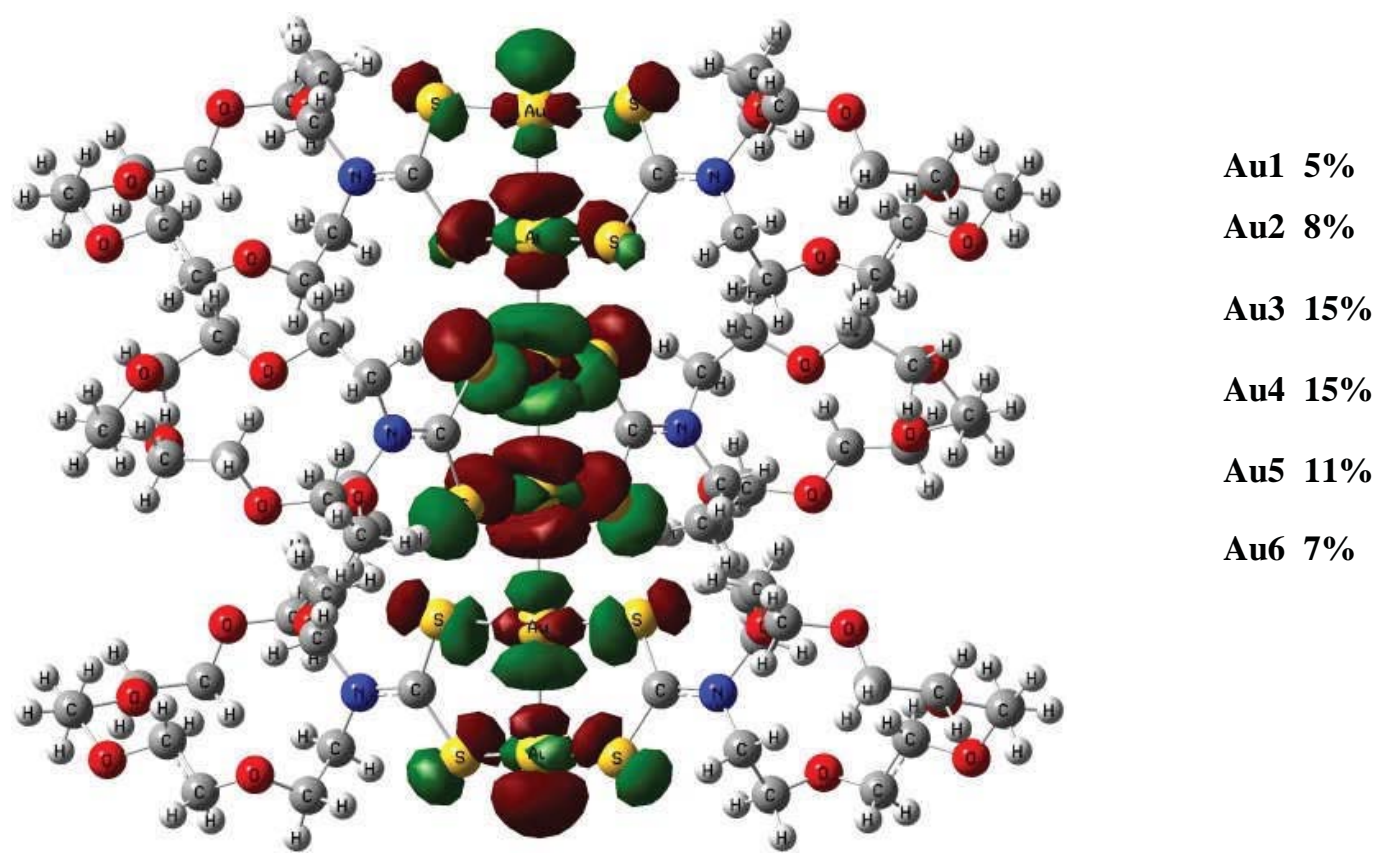




\section{Toluene}

$\left(\mathrm{S}_{0}, \mathrm{Au}-\mathrm{Au} \mathrm{u}_{\text {intra }}=(2.728,2.717,2.728), \mathrm{Au}-\mathrm{A} u_{\text {inter }}=(2.825,2.829)\right)$

LUMO (541, Au 24\%, S 14\%, C 41\%, N 17\%, isovalue = 0.02) $\quad-0.02464$ hartree

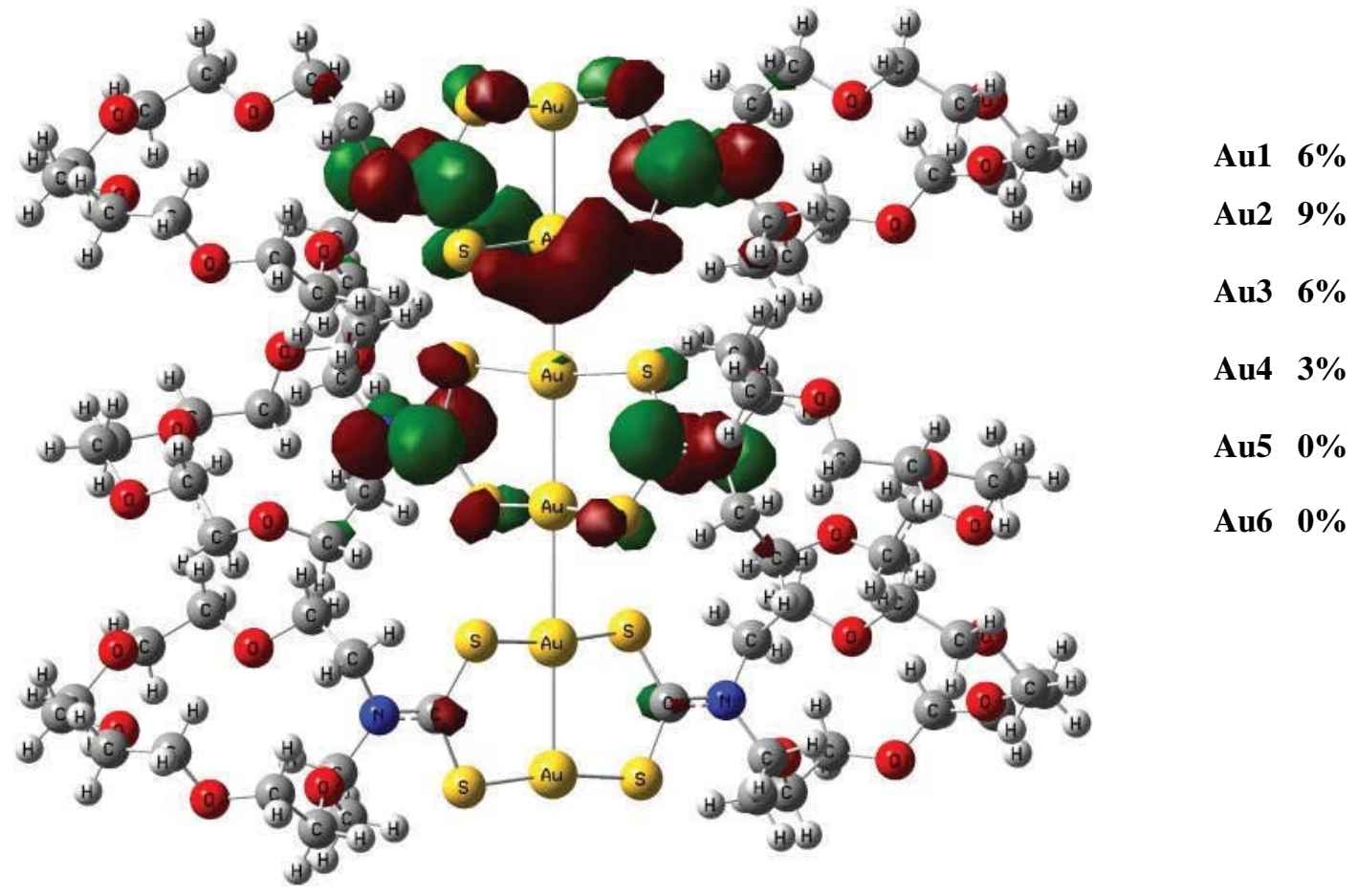

HOMO (540, Au 62\%, S 37\%, C 0\%, N 0\%, isovalue = 0.02) $\quad-0.14679$ hartree

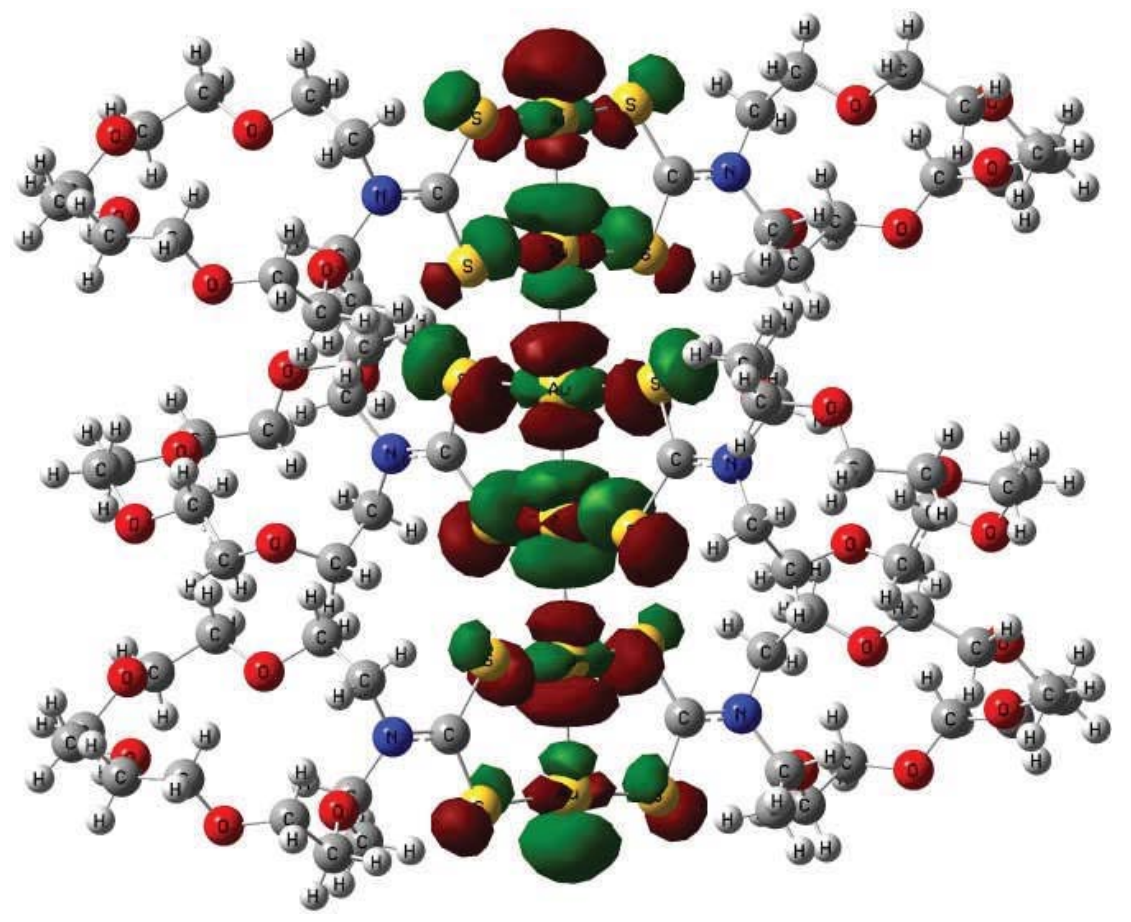

Au1 7\%

Au2 10\%

Au3 14\%

Au4 14\%

Au5 10\%

Au6 7\% 


\section{Acetonitrile}

$\left(\mathrm{S}_{0}, \mathrm{Au}-\mathrm{Au} u_{\text {intra }}=(2.719,2.725,2.719), \mathrm{Au}-\mathrm{Au} u_{\text {inter }}=2.836\right)$

LUMO (541, Au 26\%, S 13\%, C 40\%, N 17\%, isovalue = 0.02) -0.01489 hartree

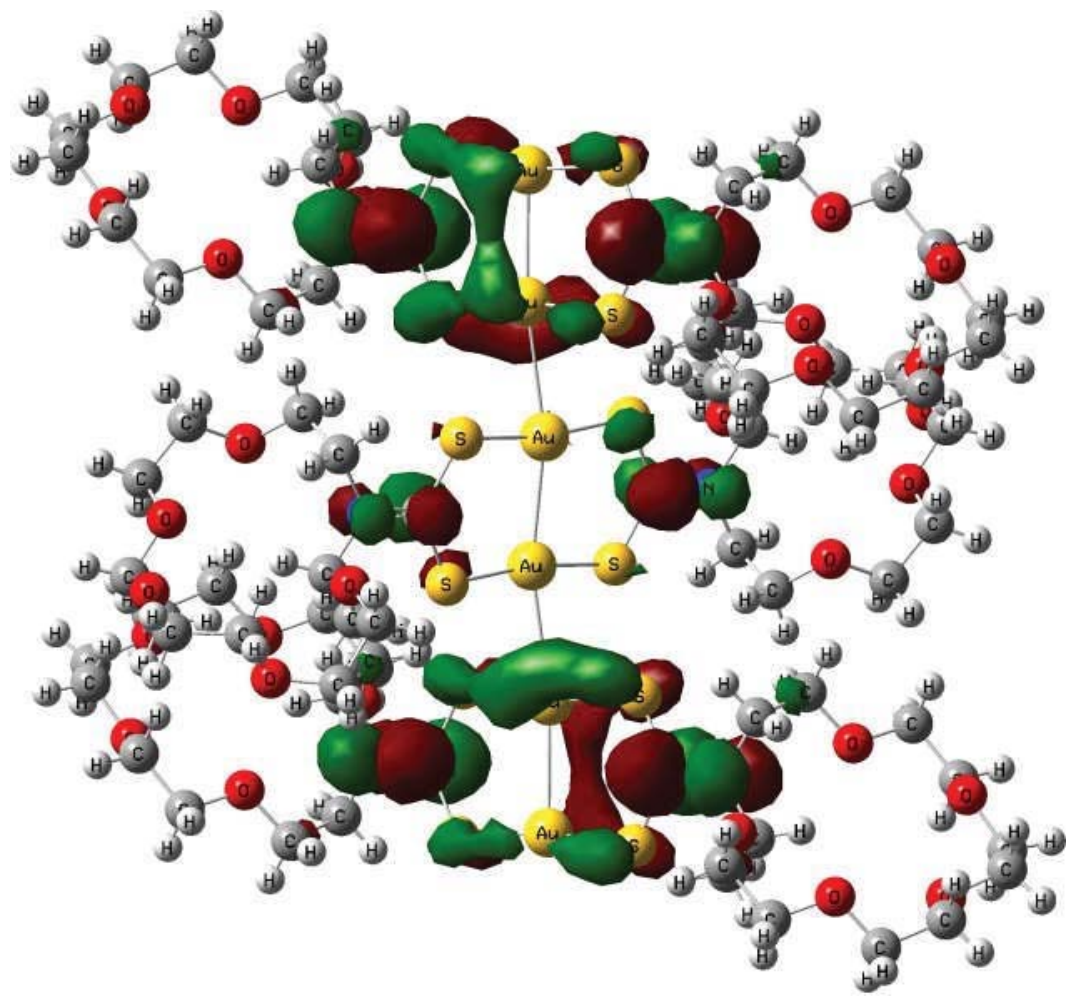

Au1 5\%

Au2 6\%

Au3 2\%

Au4 2\%

Au5 6\%

Au6 5\%

HOMO (540, Au 62\%, S 36\%, C 1\%, N 0\%, isovalue = 0.02) $\quad-0.14154$ hartree

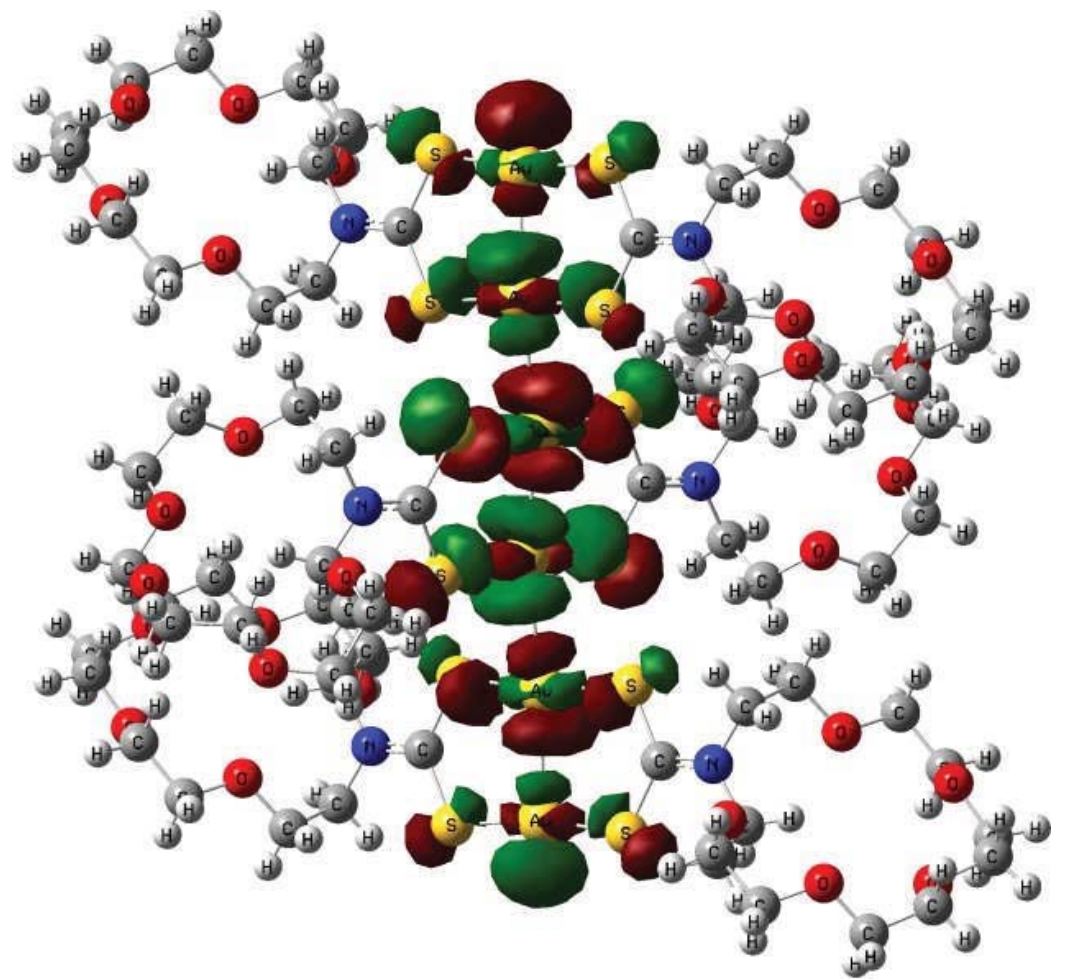

Au1 6\%

Au2 10\%

Au3 15\%

Au4 15\%

Au5 10\%

Au6 6\% 


\title{
Acetonitrile
}

$\left(\mathrm{S}_{0}, \mathrm{Au}-\mathrm{Au}_{\text {intra }}=(2.725,2.719,2.725), \mathrm{Au}-\mathrm{Au} u_{\text {inter }}=2.836\right)$

\author{
LUMO (541, Au 22\%, S 15\%, C 42\%, N 17\%, isovalue = 0.02) -0.02011 hartree
}

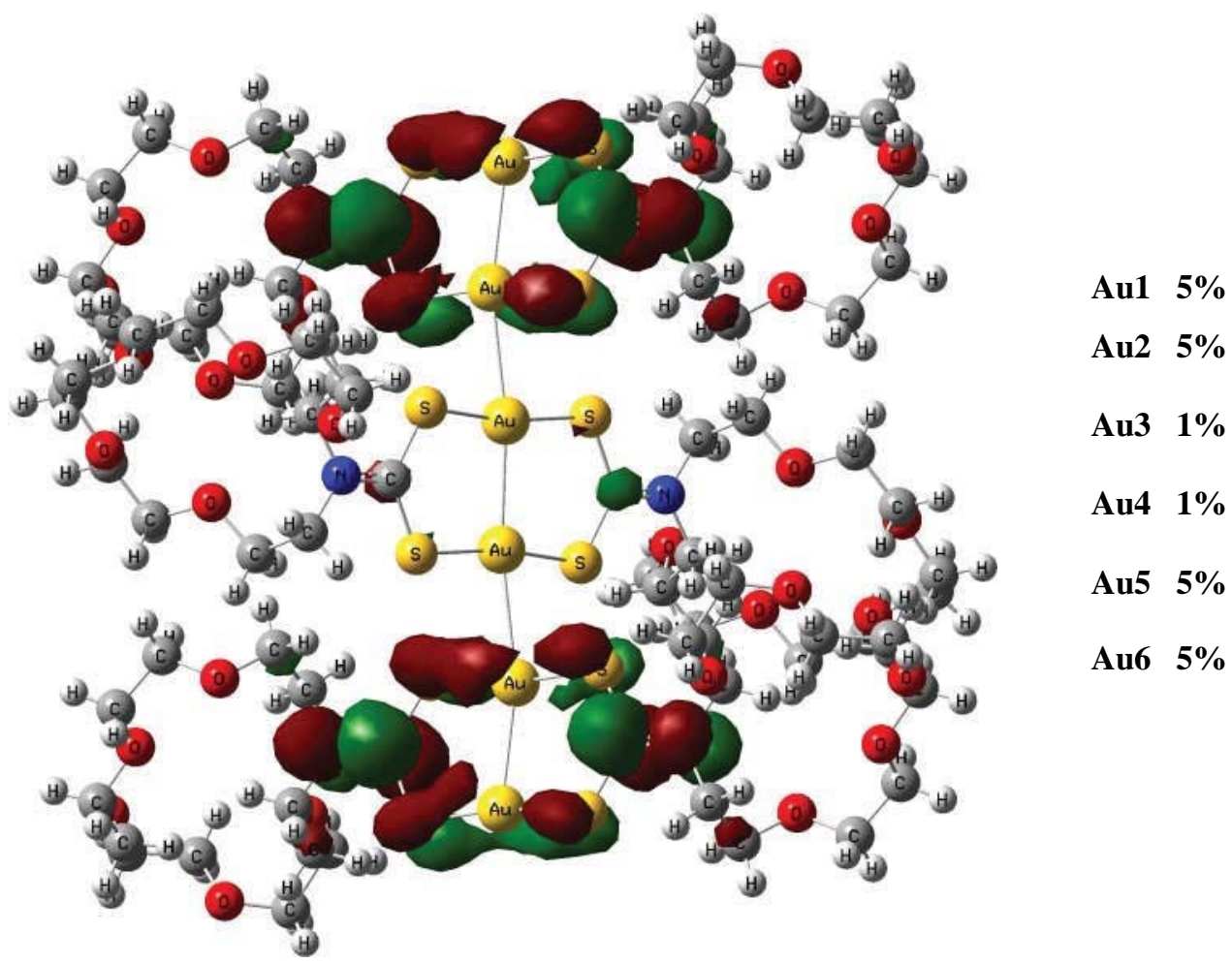

HOMO (540, Au 62\%, S 36\%, C 1\%, N 0\%, isovalue = 0.02) $\quad-0.14417$ hartree

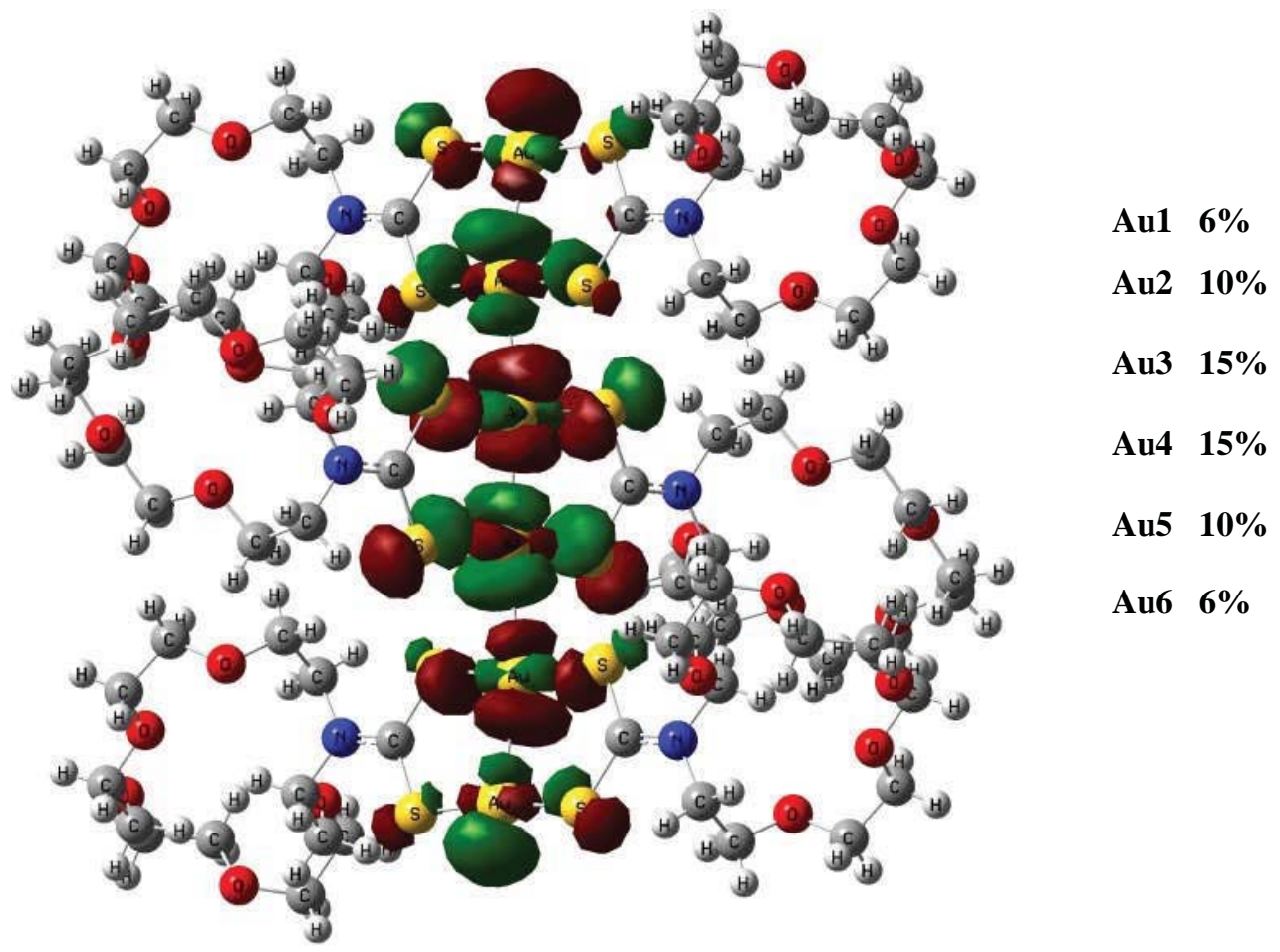




\section{Anisole}

$\left(\mathrm{S}_{0}, \mathrm{Au}-\mathrm{Au}_{\mathrm{intra}}=(2.728,2.733,2.728), \mathrm{Au}-\mathrm{Au} \mathrm{u}_{\text {inter }}=(2.854,2.856)\right)$

LUMO (541, Au 22\%, S 14\%, C 42\%, N 17\%, isovalue = 0.02) -0.02231 hartree

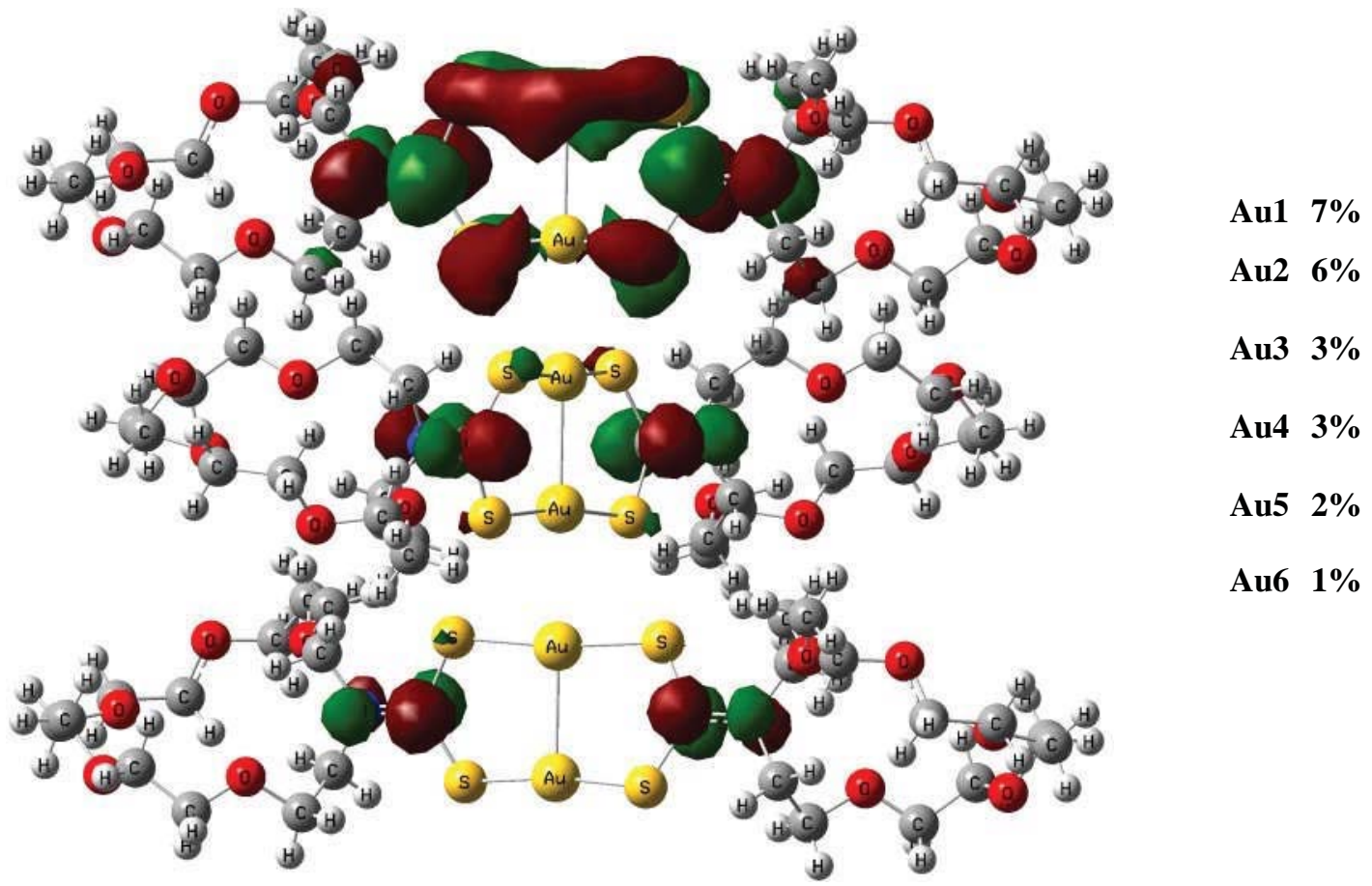

HOMO (540, Au 61\%, S 38\%, C 0\%, N 0\%, isovalue = 0.02$) \quad-0.14587$ hartree

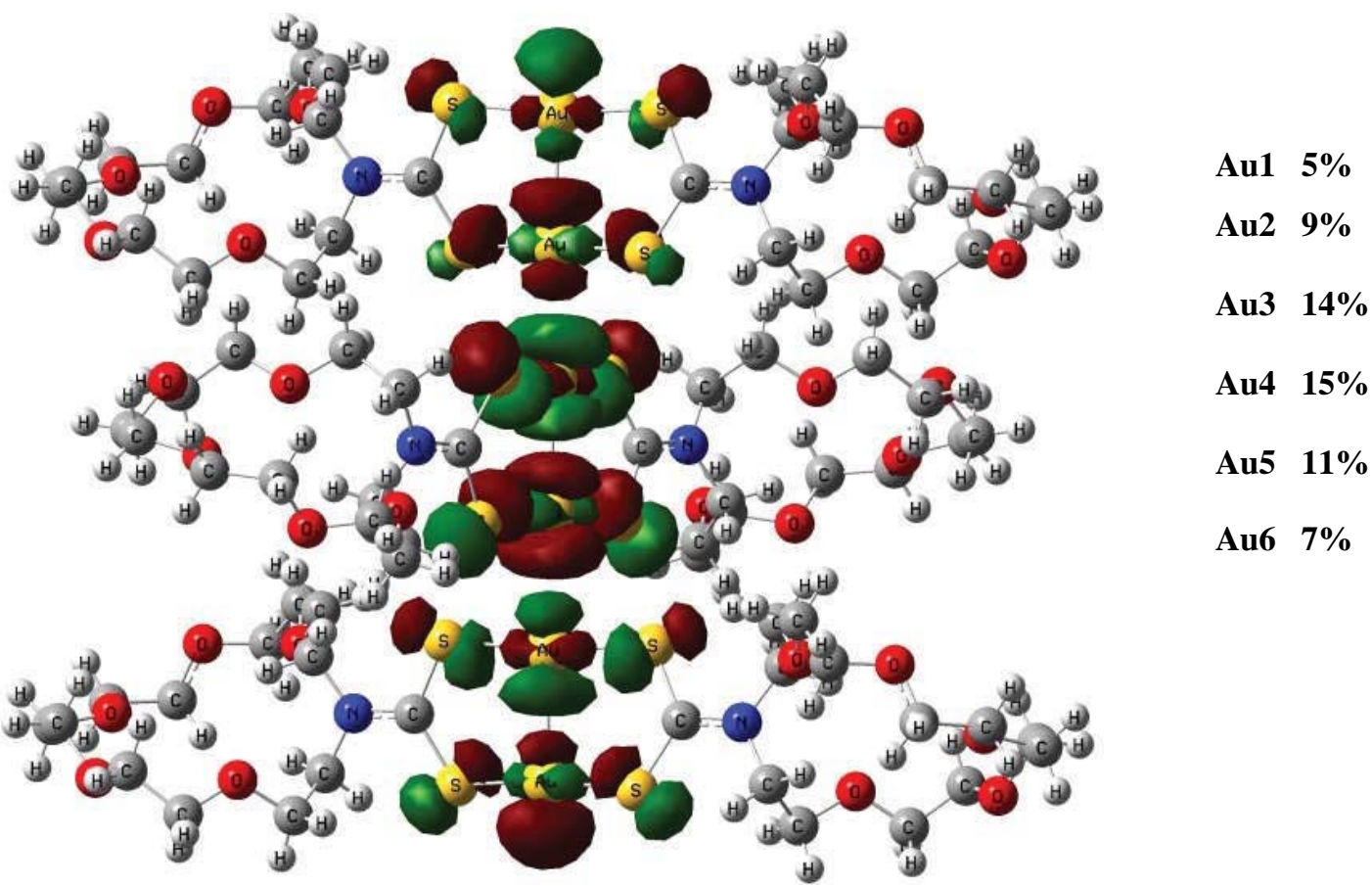




\section{Anisole}

$\left(\mathrm{S}_{0}, \mathrm{Au}-\mathrm{Au}_{\mathrm{intra}}=(2.733,2.728,2.733), \mathrm{Au}-\mathrm{Au} \mathrm{u}_{\text {inter }}=(2.854,2.856)\right)$

LUMO (541, Au 24\%, S 14\%, C 41\%, N 17\%, isovalue = 0.02) $\quad-0.02226$ hartree

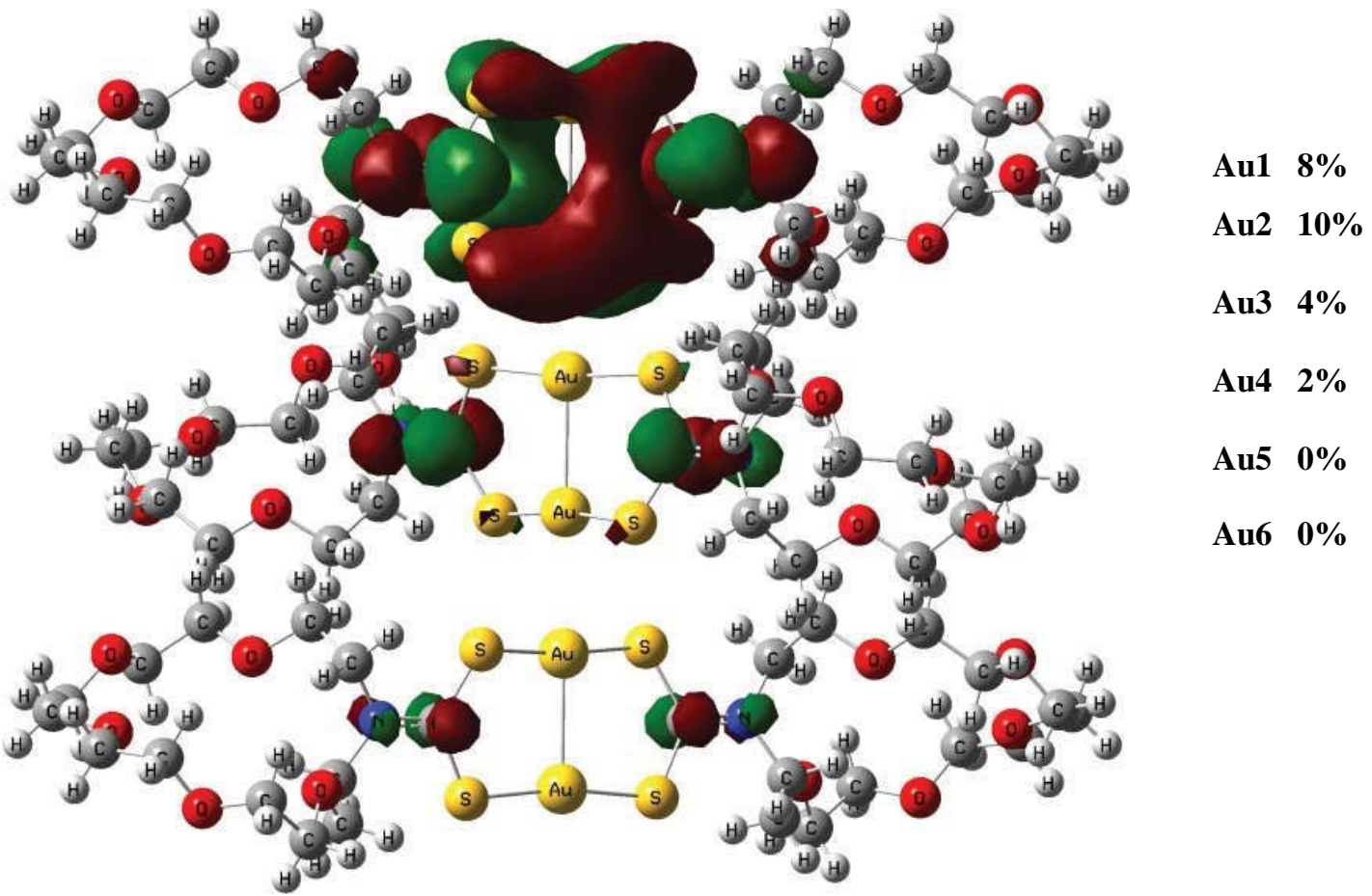

HOMO (540, Au 62\%, S 37\%, C 0\%, N 0\%, isovalue = 0.02 ) $\quad-0.14588$ hartree

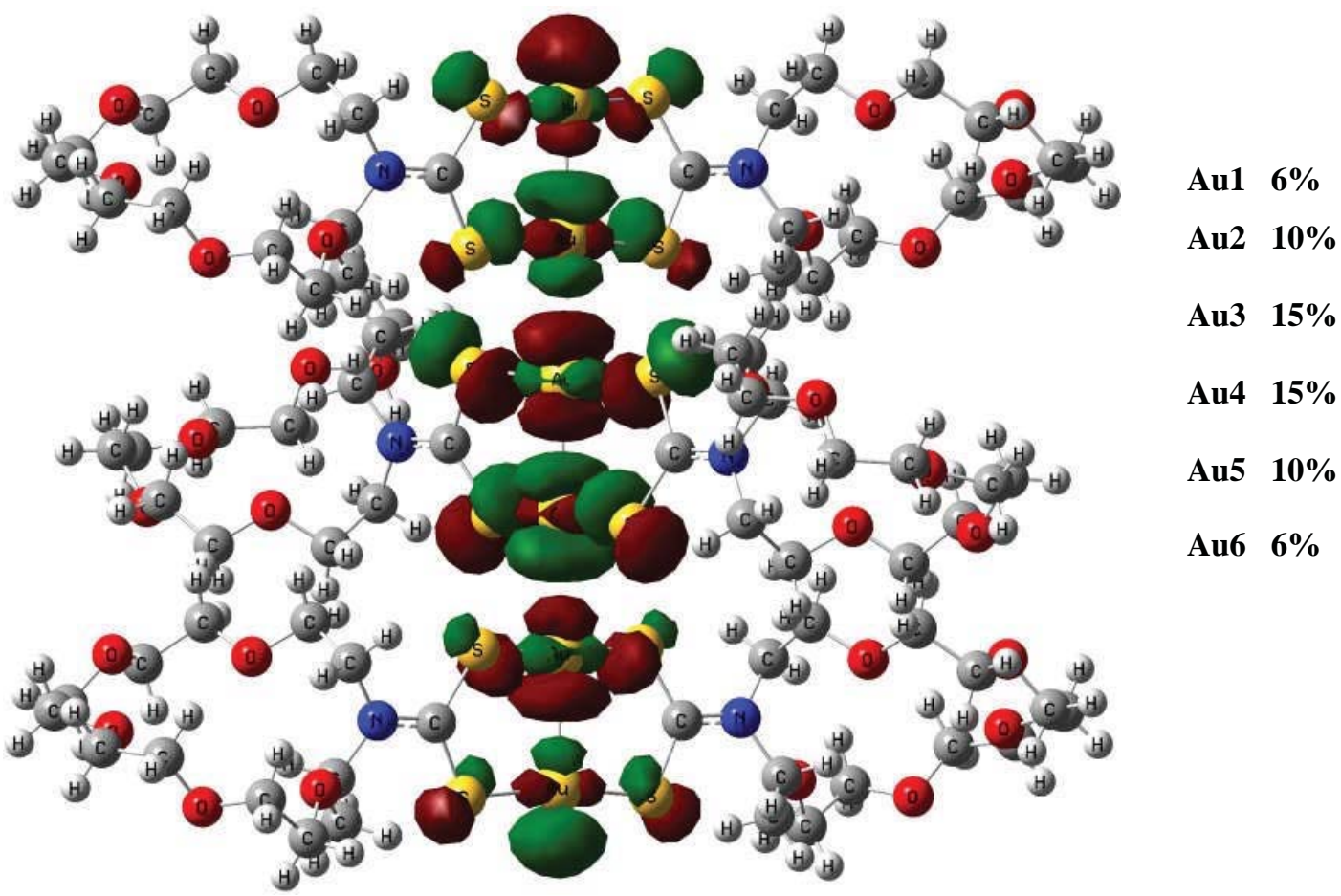




\section{THF}

$\left(\mathrm{S}_{0}, \mathrm{Au}-\mathrm{Au}_{\text {intra }}=(2.733,2.735,2.733), \mathrm{Au}-\mathrm{Au} u_{\text {inter }}=2.857\right)$

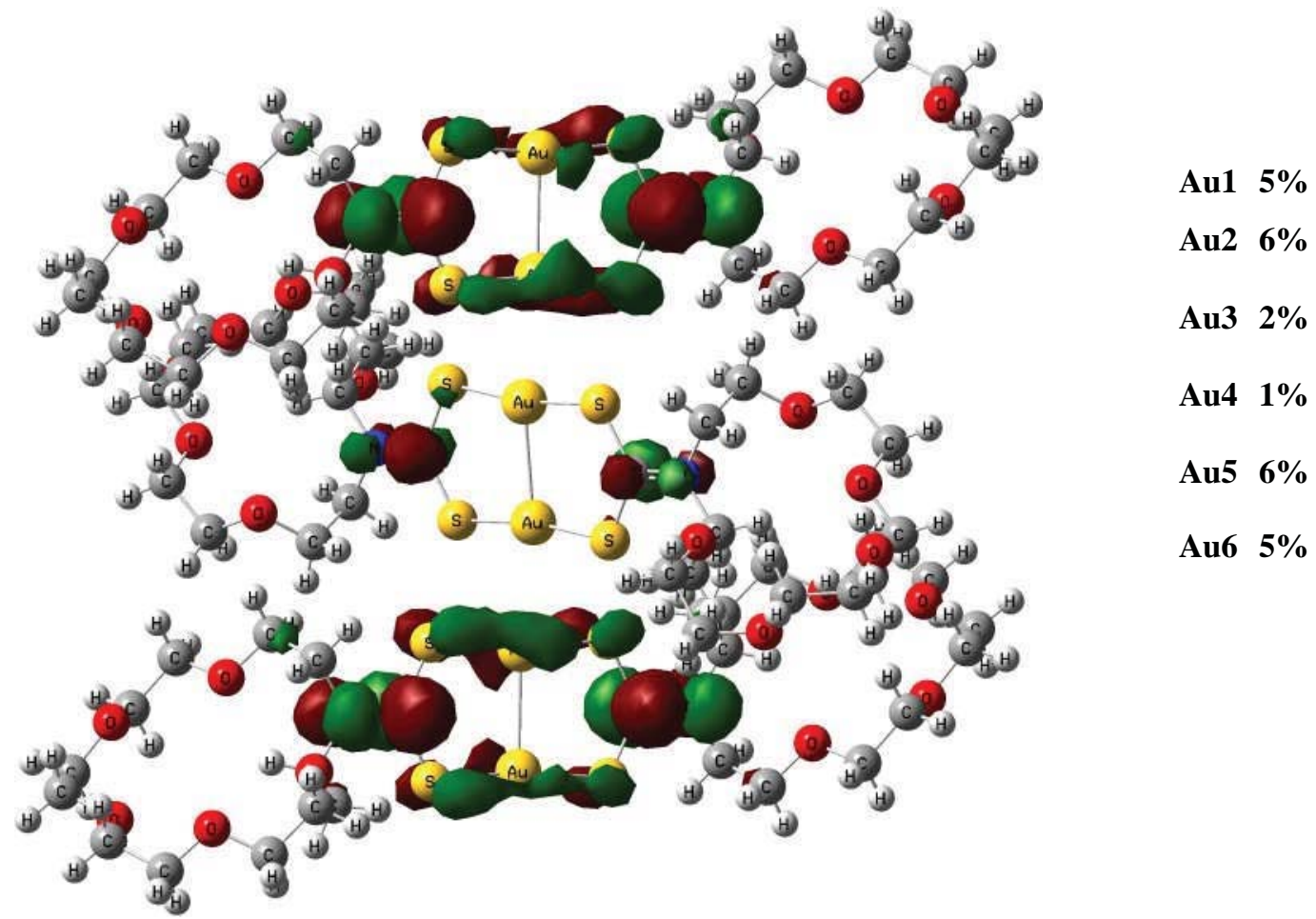

HOMO (540, Au 62\%, S 36\%, C 0\%, N 0\%, isovalue = 0.02) $\quad-0.14578$ hartree

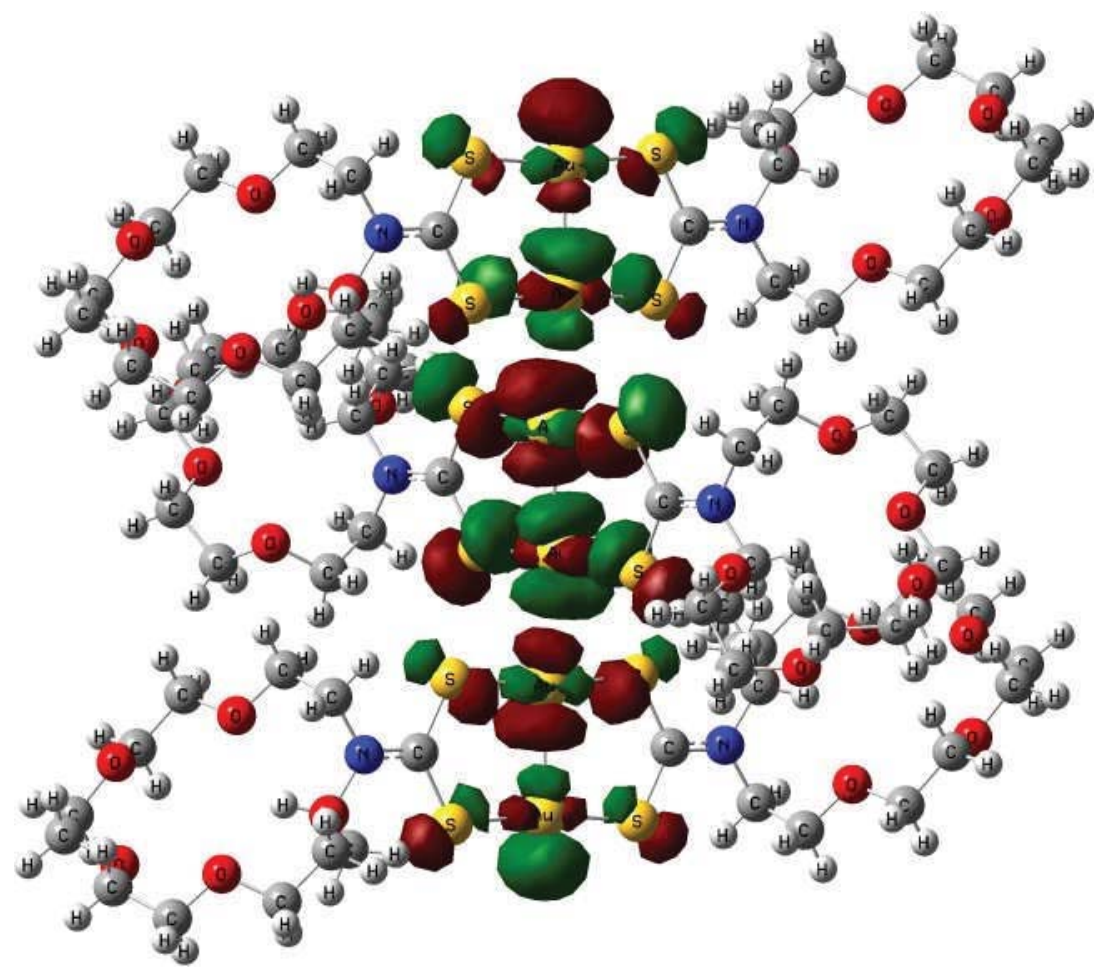

Au1 6\%

Au2 10\%

Au3 15\%

Au4 15\%

Au5 10\%

Au6 6\% 


\section{THF}

$\left(\mathrm{S}_{0}, \mathrm{Au}-\mathrm{Au}_{\text {intra }}=(2.735,2.733,2.735), \mathrm{Au}-\mathrm{Au} u_{\text {inter }}=2.857\right)$

LUMO (541, Au 23\%, S 14\%, C 41\%, N 17\%, isovalue = 0.02) $\quad-\mathbf{0 . 0 2 2 4 4}$ hartree

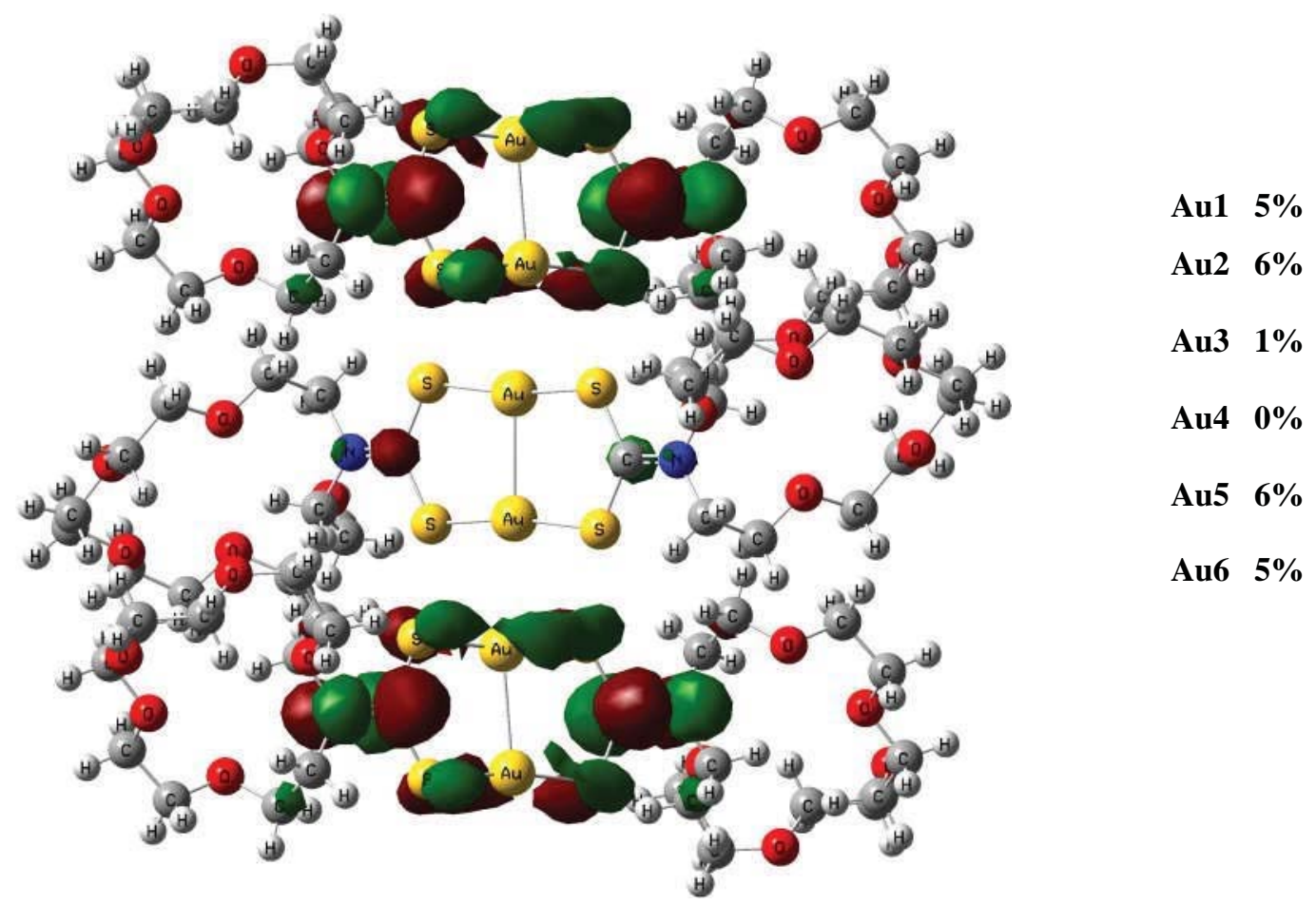

HOMO (540, Au 62\%, S 36\%, C 0\%, N 0\%, isovalue = 0.02) - 0.14737 hartree

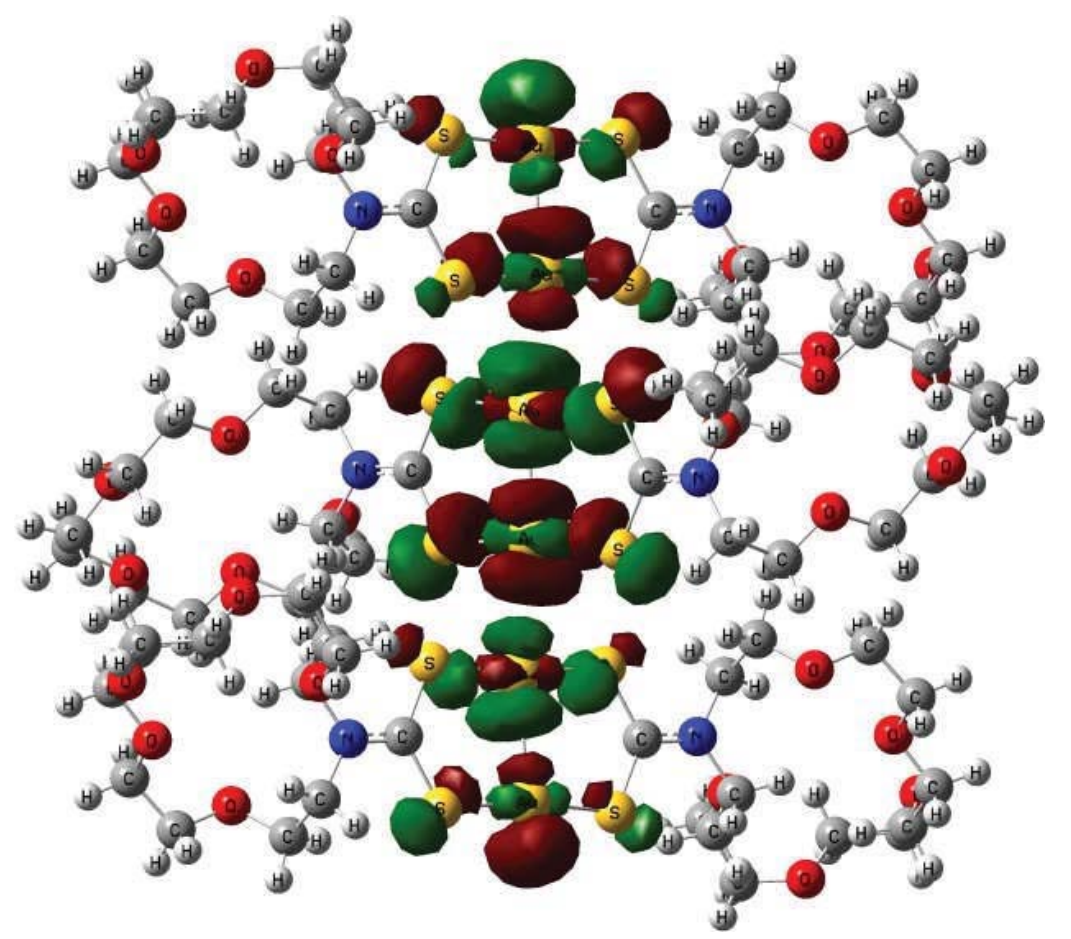

Au1 6\%

Au2 10\%

Au3 15\%

Au4 15\%

Au5 10\%

Au6 6\% 


\section{Acetone}

$\left(\mathrm{S}_{0}, \mathrm{Au}-\mathrm{Au} u_{\text {intra }}=(2.735,2.738,2.735), \mathrm{Au}-\mathrm{Au} u_{\text {inter }}=2.872\right)$

LUMO (541, Au 24\%, S 14\%, C 40\%, N 17\%, isovalue = 0.02) $\quad-\mathbf{0 . 0 2 0 7 9}$ hartree

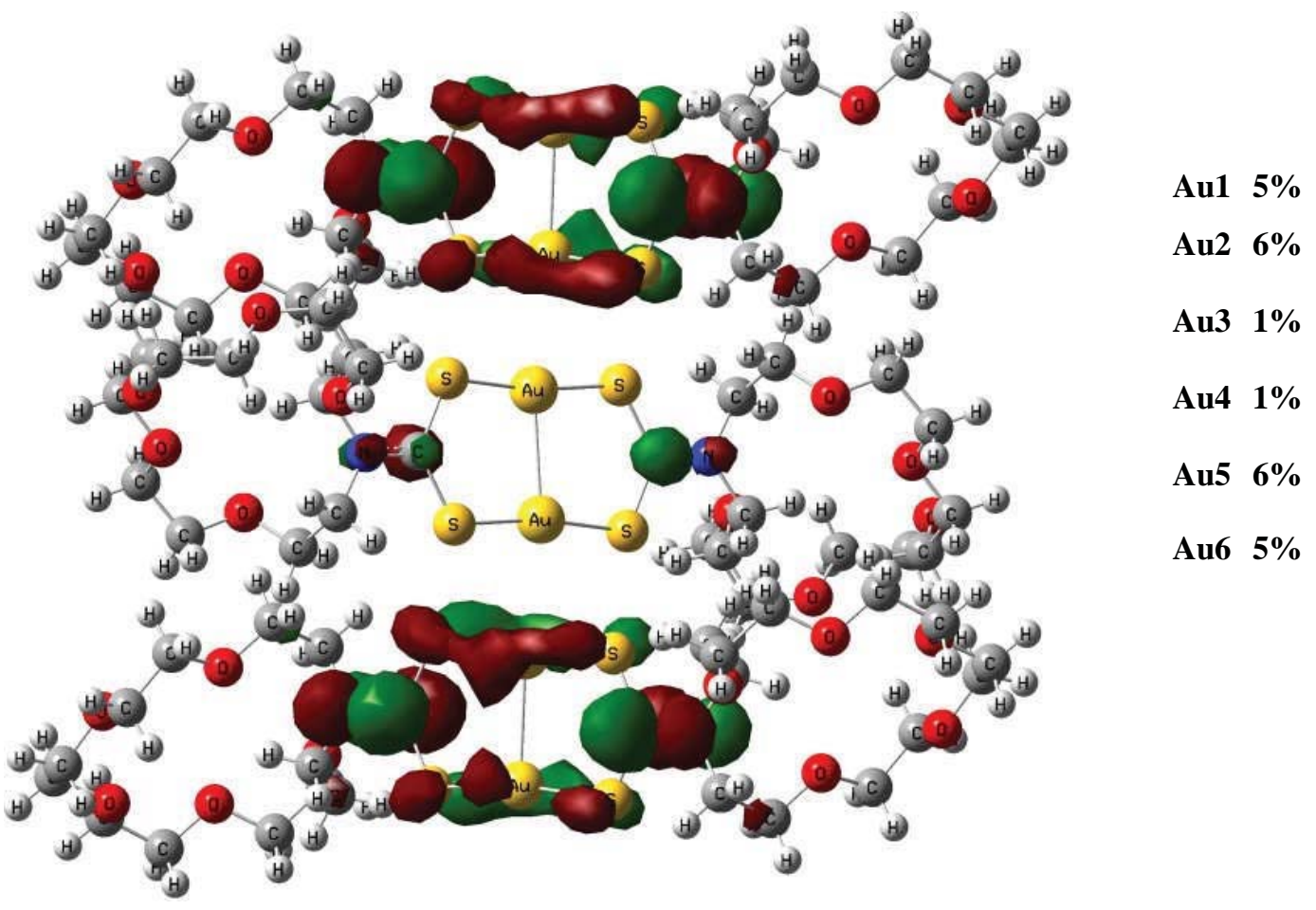

HOMO (540, Au 62\%, S 36\%, C 0\%, N 0\%, isovalue = 0.02) $\quad-0.14737$ hartree

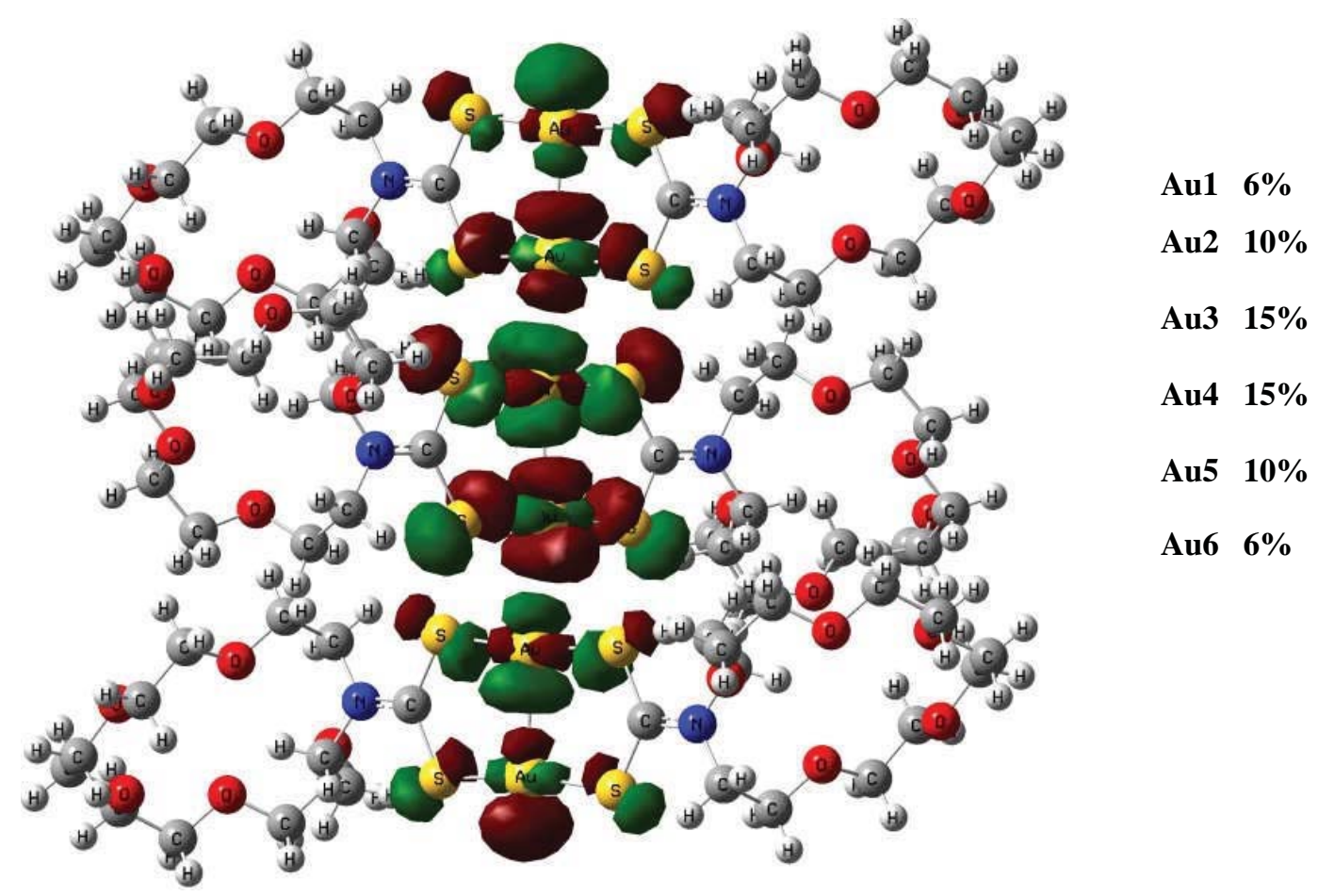




\section{Acetone}

$\left(\mathrm{S}_{0}, \mathrm{Au}-\mathrm{Au} \mathrm{u}_{\text {intra }}=(2.738,2.735,2.738), \mathrm{Au}-\mathrm{Au} u_{\text {inter }}=2.872\right)$

LUMO (541, Au 24\%, S 14\%, C 41\%, N 17\%, isovalue = 0.02 ) $\quad-0.02223$ hartree

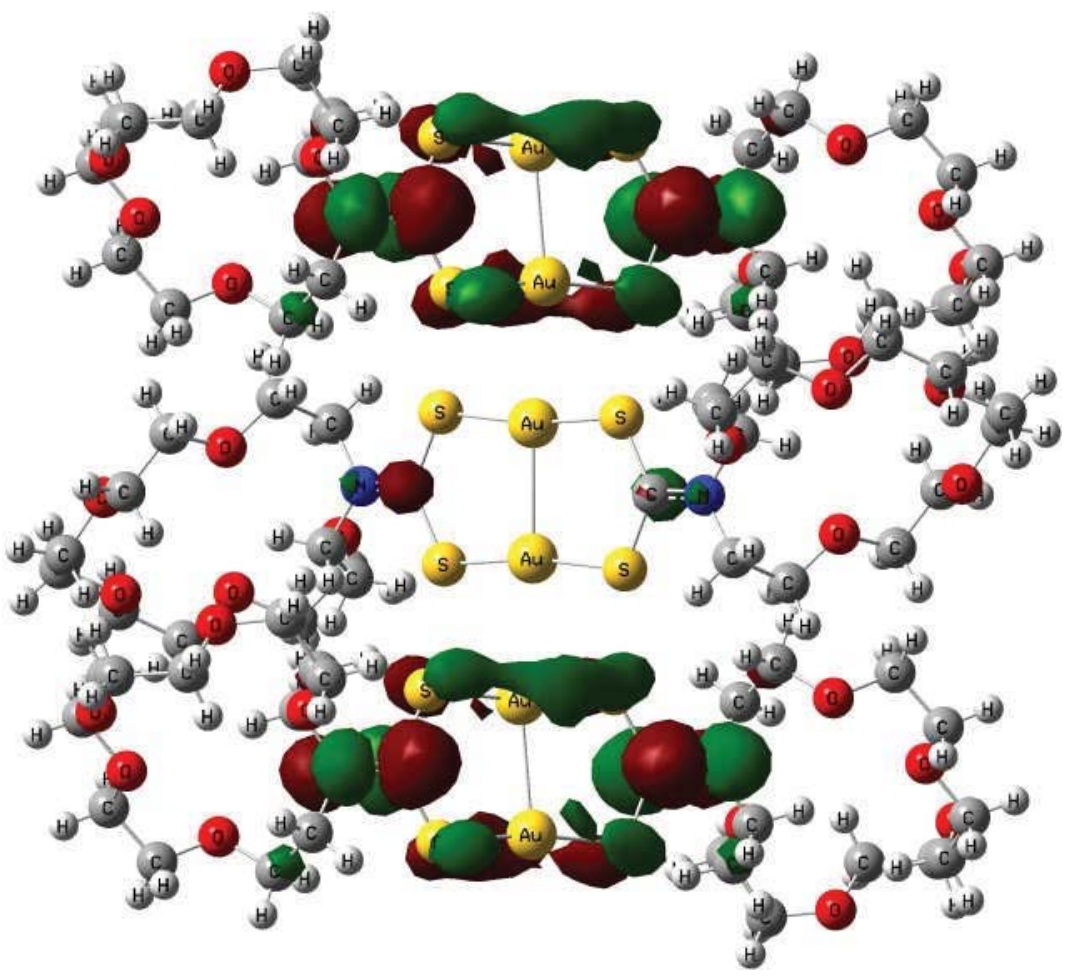

Au1 5\%

Au2 6\%

Au3 1\%

Au4 1\%

Au5 6\%

Au6 5\%

HOMO (540, Au 62\%, S 36\%, C 0\%, N 0\%, isovalue = 0.02) -0.14838 hartree

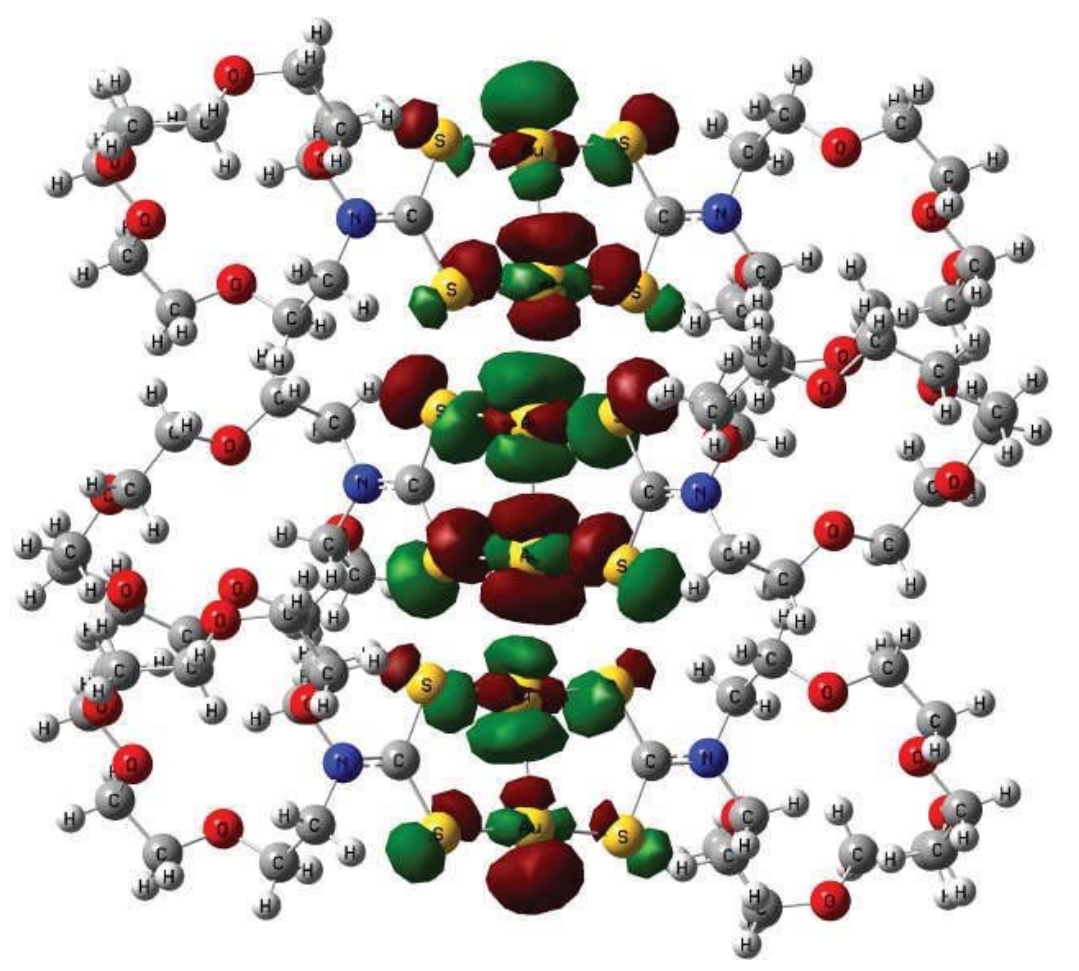

Au1 6\%

Au2 10\%

Au3 15\%

Au4 15\%

Au5 10\%

Au6 6\% 


\section{DMSO}

$\left(\mathrm{S}_{0}, \mathrm{Au}-\mathrm{Au}_{\text {intra }}=(2.729,2.739,2.729), \mathrm{Au}-\mathrm{Au} u_{\text {inter }}=2.875\right)$

LUMO (541, Au 25\%, S 14\%, C 40\%, N 17\%, isovalue = 0.02) -0.02048 hartree

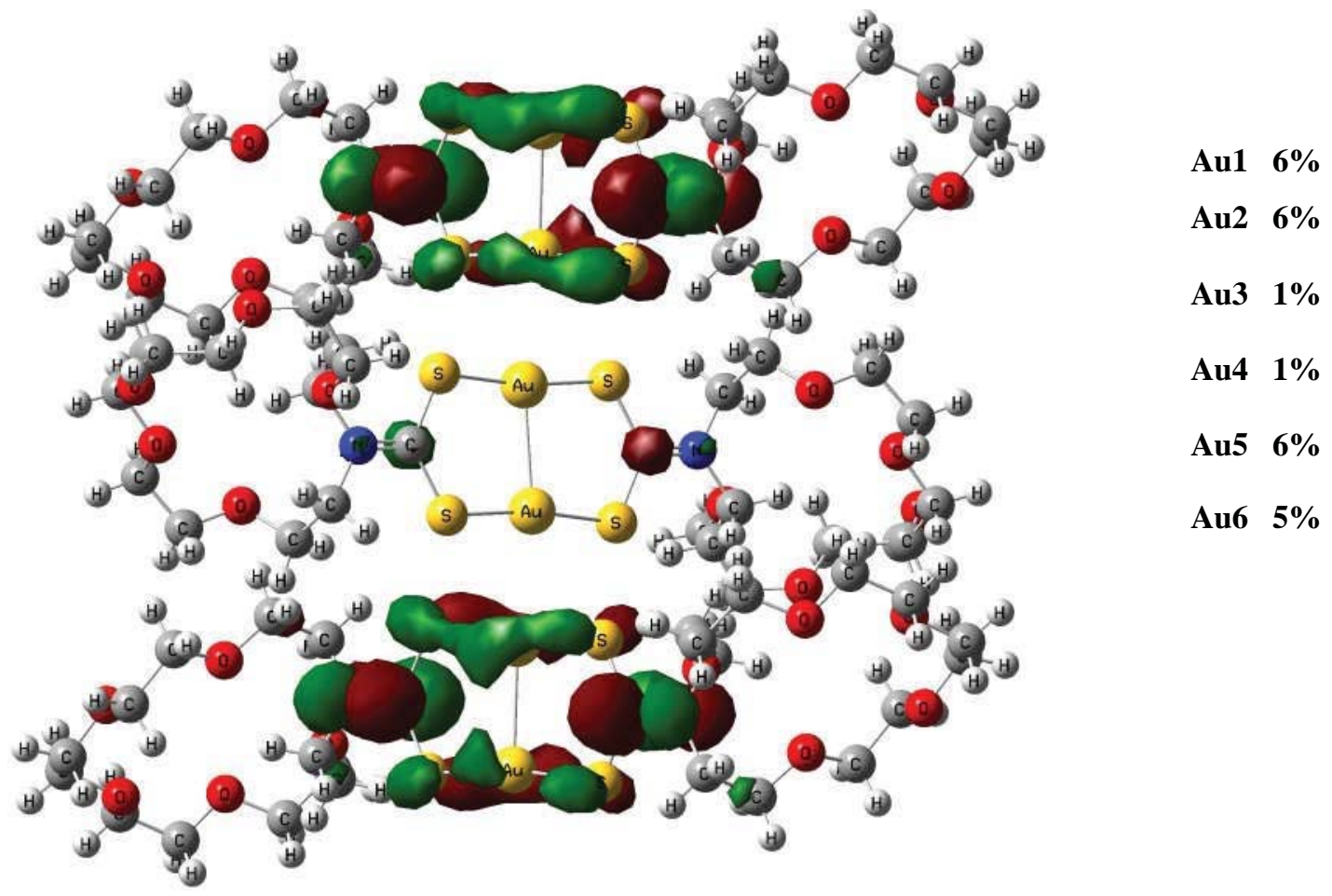

HOMO (540, Au 62\%, S 36\%, C 0\%, N 0\%, isovalue = 0.02) -0.14651 hartree

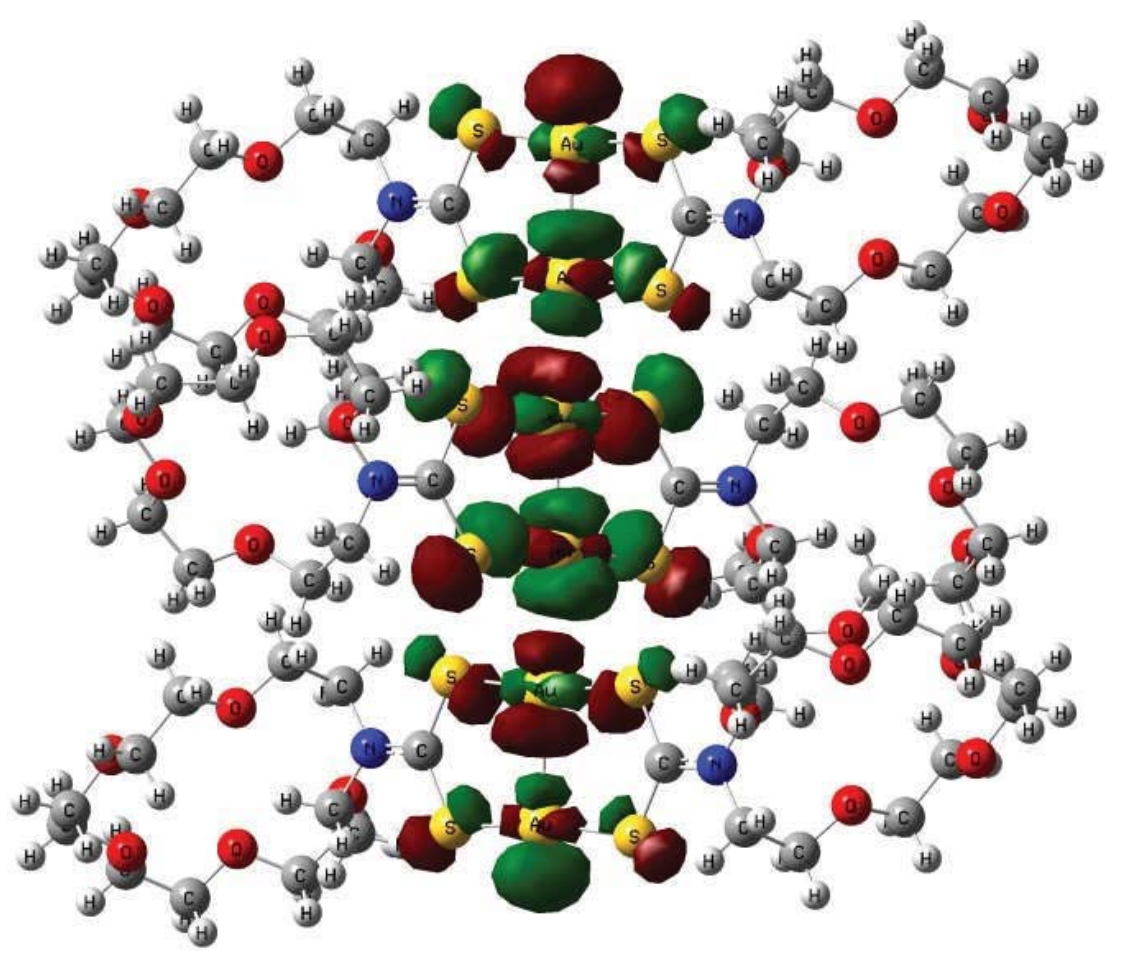

Au1 6\%

Au2 10\%

Au3 15\%

Au4 15\%

Au5 10\%

Au6 6\% 


\section{DMSO}

$\left(\mathrm{S}_{0}, \mathrm{Au}-\mathrm{Au}_{\mathrm{intra}}=(2.739,2.729,2.739), \mathrm{Au}-\mathrm{Au} u_{\text {inter }}=2.875\right)$

LUMO (541, Au 24\%, S 14\%, C 41\%, N 17\%, isovalue = 0.02) -0.02097 hartree

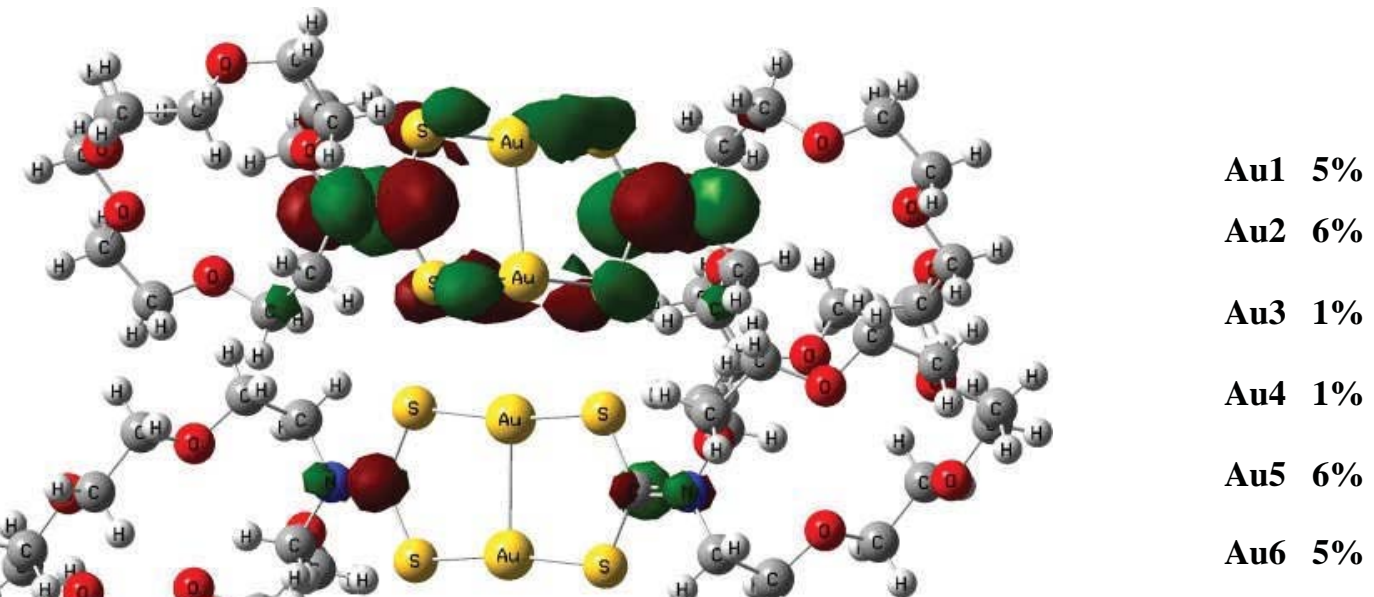

HOMO (540, Au 62\%, S 36\%, C 0\%, N 0\%, isovalue = 0.02) - 0.14793 hartree

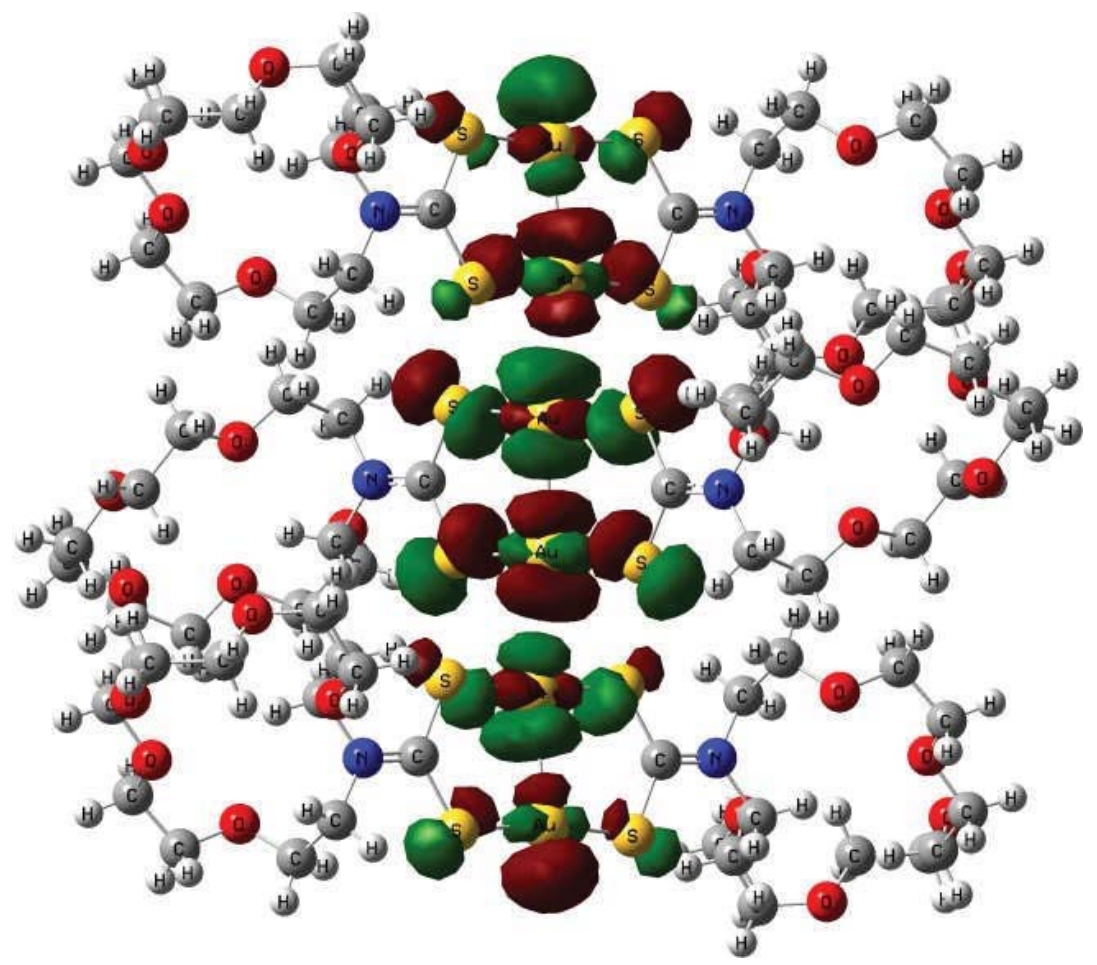

Au1 6\%

Au2 10\%

Au3 15\%

Au4 15\%

Au5 $10 \%$

Au6 6\% 


\section{m-Xylene}

$\left(S_{0}, A u-A u_{i n t r a}=(2.755,2.755,2.755), A u-A u_{\text {inter }}=(2.890,2.902)\right)$

LUMO (541, Au 23\%, S 14\%, C 42\%, N 17\%, isovalue = 0.02) $\quad-\mathbf{0 . 0 2 2 3 4}$ hartree

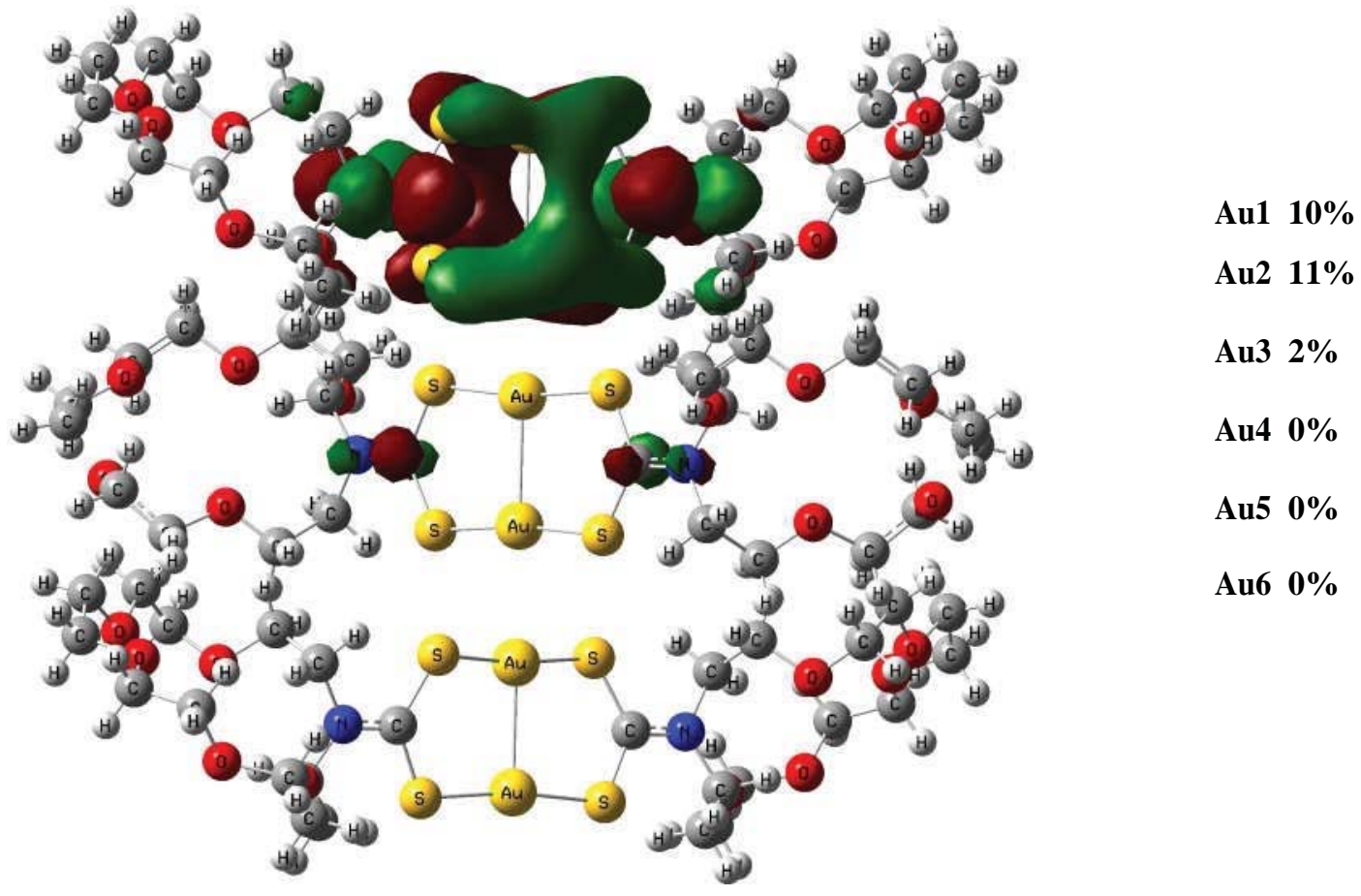

HOMO (540, Au 62\%, S 37\%, C 0\%, N 0\%, isovalue = 0.02) -0.14684 hartree

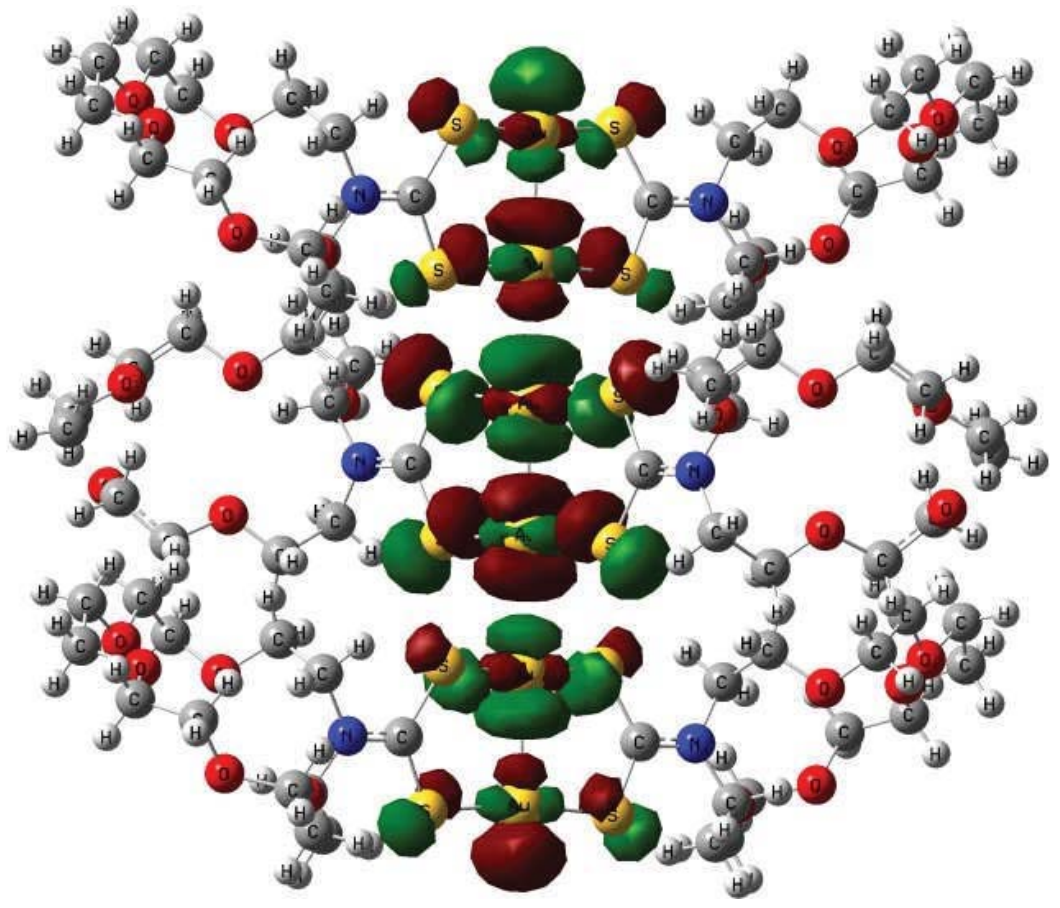

Au1 6\%

Au2 9\%

Au3 15\%

Au4 15\%

Au5 10\%

Au6 7\% 


\section{m-Xylene}

$\left(\mathrm{S}_{0}, \mathrm{Au}-\mathrm{Au}_{\text {intra }}=(2.764,2.764,2.764), \mathrm{Au}-\mathrm{Au}\right.$ inter $\left.=2.893\right)$

LUMO (541, Au 19\%, S 15\%, C 43\%, N 17\%, isovalue = 0.02) -0.03544 hartree

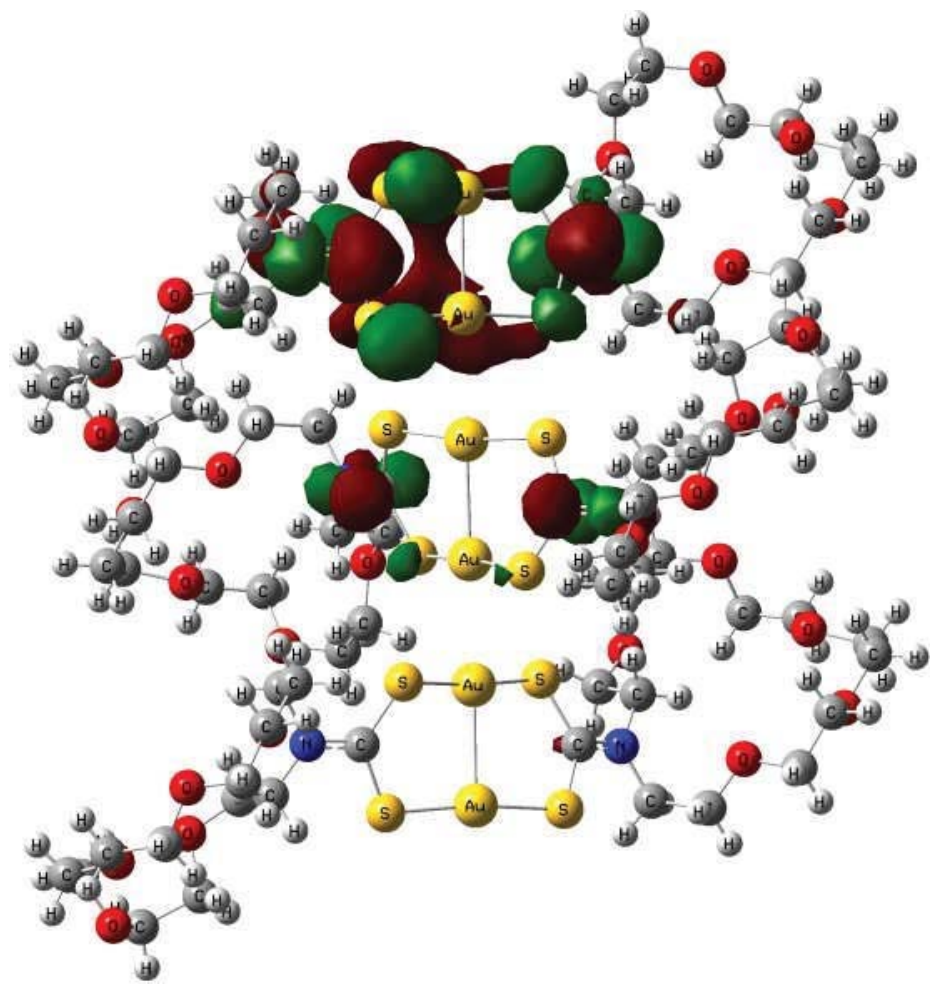

Au1 7\%

Au2 8\%

Au3 3\%

Au4 1\%

Au5 0\%

Au6 0\%

HOMO (540, Au 61\%, S 38\%, C 0\%, N 0\%, isovalue = 0.02) $\quad-\mathbf{0 . 1 5 8 2 8}$ hartree

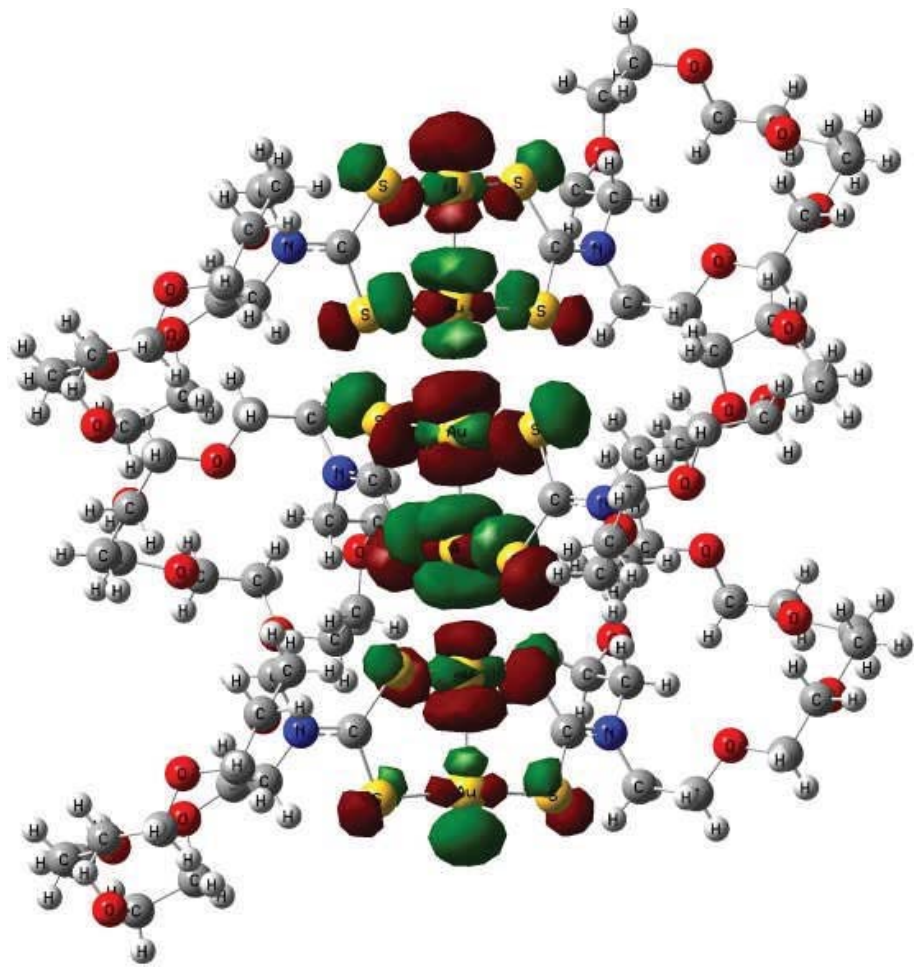

Au1 6\%

Au2 10\%

Au3 15\%

Au4 15\%

Au5 9\%

Au6 6\% 


\section{m-Xylene}

$\left(S_{0}, A u-A u_{i n t r a}=(2.755,2.755,2.755), A u-A u_{\text {inter }}=(2.890,2.902)\right)$

LUMO (541, Au 22\%, S 15\%, C 42\%, N 17\%, isovalue = 0.02) -0.02309 hartree

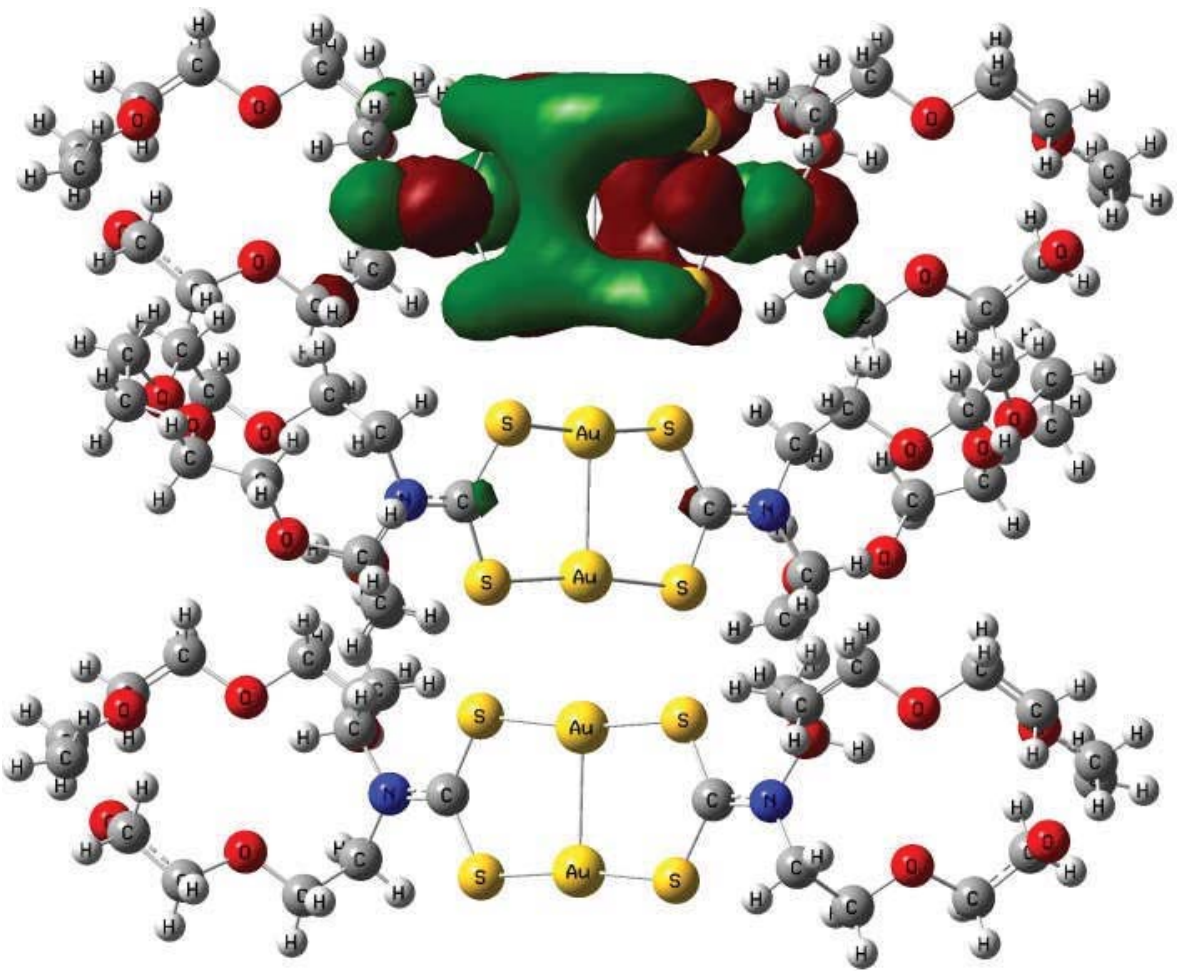

Au1 11\%

Au2 11\%

Au3 0\%

Au4 0\%

Au5 0\%

Au6 0\%

HOMO (540, Au 62\%, S 37\%, C 0\%, N 0\%, isovalue = 0.02) -0.14705 hartree

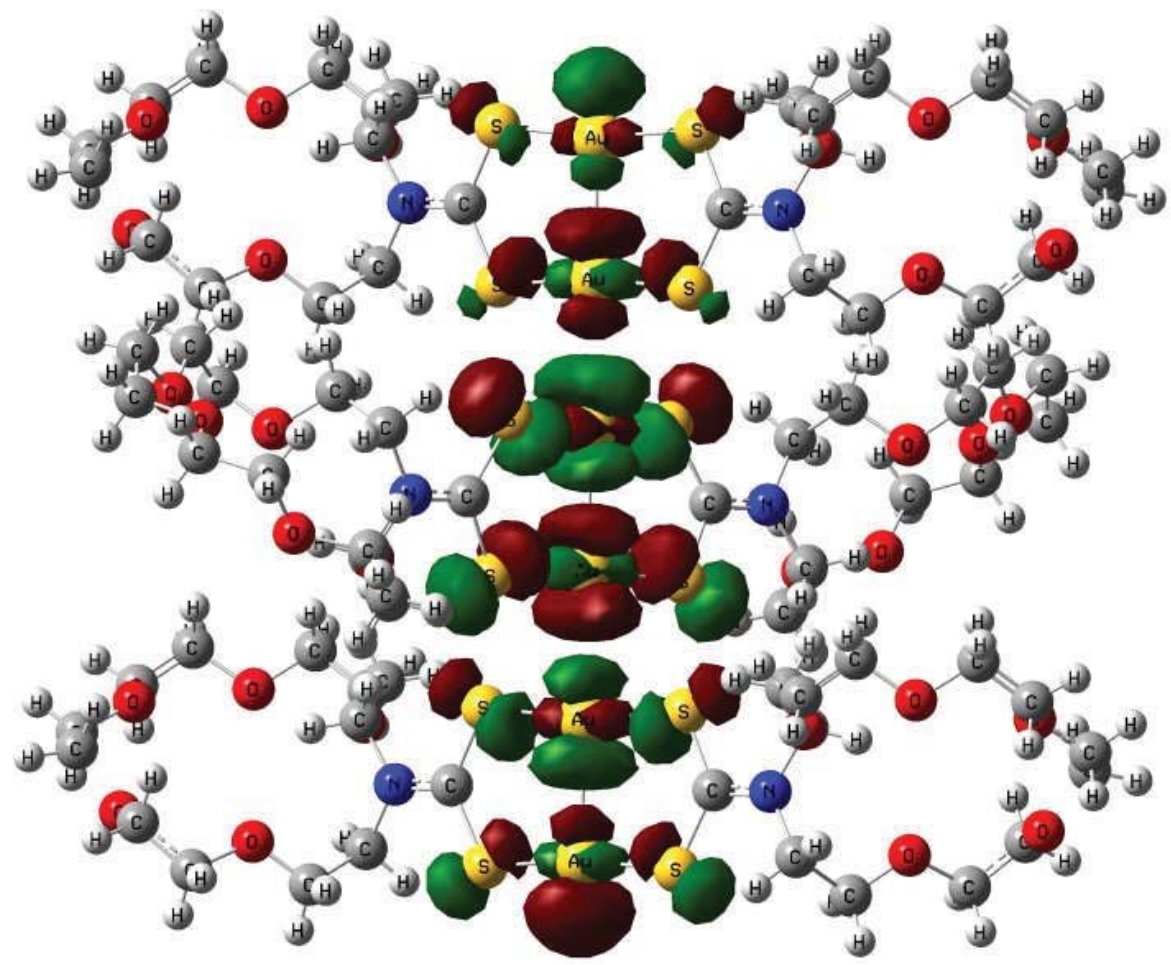

Au1 5\%

Au2 8\%

Au3 14\%

Au4 15\%

Au5 12\%

Au6 8\% 


\section{DMF}

$\left(\mathrm{S}_{0}, \mathrm{Au}-\mathrm{Au} \mathrm{u}_{\text {intra }}=(2.741,2.746,2.741), \mathrm{Au}-\mathrm{Au} \mathrm{u}_{\text {inter }}=2.902\right)$

LUMO (541, Au 26\%, S 13\%, C 40\%, N 17\%, isovalue = 0.02) $\mathbf{- 0 . 0 2 0 8 8 ~ h a r t r e e ~}$

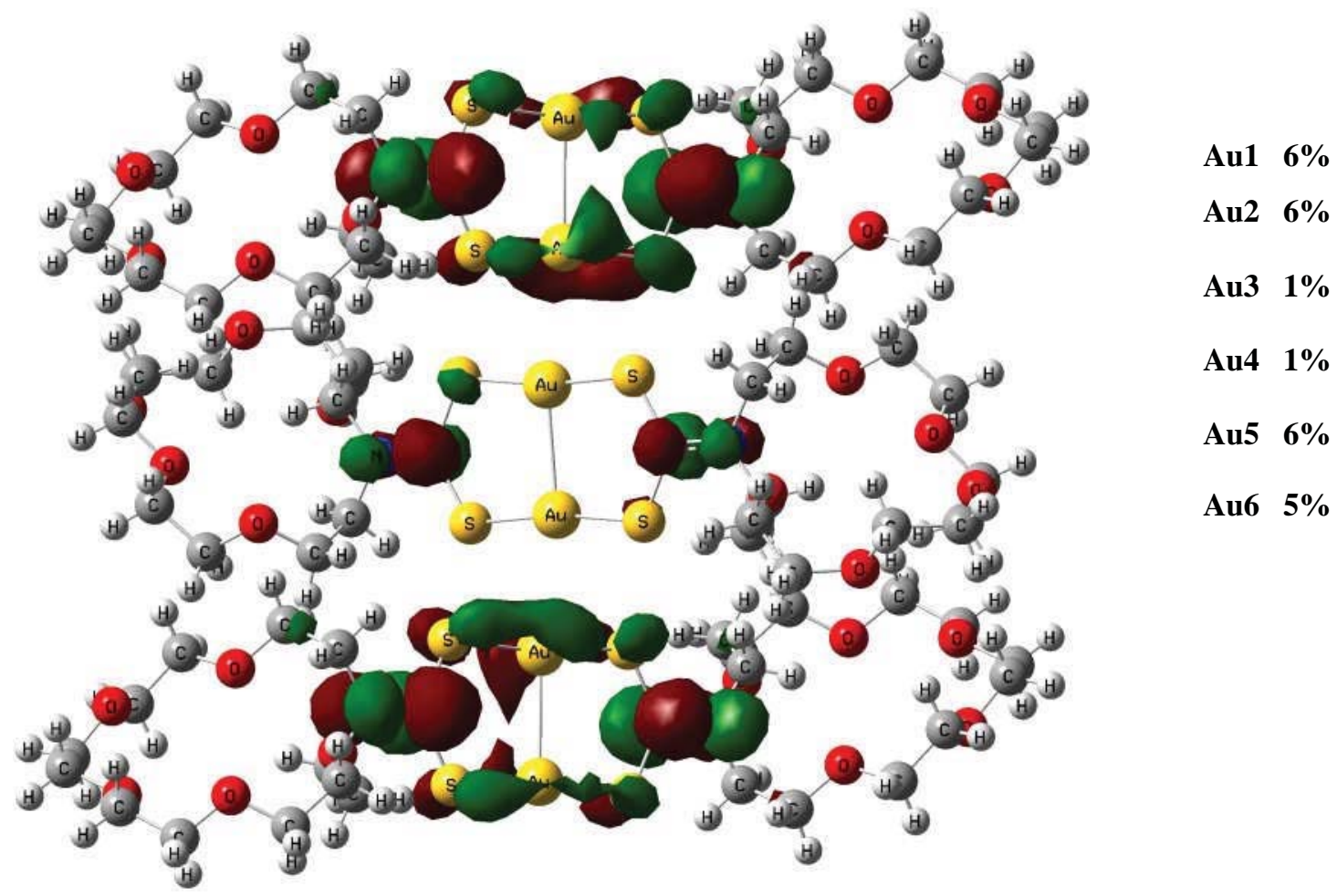

HOMO (540, Au 62\%, S 36\%, C 0\%, N 0\%, isovalue = 0.02) -0.14963 hartree

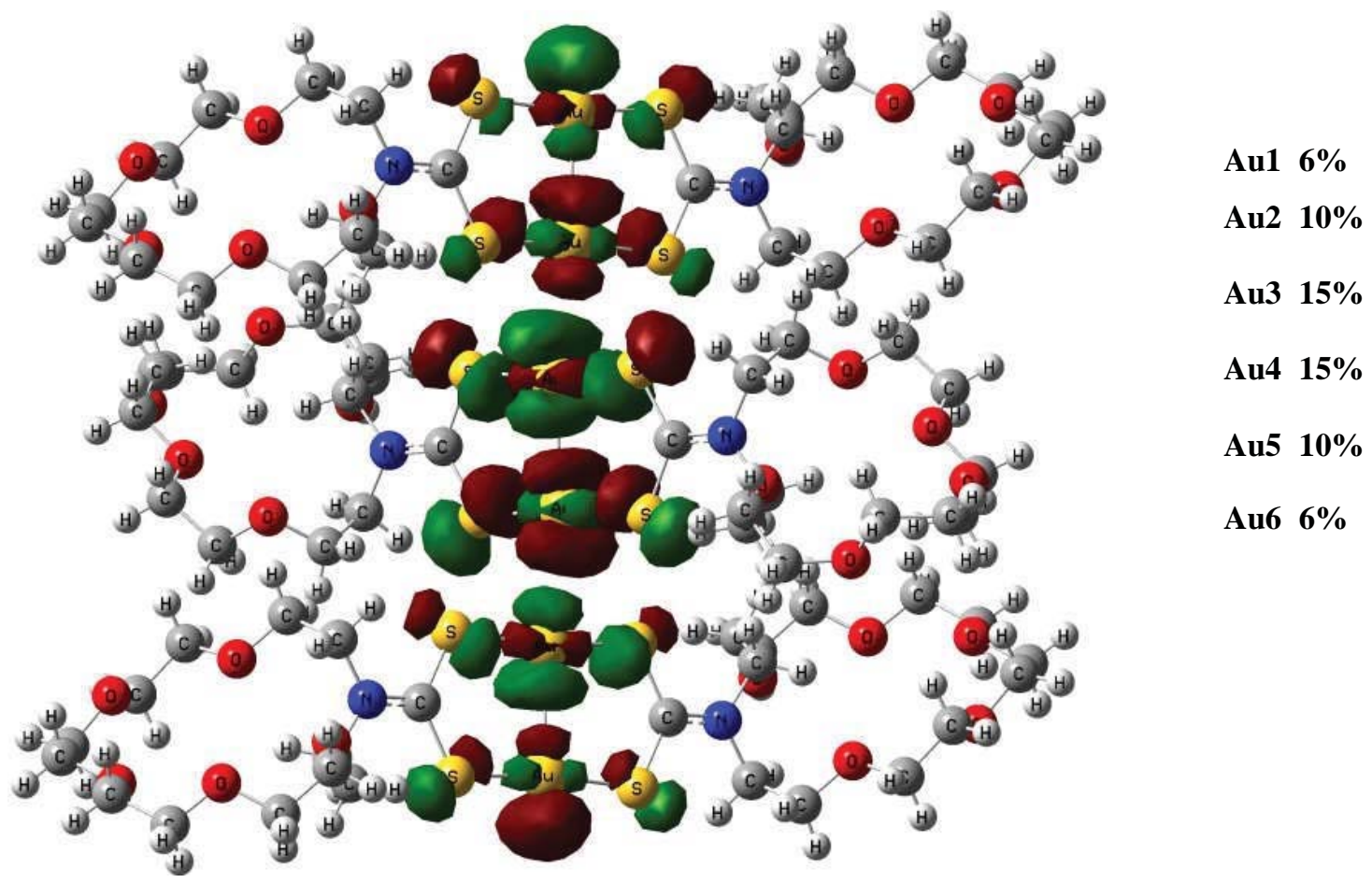




\section{DMF}

$\left(\mathrm{S}_{0}, \mathrm{Au}-\mathrm{Au} u_{\text {intra }}=(2.746,2.741,2.746), \mathrm{Au}-\mathrm{A} \mathrm{u}_{\text {inter }}=2.902\right)$

LUMO (541, Au 23\%, S 14\%, C 41\%, N 17\%, isovalue = 0.02) -0.02396 hartree

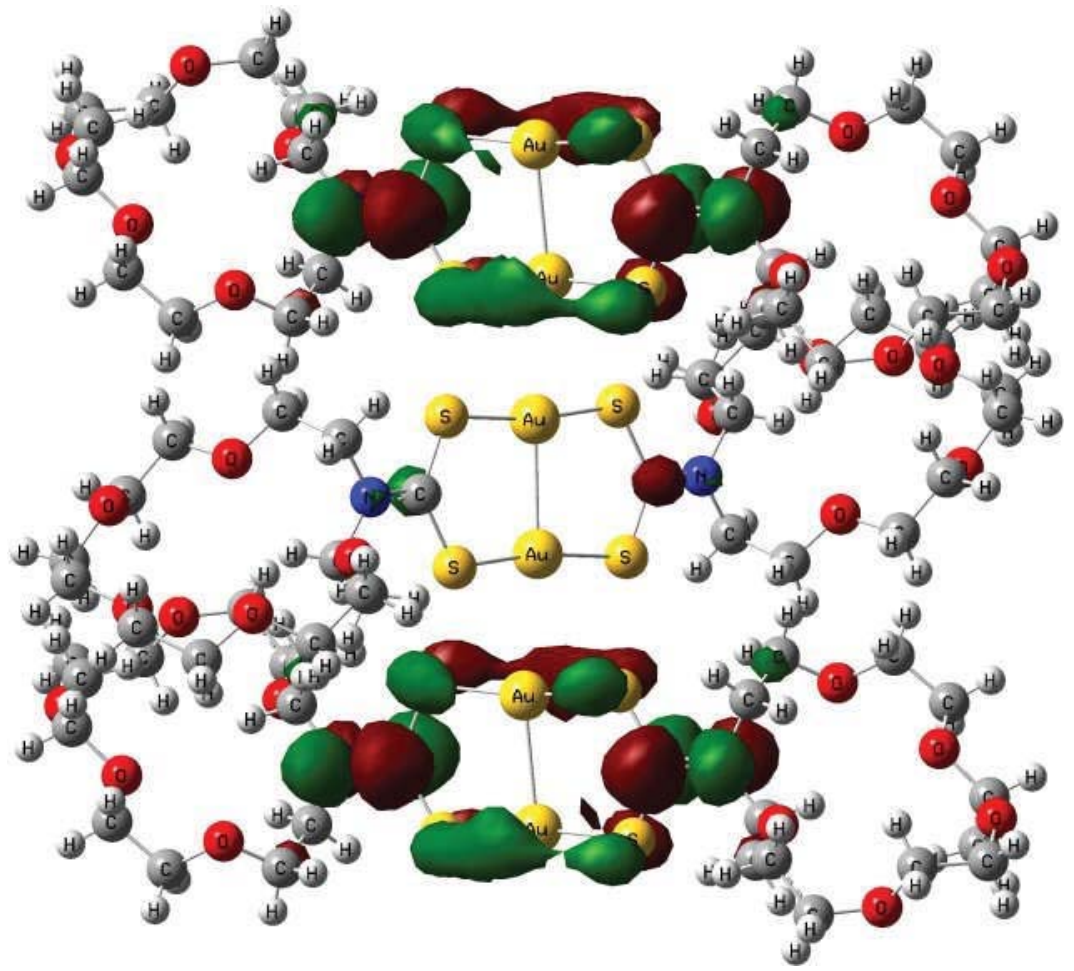

Au1 5\%

Au2 6\%

Au3 1\%

Au4 0\%

Au5 6\%

Au6 5\%

HOMO (540, Au 62\%, S 36\%, C 0\%, N 0\%, isovalue = 0.02) -0.15104 hartree

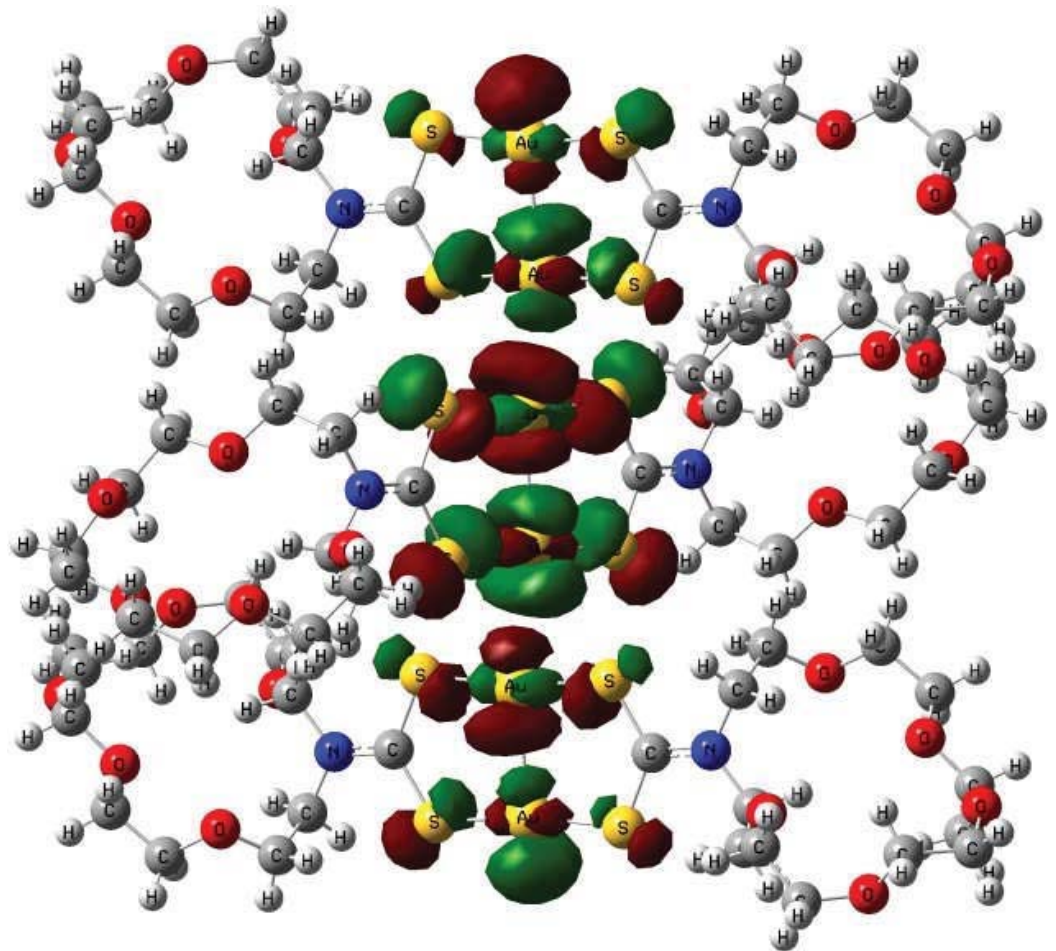

Au1 6\%

Au2 10\%

Au3 15\%

Au4 15\%

Au5 10\%

Au6 6\% 